University of San Diego

Digital USD

2011-06-01

\title{
A Study of the Impact of the Workplace Learning Function on Organizational Excellence by Examining the Workplace Learning Practices of Six Malcolm Baldrige National Quality Award Recipients
}

Cynthia J. Lewis EdD

University of San Diego

Follow this and additional works at: https://digital.sandiego.edu/dissertations

Part of the Leadership Studies Commons

\section{Digital USD Citation}

Lewis, Cynthia J. EdD, "A Study of the Impact of the Workplace Learning Function on Organizational Excellence by Examining the Workplace Learning Practices of Six Malcolm Baldrige National Quality Award Recipients" (2011). Dissertations. 820.

https://digital.sandiego.edu/dissertations/820

This Dissertation: Open Access is brought to you for free and open access by the Theses and Dissertations at Digital USD. It has been accepted for inclusion in Dissertations by an authorized administrator of Digital USD. For more information, please contact digital@sandiego.edu. 


\title{
A STUDY OF THE IMPACT OF THE WORKPLACE LEARNING \\ FUNCTION ON ORGANIZATIONAL EXCELLENCE BY EXAMINING \\ THE WORKPLACE LEARNING PRACTICES OF SIX MALCOLM \\ BALDRIGE NATIONAL QUALITY AWARD RECIPIENTS
}

by

Cynthia J. Lewis

\author{
A Dissertation Submitted to the Faculty of \\ San Diego State University and the University of San Diego \\ in Partial Fulfillment \\ of the Requirements for the Degree \\ Doctor of Education \\ Dissertation Committee: \\ Dr. Ian Pumpian, San Diego State University \\ Dr. Douglas Fisher, San Diego State University \\ Dr. Nancy Frey, San Diego State University
}

June 2011 
Copyright (C) 2011

by

Cynthia J. Lewis

All Rights Reserved 


\section{DEDICATION}

This paper is dedicated to my family: my husband, my children, my grandchildren, and to the memory of my parents. To my husband David for his love, support and understanding throughout these last seven years and for providing an opportunity that tested my commitment to this project.

To my children Brigette and Travis, for helping me maintain perspective and for cheering me on and to my grandchildren Ryan, Sophia, Jacob, and Max for providing countless moments of joy.

And finally, to the memory of my parents Robert \& Ruby Fern Lewis for passing on the qualities that helped me finish this project: perseverance, a sense of humor, a hard work ethic and a love of learning, 


\title{
ABSTRACT OF THE DISSERTATION
}

\author{
A Study of the Impact of the Workplace Learning Function on \\ Organizational Excellence by Examining the Workplace Learning \\ Practices of Six Malcolm Baldrige National Quality Award \\ Recipients \\ by \\ Cynthia J. Lewis \\ Doctor of Education \\ San Diego State University and the University of San Diego, 2011
}

The purpose of this study was to evaluate the role the learning function plays in the pursuit of organizational excellence with the goal of identifying key factors, models and descriptions of successful workplace learning practices. A total of six Malcolm Baldrige National Quality Award Recipients, one from each Baldrige sector participated in this study. Data was collected through in depth, semi-structured, face-to-face interviews with the person responsible for workplace learning or their representative in each organization. The findings indicated that workplace learning professionals should be part of the strategic planning process within an organization and that workplace learning benefits strongly from the support of the senior executives and the CEO or equivalent. The findings also supported current research regarding workplace learning evaluations and delivery methods. 


\section{TABLE OF CONTENTS}

PAGE

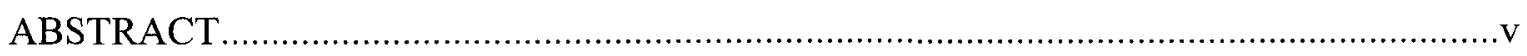

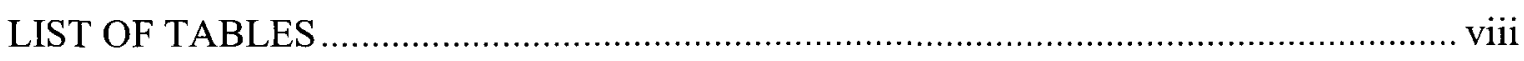

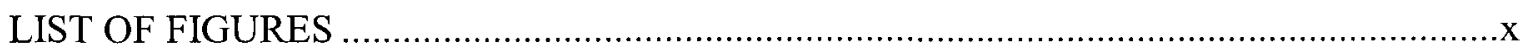

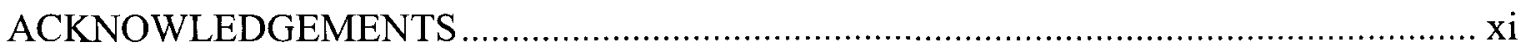

CHAPTER

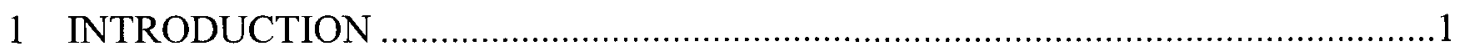

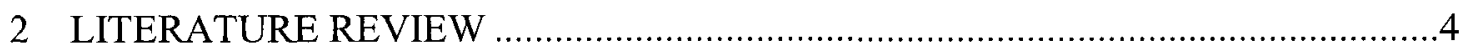

The Malcolm Baldrige National Quality Award ..............................................4

Baldrige Criterion One: Leadership ....................................................... 5

Baldrige Criterion Two: Strategic Planning .............................................. 15

Baldrige Criterion Three: Customer Focus..............................................21

Baldrige Criterion Four: Measurement, Analysis, and Knowledge

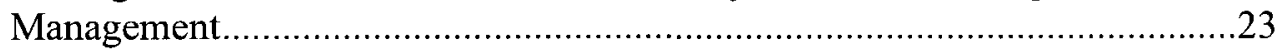

Baldrige Criterion Five: Workforce Focus ..............................................26

Baldrige Criterion Six: Process Management.......................................... 30

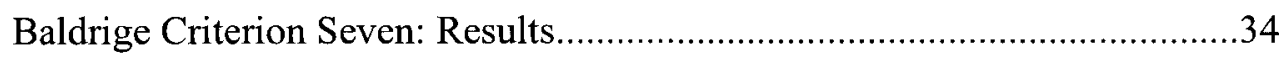

The American Society of Training and Development's BEST Award.................36

BEST Criterion One: Strategic Alignment with Organizational Goals ...........36

BEST Criterion Two: Measurement of Workplace Learning

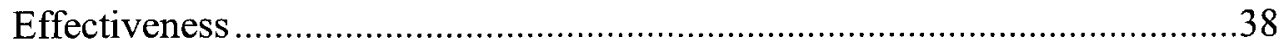

BEST Criterion Three: Delivery Methods..................................................47

BEST Criterion Four: Perceived Value of Workplace Learning Within

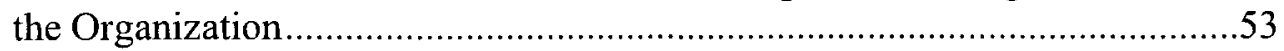

Relationship between Organizational Excellence and Workplace Learning

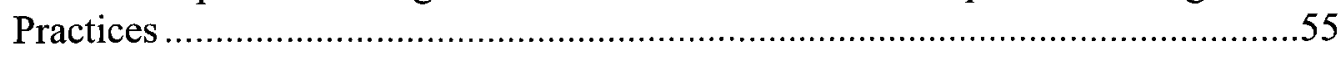

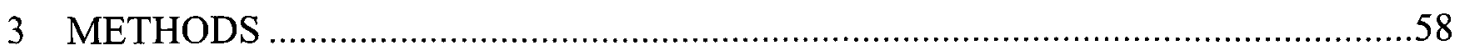

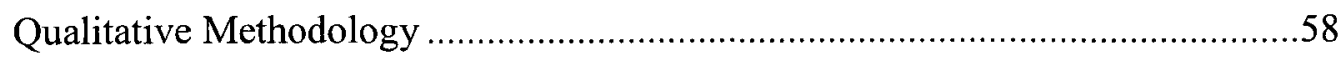

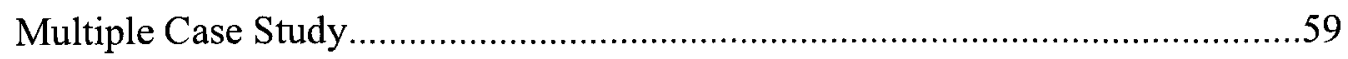




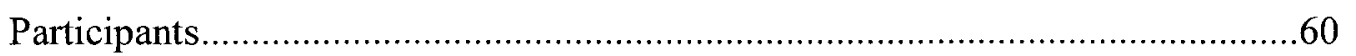

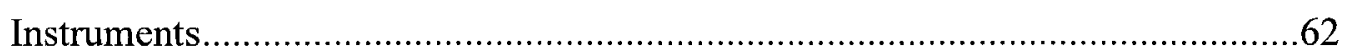

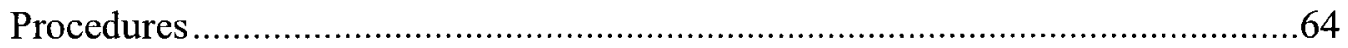

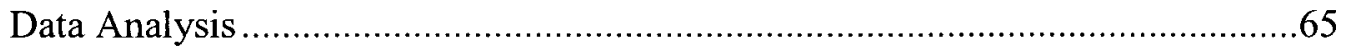

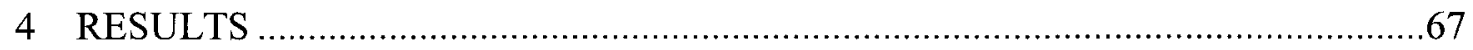

Research Question Results....................................................................67

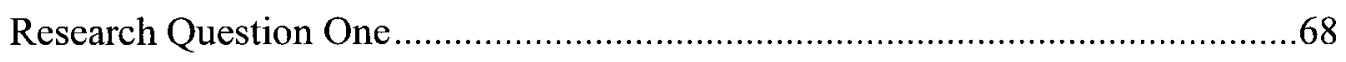

Summary Research Question One .......................................................94

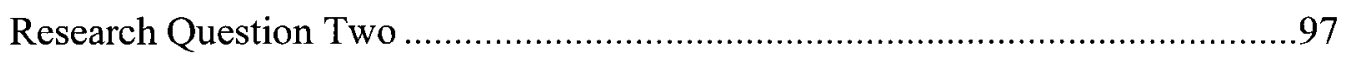

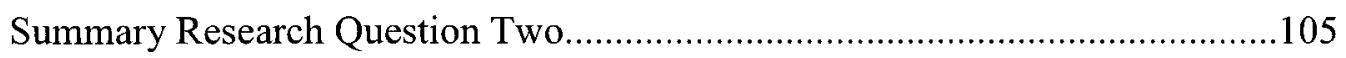

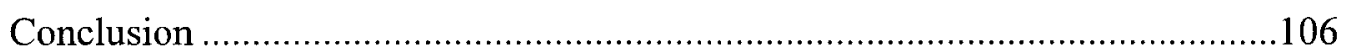

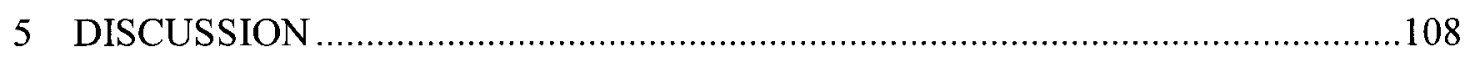

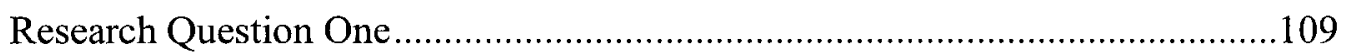

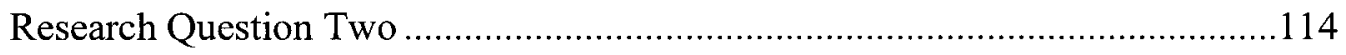

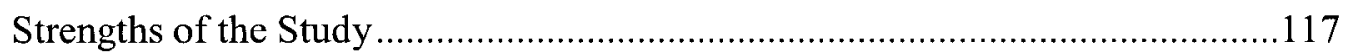

Limitations of the Study ...............................................................118

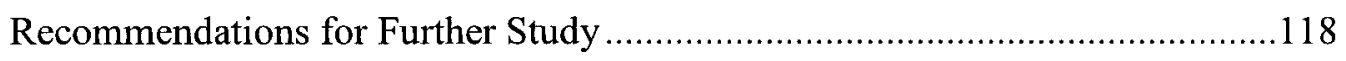

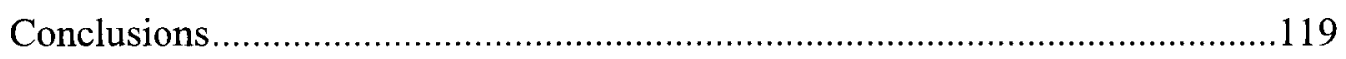

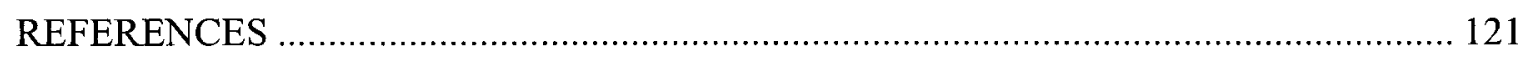

\section{APPENDIX}

INTERVIEW ITEMS 


\section{LIST OF TABLES}

PAGE

Table 1. The Five Practices and Ten Commitments of Leadership ..................................13

Table 2. The 20 Insights of Developing Great Leaders ...............................................16

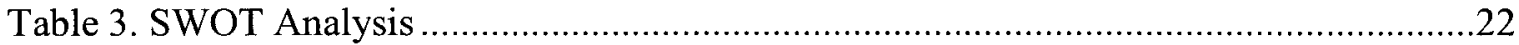

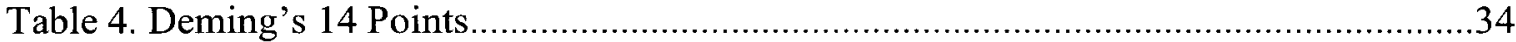

Table 5. Comparison of Katzell's and Kirkpatrick's Evaluation Models..............................40

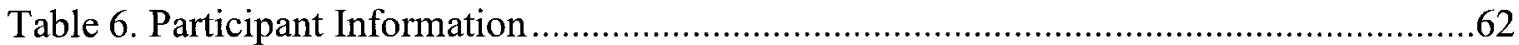

Table 7. Item Number 1: What Factors Does Your Organization Consider when Making a Decision to Provide Workplace Learning?

Table 8. Item Number 2a: How Are Your Workplace Learning Initiatives Planned?

What Stakeholders Participate?

Table 9. Item Number 2b: How Are Your Workplace Learning Initiatives Approved? What Stakeholders Participate?

Table 10. Item Number 2c: How Are Your Workplace Learning Initiatives Communicated to the Organization? What Stakeholders Participate?

Table 11. Item Number 3: Is the CEO or Equivalent Directly Involved in the Planning of, Participating in or Evaluating of Your Workplace Learning Initiatives?

Table 12. Item Number 4. Is There an Annual Planning Schedule for Workplace Learning or Are Training Programs Developed and Delivered as the Need Arises?

Table 13. Item Number 5. What One Workplace Learning Initiative Do You Believe Has Impacted Your Organization the Most and How, e.g., Sales Training that Increased Sales; Change Management Training that Helped the Employees Embrace a Significant Change in the Way Things Are Done; Customer Service Training that Reduced the Number of Customer Complaints

Table 14. Item Number 6. What Role Do You Believe Your Workplace Learning Strategy Played in Helping Your Organization Receive the Baldrige?

Table 15. Item Number Seven. Do You Want to Say Anything Else about How You Conceptualize and Deliver a Strategic Plan for Workplace Learning?

Table 16. Item Number 8. Do You Evaluate and Measure the Effectiveness of Your Workplace Learning Initiatives? If Not, Why? If so, Are All Programs Evaluated and with What Metrics, e.g., Training Attendance, Employee 
Retention Figures, Employee Satisfaction Surveys, Productivity, Increased

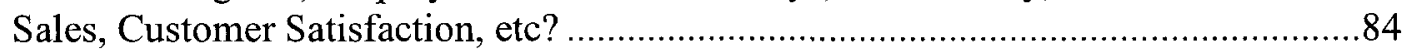

Table 17. Item Number 9. What Delivery Methods Do You Use?.......................................87

Table 18. Item Number 10. What Determines the Delivery Method? .................................89

Table 19. Item Number 11. Do You Develop Training within the Organization, Hire Consultants, Buy Off-the-shelf Content or Use a Combination?

Table 20. Item Number 12. What Would You Say Are the Most Critical Issues Facing Your Organization Today and How Will the Learning Function Provide Solutions to These Issues?

Table 21. Item Number 13. Is There a C Level Officer of Learning? If Not, What Is the Title of the Person Responsible for the Workplace Learning Function and to Whom Does This Person Report?

Table 22. Item Number 14. Is the Person Responsible for the Workforce Learning Function Included in the Organization's Strategic Planning Sessions? If Not, How Are New Strategic Plans and Organizational Changes Conveyed to This Person?.

Table 23. Item Number 15. In What Other Ways Do Senior Level Members Show Support for Workplace Learning?

Table 24. Item Number 16. Do You Have a Leadership Development Program(s) and if so How Are Participants Chosen?

Table 25. Item Number 17. How Does Workplace Learning Factor into Your Employees' Performance Review? Do Your Employees Write Performance Goals that Include Training? 


\section{LIST OF FIGURES}

PAGE

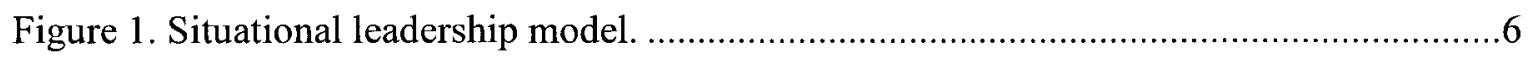

Figure 2. The leadership code model ..................................................................... 11

Figure 3. The Zenger/Folkman leadership tent model................................................14

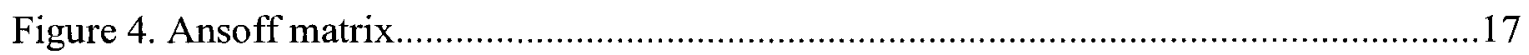

Figure 5. Porter's five forces model of competition. ................................................... 18

Figure 6. Michael Porter's value chain. ........................................................................19

Figure 7. Strategy maps: The simple model of value creation. ..........................................20

Figure 8. A simple process model.......................................................................... 31

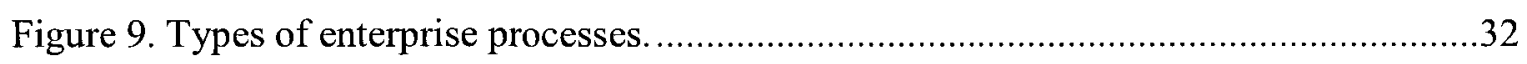

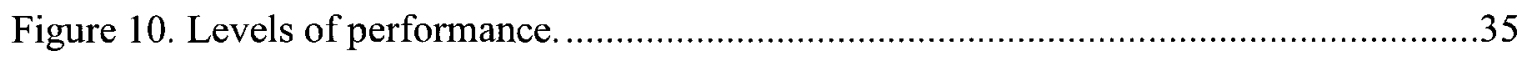

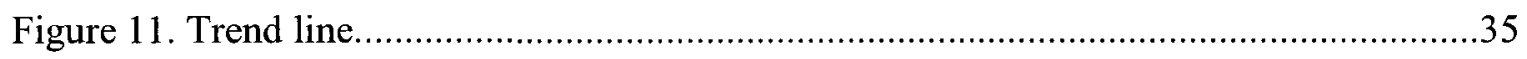

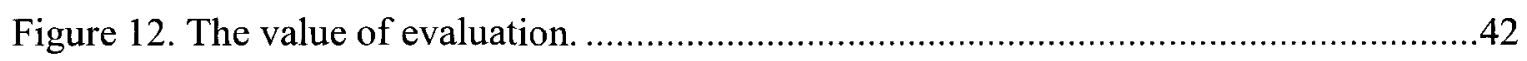

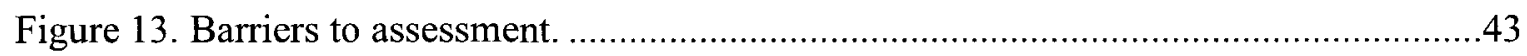

Figure 14. Ratio of organization who reported using a Successful Case evaluation..............44

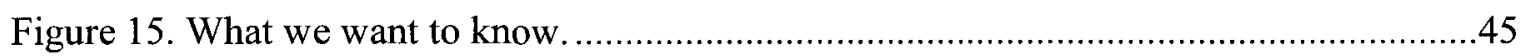




\section{ACKNOWLEDGEMENTS}

I would first like to thank my chair, Dr. Ian Pumpian, for his guidance and patience throughout this dissertation process. His willingness to take me under his wing and add my project to his very long list of responsibilities is very much appreciated. I also want to thank my committee Dr. Douglas Fisher and Dr. Nancy Frey for agreeing to step in at the last minute to help me finish. A simple thank you is not enough to express my gratitude. I would also like to thank former committee members, who for various reasons were unable to complete this project with me, Dr. David Herrera and Dr. Athena Perrakis. A special thank you belongs to Dr. Herrera for his thoughtful assistance and wisdom, I will always be grateful.

I wish to thank all of my very talented joint doc colleagues who made this journey enjoyable and memorable with special thanks to Dr. Lorah Bodie, Dr. Jane Leonard, Dr. Sabine Lawless-Reljic, Dr. Vera Ashley, and Dr. DeVere Wolsey for their friendship.

I would like to acknowledge some of my coworkers at the San Diego County Regional Airport Authority: Diann Wilson for knowing I was in this program and hiring me anyway, Vatana Kang for her questioning spirit and friendship, David Boenitz for his process management knowledge and willingness to share it and Dennise Acosta for her hard work transcribing the interviews.

Finally, my sincerest thank you to all of the participants who allowed me into their work lives and who provided the interviews that made this project possible: Mesa Products, Inc., Jenks Public School District, the VA's Cooperative Studies Program Clinical Research Pharmacy Coordinating Center, The Ritz-Carlton in Laguna Niguel, Solar Turbines, Inc. \& Sharp HealthCare. 


\section{CHAPTER 1}

\section{INTRODUCTION}

A journey of a thousand miles begins with a single step.

Lao-tzu

In the world of sports proof of excellence is an Olympic gold medal, a green jacket, or an invitation to the NCAA's Sweet Sixteen party. In the entertainment industry excellence is called Oscar, Emmy, or Tony, and for organizations, proof of excellence is named Malcolm Baldrige.

The Malcolm Baldrige National Quality Award (Baldrige) was created by congress in 1987 to: identify and recognize role-model businesses; establish criteria for evaluating improvement efforts; and disseminate and share best practices (National Institute of Standards and Technology [NIST], 2009b). It is given to U.S. businesses in six sectors: manufacturing, service, small business, education, health care and public/nonprofit. Each organization is judged to be outstanding in seven areas: leadership; strategic planning; customer focus; measurement, analysis, and knowledge management; workforce focus; process management; and results (NIST, 2009b).

While recipients of the Baldrige must excel in all seven criteria this study examined a sub-section of the workforce focus criteria which explores the learning function within an organization. The workforce criterion examines how an organization develops its leaders and workforce, how it determines learning needs and how it evaluates the effectiveness of its learning practices (NIST, 2009b).

Even though the scope of this study is narrow, it is believed that the learning function within Baldrige recipient organizations plays a significant role in supporting each of the other six criteria. The learning function supports the leadership criteria by designing programs that develop leaders and improve leadership effectiveness, by developing training that helps the employee clearly understand his or her role in the organization's strategic plan, by examining customer and market data and creating educational opportunities to help the organization improve performance, e.g., sales or customer service training. 
The learning function also helps manage the organization's knowledge and finds methods for distributing that knowledge to ensure organizational sustainability, it facilitates training and education regarding process improvements and manages the organization's workforce learning function results.

The purpose of this study is threefold: (1) to evaluate the role the learning function plays in the pursuit of organizational excellence with the goal of identifying key factors, models and descriptions of successful workplace learning practices, (2) to contribute to the field of research in the area of workplace learning practices, and (3) to bring together academic theorizing and practitioner practicality.

One of the assumptions of this study is a positive relationship between receiving the Baldrige (obtaining organizational excellence) and the effectiveness of workplace learning efforts. To offer a framework for understanding excellence in workplace learning this study will use the criteria established by the American Society for Training and Development (ASTD).

The ASTD is the world's largest professional association dedicated to understanding workplace learning and has conducted research on workplace learning excellence since 1943 (American Society for Training \& Development [ASTD],2009a). In 2002 ASTD introduced its BEST Award which is given to organizations for demonstrating enterprise-wide success as a result of employee learning and development (ASTD, 2009a). The BEST criteria looks at the following variables: learning and its value in the organization's culture, a link between learning and performance, and the presence of innovative learning initiatives (ASTD, 2009a).

In addition to presenting the BEST award annually, the ASTD also honors one doctoral student by awarding the ASTD's Dissertation Award for fostering and disseminating research in the practice of workplace learning and performance and is presented to the person who has submitted the best doctoral dissertation for which a degree has been granted (ASTD, 2011).

The ASTD has honored dissertations for research in the areas of determining job stress in health organizations (Gilbert, 2003), the impact of gender on performance ratings and potential career-related outcomes (Frame, 2004), feedback for development purposes (Byham, 2006; Orvis, 2007), and the transfer of learning from an executive education program (Ciporen, 2008). One dissertation used the Baldrige healthcare criteria as a 
framework for a study about the relationship between human resource practices and performance outcomes in the long-term healthcare industry (Akdere, 2005) but no award recipients have examined the role workplace learning practices play in achieving public recognition for overall organizational excellence.

It is believed this study will advance research in this area and is needed to provide any evidence that a relationship might exist with respect to meeting criteria for public recognition awards for overall organizational excellence and excellence in workplace learning practices. It will do this by examining the workplace learning practices of organizations that have earned recognition for organizational excellence by receiving the Malcolm Baldrige National Quality Award and comparing their workplace learning practices to the criteria established by the ASTD.

If, as hypothesized, these relationships exist, organizational leaders and those responsible for workplace learning would be justified in concentrating their efforts on promoting workplace learning practices as one key factor toward achieving overall organizational excellence. Further, this study is designed to improve approaches organizations use to design and deliver workplace learning and to provide support for advocating for increases in dollars and resources allocated to those strategic plans.

Aristotle said, "We are what we repeatedly do...excellence, then, is not an act, but a habit." If this is so, organizations that wish to pursue superior performance at all levels must work to ensure that the characteristics defining excellence are practiced, and then practiced again, until they, ..., become an involuntary reaction (Capodagli \& Jackson, 1999).

This study may inform organizational leaders that investing in a culture of learning may be a key to organizational excellence. 


\section{CHAPTER 2}

\section{LITERATURE REVIEW}

Outside of a dog, a book is a man's best friend. Inside of a dog it's too dark to read. Groucho Marx

This chapter is dedicated to understanding two concepts: organizational excellence and workplace learning excellence. These two concepts, and the relationship between them will be reviewed by examining the literature on the criteria for two awards of excellence: the Malcolm Baldrige Quality Award (Baldrige), given for organizational performance excellence and the BEST Award given by The American Society of Training and Development for workplace learning excellence.

This chapter is divided into three sections. The first section reviews the literature on the criteria topics used by the Baldrige Award, section two examines the literature on the BEST Award criteria topics and the third section finishes the chapter with a discussion of the observed and theoretical relationship between organizational and workplace learning excellence.

\section{The Malcolm Baldrige National Quality Award}

The Malcolm Baldrige National Quality Award was created by Public Law 100-107 and was signed into law on August 20, 1987. The Award was named for Malcolm Baldrige, who served as Secretary of Commerce from 1981 until his death in 1987. Baldrige was an advocate of quality management as a key to U.S. prosperity and sustainability and believed that American companies needed to focus on quality in order to compete in an everexpanding, demanding global market (NIST, 2009b).

The Award has been given by the President of the United States to 87 organizations in both the public and private sectors since 1988. Recipients have varied considerably by size and type but all are judged to be outstanding in seven areas: leadership; strategic planning; customer focus; measurement, analysis, and knowledge management; workforce focus; process management; and results. 


\section{Baldrige Criterion One: Leadership}

In 1985 Warren Bennis and Burt Nanus wrote in their iconic book Leaders that decades of academic analysis had given us more than 350 definitions of leadership (p. 4). Today, in 2010, a Google search of the word leadership produces over 150,000,000 hits. Refining that search to organizational leadership results in $8,980,000$ hits. Bottom line conducting research on leadership is an arduous task.

The anthology on leadership includes the work of many scholars that have conducted extensive research in this area and developed respected theories and while their work is not examined in this study they may have influenced the work of those that are. They include: James MacGregor Burns (2003) and his work on transformational leadership, Robert Greenleaf (1977) and servant leadership, and The University of San Diego's own Joseph Rost's (1993) work on post-industrial leadership. Earlier authors in this area that may also have influenced the theories presented in this study include: Robert Blake and Jane Mouton (1964) and their managerial grid, Douglas McGregor's (1960) theory X and theory Y, and Rensis Likert's (1961) four systems of management: exploitive authoritative, benevolent authoritative, consultative, and participative.

The information on leadership presented in this study comes from some of those considered contemporary thought leaders in the field. Each individual has published work and developed a theory on evidenced based research. They are Paul Hersey, Ken Blanchard, Dewey Johnson, Marshall Goldsmith, Dave Ulrich, Norm Smallwood, Kate Sweetman, Jim Kouzes, Barry Posner, John Zenger \& Joe Folkman.

In the late 60's Paul Hersey and Ken Blanchard came together and conducted research on their observation that an organization is a unique living organism whose basic component is the individual. Their concentration was on the interaction of people, motivation, and leadership within an organization and not between organizations. Their resulting theory is known as Situational Leadership and is comprised of two dimensions: a leader's leadership style and a follower's readiness level. In 1982 Ken Blanchard and his colleagues at Blanchard Training and Development began to modify the original model and developed their approach called Situational Leadership II. The model reported in this study comes from Paul Hersey, Ken Blanchard and Dewey Johnson's (2001) book Management of 
Organizational Behavior. Leading Human Resources Etghth Edition and reflects what is currently taught at Paul Hersey's Center for Leadership Studies

Accordıng to Situational Leadership, there is no one best way to influence people Which leadership style a person uses with individuals or groups depends on the readiness level of the people the leader is attempting to influence (Hersey et al, 2001)

Hersey et al. (2001) define leadershıp style as the behavior by the leader as perceived by the followers and is made up of task behavior and relationshıp behavior (Hersey et al, 2001) The Situational Leadership Model (Figure 1) shows the relationship between task behavior located on the $\mathrm{x}$ axis and relationship behavior located on the $\mathrm{y}$ axis.

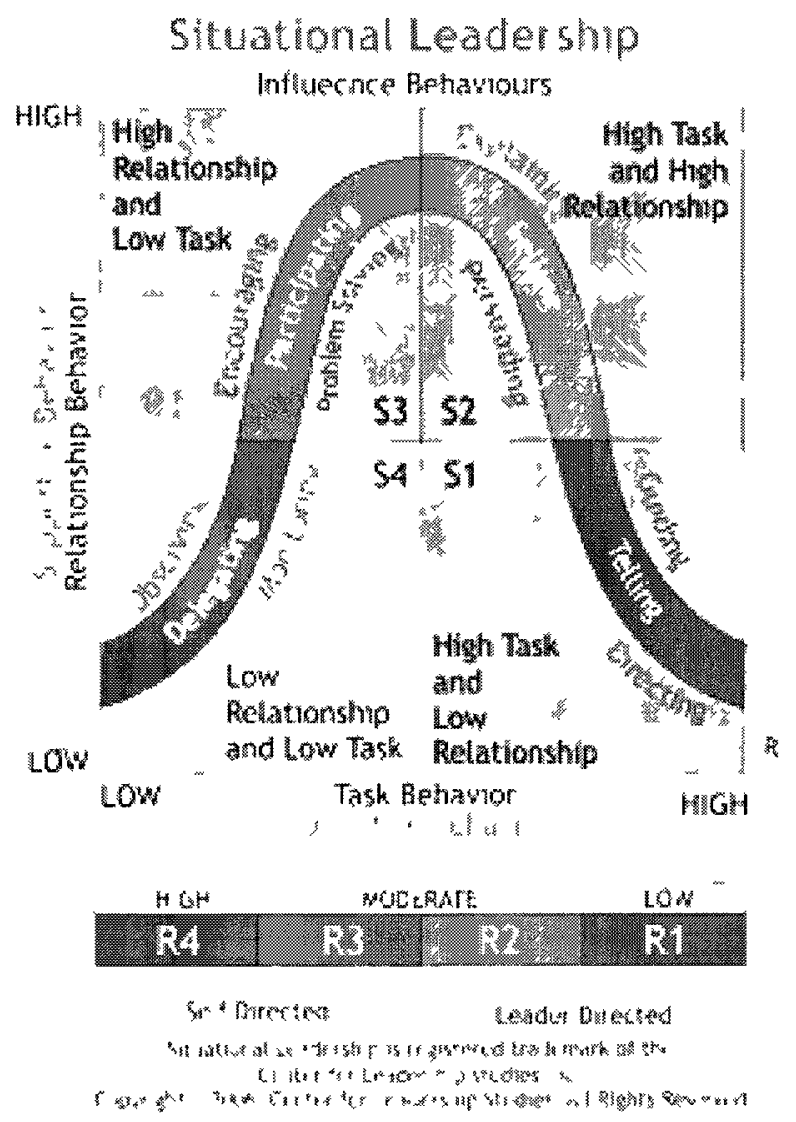

Figure 1. Situational leadership model. Source: Hersey, P., Blanchard, K., \& Johnson, D. (2001). Management of organizational behavior: Leading human resources (8th ed.). Upper Saddle River, NJ: Prentice Hall. 
Task behavior and relationship behavior are separate and distinct dimensions. Task behavior is defined as the extent to which the leader engages in spelling out the duties and responsibilities of an individual or group. These behaviors include telling people what to do, how to do it, when to do it, where to do it, and who is to do it (Hersey et al, 2001).

Relationship behavior is defined as the extent to which the leader engages in two-way or multi-way communication. The behaviors include listening, facilitating, and supportive behaviors (Hersey et al, 2001).

From this matrix four leadership style quadrants emerge. They range from High Task and Low Relationship to Low Task and Low Relationship. They are defined as follows: Style 1 (S1). This leadership style is characterized by above average amounts of task behavior and below-average amounts of relationship behavior. Style 2 (S2). This leadership style is characterized by above average amounts of both task and relationship behavior. Style 3 (S3). This leadership style is characterized by above average amounts of relationship behavior and below average amounts of task behavior. Style 4 (S4). This style is characterized by below average amounts of both relationship and task behavior (Hersey et al, 2001).

The second dimension of Situational Leadership is the Readiness Level of the follower(s). Readiness in Situational Leadership is defined as the extent to which a follower demonstrates the ability and willingness to accomplish a specific task. The two major components of readiness are ability and willingness. Ability is the knowledge, the demonstrated understanding of a task; experience, the demonstrated ability gained from performing a task; and skill, the demonstrated proficiency in a task, that an individual or group brings to a particular task or activity (Hersey et al, 2001).

Willingness is the extent to which an individual or group has the confidence, the demonstrated assurance in the ability to perform a task; commitment, the demonstrated duty to perform a task; and motivation, the demonstrated desire to perform a task (Hersey et al, 2001).

To use Situational Leadership effectively one must determine the readiness level of the follower. For example, a leader would begin by asking, "Can the follower do the task?" In other words is the follower able. If the answer is yes they are either in readiness level 3 or 4 , if not then they would be placed in readiness level 1 or 2 . Next, ask "Is the follower 
willing to do the task?" If the answer is yes and able they will fall into readiness level 4 if yes and unable then level 2 best describes their readiness level. If the answer is no, they are unwilling, then the follower falls into readiness level 1 if unable to do the task but in readiness level 3 if able to do the task but unwilling (Hersey et al 2001). Typically leaders would follow the four quadrants from $\mathrm{S} 1$ to $\mathrm{S} 4$ for employees that are new and are building ability and would follow the quadrants in reverse order from S4 to S1 for employees whose performance is slipping.

This concept is best illustrated by an example. Employee 1 is a new hire and a recent college graduate but insecure about applying college theory to workplace practice.

Employee 2 is a very experienced employee who has been passed over for promotions due to the lack of a college degree and is angry. Employee 2 is demonstrating an unwillingness to perform tasks to a previously demonstrated higher standard. Leader A now needs to determine which leadership style to use on each of these employees.

Leader A begins by asking, "Are these employees able to do the task?" Employee 1 is new and has no practical experience performing the task so the answer is, no. Employee 2 on the other hand has years of experience which has been demonstrated. The answer is clearly, yes. Now Leader A must ask, "Are these employees willing to do the task?" Employee 1 is eager and very willing but insecure. Employee 2 is very unwilling to cooperate.

Using the Situational Leadership Model to determine placement of each employee the results conclude that Employee 1 falls into readiness level 1 (R1) while Employee 2 resides in readiness level 3 (R3). Looking at the leadership style quadrants (Figure 1) Leader A simply needs to match leadership styles with the correct readiness level. In this case, Employee 1 would need Leader A to provide specific instructions and to closely supervise her performance. As her confidence and ability increase Leader A would adapt by directing less and delegating more.

Employee 2 would need Leader A to start problem solving with him. If a solution is found then Employee 2 will quickly move back into R4 status but if Employee 2 regresses further, Leader A would move backward to persuading in quadrant S2 and possibly all the way back to directing in quadrant S1. 
Situational Leadership Theory provides a roadmap while acknowledging the importance of a leader adapting their own preferred leadership style to the readiness level of each member of their team.

Another leadership development method that has increased in popularity over the last 5 to 8 years is executive coaching and there is no bigger name in the executive coaching world than Marshall Goldsmith.

In an article he and Howard Morgan wrote for strategy + business in August of 2004 titled "Leadership is a Contact Sport: The 'Follow-up Factor' in Management Development" Goldsmith details the findings of a study conducted to see if there were consistent principles of success underling different approaches to leadership development (p. 72). They reviewed leadership development programs in eight major corporations each using different leadership development methodologies: offsite training versus onsite coaching, short duration versus long duration, internal coaches versus external coaches, and traditional classroom-based training versus on-the-job interaction (Goldsmith \& Morgan, 2004, p. 72).

All eight organizations placed a set of expectations upon their participants. The developing leaders were expected to: review their 360-degree feedback with an internal or external consultant; identify one to three areas for improvement; discuss their areas for improvement with key co-workers; ask colleagues for suggestions on how to increase effectiveness in selected areas for change; follow up with co-workers to get ideas for improvement; and have co-worker respondents complete a confidential customer-designed "mini-survey" three to 15 months after the start of their programs (Goldsmith \& Morgan, 2004, p. 72).

Each of the eight companies measured the participants' perceived increase in leadership effectiveness over time. "Increased effectiveness" was not determined by the participants in the development effort; it was assessed by preselected co-workers and stakeholders (Goldsmith \& Morgan, 2004, p. 72).

The results of this study showed one variable central to the success of positive longterm change: the participant's ongoing interaction and follow-up with colleagues. They found that leaders who discussed their own improvement priorities with their co-workers, and then regularly followed up with these co-workers, showed striking improvement. Leaders who did not have ongoing dialogue with colleagues showed improvement that barely exceeded 
random chance. This was true whether the leader had an external coach, an internal coach, or no coach. It was also true whether the participants went to a training program for five days, went for one day, or did not attend a training program at all (Goldsmith \& Morgan, 2004, p. 72).

Goldsmith and Morgan (2004) came to four conclusions with this study. The first and core conclusion was, for most leaders, the great challenge is in not understanding the practice of leadership: it is practicing their understanding of leadership (p. 75). The second conclusion was that the follow-up factor correlates with improved leadership effectiveness among both U.S. and non-U.S. executives (p. 77). The third conclusion found that both internal and external coaches can make a positive difference and the fourth and last conclusion was that feedback or coaching by telephone works about as well as feedback or coaching in person (p. 78).

The Leadership Code: Five Rules to Live By (2008) was written by Dave Ulrich, Norm Smallwood, and Kate Sweetman and presents five rules that are aligned with five roles they believe are essential for leaders to adopt if they want to be successful. Figure 2 illustrates The Leadership Code model. The model is placed on two dimensions: time and focus. At the center of the model is the fifth rule they call personal proficiency. It is placed at the center as an underlying support for the time and focus dimensions (p. 13).

Rule number one is called Shape the Future. It is long term, strategic, time bound, and organizationally focused. The strategist role embodies this first rule. Strategists answer the question "Where are we going?" Strategists figure out where the organization needs to go to succeed, they test their ideas pragmatically against current resources, and they work with others to figure out how to get from the present to the desired future. The rules for strategists are about creating, defining, and delivering principles of what can be (Ulrich et al., 2008, p. 14-15).

Rule number two is labeled Make Things Happen and is about turning what you know into what you do. The role aligned with this rule is the executor who must focus on this question, "How will we make sure we get to where we are going?" The executor takes a near term, operational look at the organization and translates the strategy into action. The rules for executors revolve around disciplines for getting things done (Ulrich et al., 2008, p. 15). 


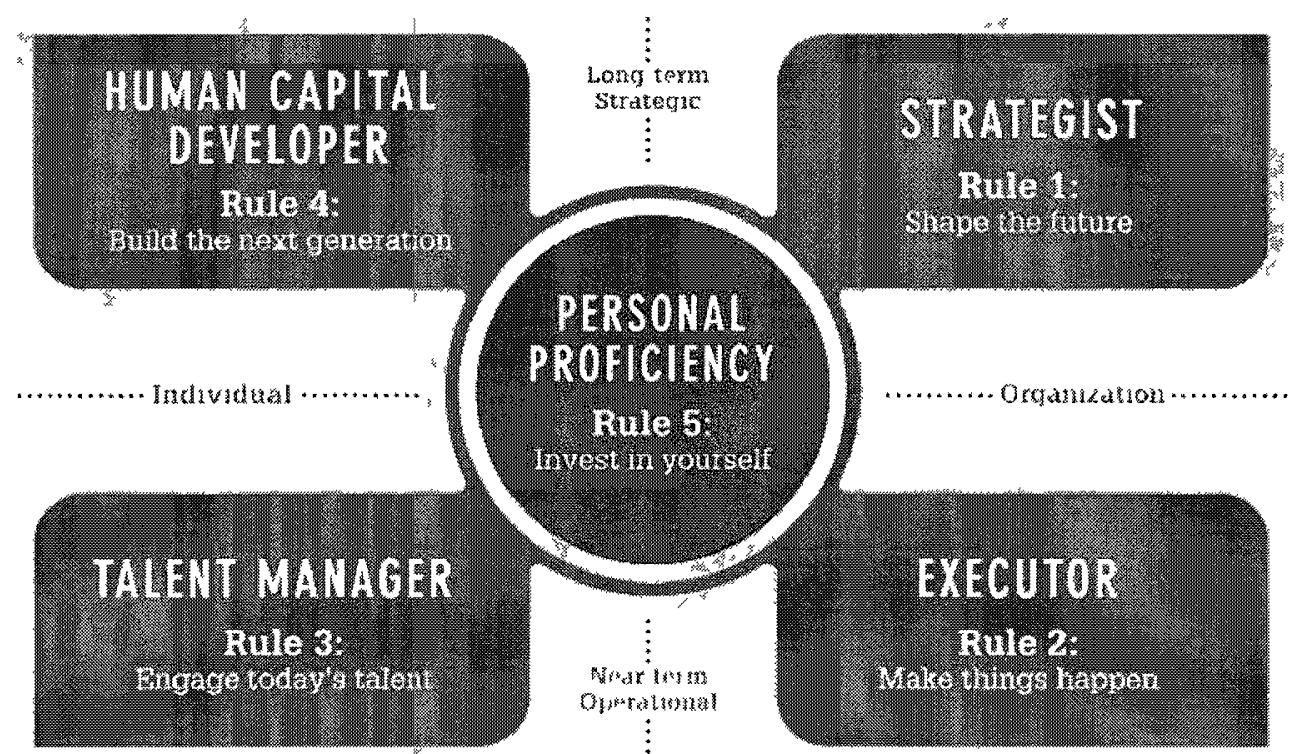

Figure 2. The leadership code model. Source: Ulrich, D., Smallwood, N., \& Sweetman, K. (2008). The leadership code: Five rules to lead by. Boston, MA: Harvard Business Press.

Engage Today's Talent is rule number three. The talent manager role is responsible for answering the question, "Who goes with us on our business journey?" Talent mangers must be gifted at generating intense personal, professional, and organizational loyalty. The rules for talent managers center around resolutions that help people develop themselves for the good of the organization (Ulrich et al., 2008, p. 15-16).

The fourth rule is Build the Next Generation. Leaders who take on the role of human capital builders are looking at individuals for the long term strategic success of the organization. They answer the question, "Who stays and sustains the organization for the next generation?" This role focuses on developing future leaders to insure success of the organization. Human capital builders put into place the rules that demonstrate a pledge to building the next generation of talent (Ulrich et al, 2008, p. 16).

The fifth and final rule is Invest in Yourself. Personal proficiency lies at the heart of this rule and the code both literally and figuratively. Leaders are learners, they are passionate about their beliefs and interests, they inspire loyalty and goodwill in others, are decisive and impassioned and confident in their ability to deal with situations. Personally proficient leaders can tolerate ambiguity. Leaders who demonstrate personal proficiency follow rules 
about developing and increasing personal insight so that they model the change they want to see in others (Ulrich et al., 2008, p. 18).

Ulrich et al.'s (2008) research and resulting leadership code theory is based on four summary observations: all leaders must excel at personal proficiency; all leaders must have one towering strength with regard to the other four roles; all leaders must be at least average in their "weaker" role; and the higher up the organization the leader rises, the more he or she needs to develop excellence in more than one of the four domains (p. 19).

The Leadership Challenge written by Jim Kouzes and Barry Posner (2002) has its origins in a research project Kouzes and Posner began in 1983. They wanted to know what people did when they were at their "personal best" in leading others. They started with the assumption, however, that they did not have to interview and survey star performers in excellent companies to discover best practices. They assumed that by asking ordinary people to describe extraordinary experiences, they would find patterns of success (Kouzes \& Posner, 2002).

After some preliminary research, Kouzes and Posner devised a personal-best leadership survey consisting of thirty-eight open-ended questions. By 1987, they had performed more than 550 of these surveys, each requiring one to two hours of reflection and expression. At the same time, a shorter, two-page form was completed by another group of 80 managers, and the researchers conducted an additional 42 in-depth interviews. In the initial study, they examined the cases of middle and senior level managers in private and public sector organizations. Since that time they have expanded their research and collected thousands of additional cases. This expanded coverage included community leaders, student leaders, church leaders, government leaders, and hundreds of others in non-managerial positions (Kouzes \& Posner, 2002).

Their research revealed that leadership is a reciprocal process between a leader, someone who aspires to lead and a constituent, someone who chooses to follow. Any discussion of leadership must attend to the dynamics of this relationship. Strategies, tactics, skills, and practices are empty without an understanding of the fundamental human aspirations that connect leaders and constituents (Kouzes \& Posner, 2002). The study of this dynamic led them to the development of a model they call The Five Practices of Exemplary Leadership. Embedded in The Five Practices are behaviors that serve 
as the basis for learning to lead. Kouzes and Posner call these behaviors The Ten Commitments. Table 1 shows the relationship between the practices and commitments.

Table 1. The Five Practices and Ten Commitments of Leadership

\begin{tabular}{|c|c|}
\hline \multicolumn{2}{|c|}{ THE FIVE PRACTICES AND TEN COMMITMENTS OF LEADERSHIP } \\
\hline Practices & Commitments \\
\hline Model the Way & $\begin{array}{l}\text { Find your voice by clarifyıng your personal values. } \\
\text { Set the example by alıgning actions with shared values. }\end{array}$ \\
\hline Inspire a Shared Vision & $\begin{array}{l}\text { Envision the future by ımagınıng excitıng and ennobling possibılities } \\
\text { Enlist others in a common visıon by appealıng to shared aspirations. }\end{array}$ \\
\hline Challenge the Process & $\begin{array}{l}\text { Search for opportunities by seeking innovatıve ways to change, grow, and improve. } \\
\text { Experiment and take risks by constantly generatıng small wins and learning from } \\
\text { mistakes. }\end{array}$ \\
\hline Enable Others to Act & $\begin{array}{l}\text { Foster collaboration by promoting cooperative goals and building trust. } \\
\text { Strengthen others by sharıng power and discretion. }\end{array}$ \\
\hline Encourage the Heart & $\begin{array}{l}\text { Recognize contributions by showing appreciation for individual excellence. } \\
\text { Celebrate the values and victories by creating a spirit of community. }\end{array}$ \\
\hline
\end{tabular}

Source: Kouzes, J., \& Posner, B. (2002). The leadership challenge (3rd ed.) San Francisco, CA: Jossey-Bass

One of the most comprehensive methods for studying the behavior of a leader is through the lens of a 360-degree questionnaire. A 360-degree questionnaire is a view of a leader's behavior looked at through the eyes of those being led (their subordinates), those being influenced (their peers), and those who manage them (their bosses). John Zenger and Joseph Folkman's book The Extraordinary Leader: Turning Good Managers into Great Leaders (2002) is the result of their research which reports the findings from their database of some 200,000 responses, using 360-degree questionnaires.

Zenger and Folkman (2002) focused on the question: What do these three groups (subordinates, peers, and bosses) see in "great leaders" that sets them apart from the average ones? Of those three perspectives, they concluded, the view they valued most was that of the subordinate because they believed subordinates have the most complete and accurate data. Peers and bosses see only slices of a leader's behavior and evidence shows that their perceptions are less accurate than those of the people who report directly to the leader (Zenger \& Folkman, 2002, p. 10). 
Their research concluded that all vital and differentiating leadership competencies could be grouped into five clusters: Character, Personal Capability, Focus on Results, Interpersonal Skills, \& Leading Organizational Change. The conceptual model they choose for ease in remembering and analysis was a tent (I think because all the pyramids were gone that day) as illustrated in Figure 3.

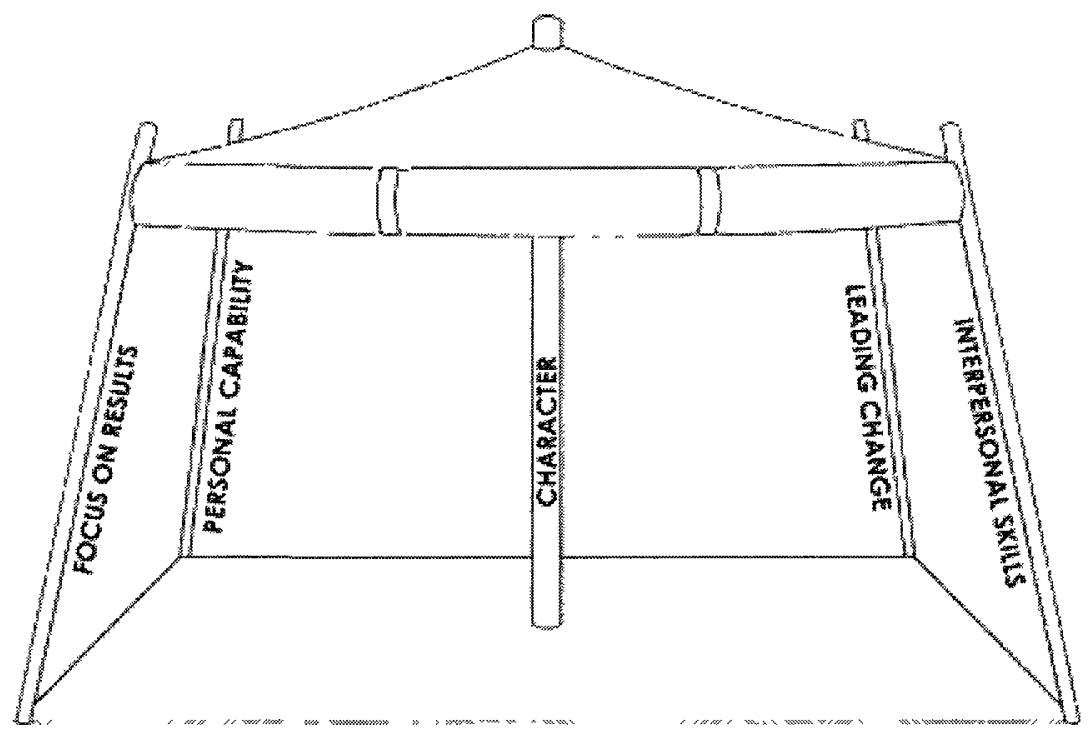

Figure 3. The Zenger/Folkman leadership tent model. Source: Zenger, J., \& Folkman, J. (2002). The extraordinary leader: Turning good managers into great leaders. New York, NY: McGraw-Hill.

The first competency of the Zenger/Folkman model is Character and is represented as the center pole of the tent because they believe personal character is the core of all leadership effectiveness (Zenger \& Folkman, 2002, p. 13). Included in the character competency are ethical standards, integrity, and authenticity. Zenger/Folkman believe that leaders with a strong character are never afraid to be open and transparent (Zenger \& Folkman, 2002, p. 13).

The next competency is Personal Capability which describes the intellectual, emotional, and skill makeup of the individual. It includes analytical and problem-solving capabilities, along with the technical competence the leader possesses. It requires an ability to create a clear vision and sense of purpose for the organization (Zenger \& Folkman, 2002, p. 14). 
The third competency represents the behaviors that enable one to Focus on Results. It describes the ability to have an impact on the organization and being capable of getting things accomplished (Zenger \& Folkman, 2002, p.14).

The fourth tent pole is Interpersonal Skills and captures in this one cluster all of the people skills. It is the communication process and is the impact that the leader has on a group of people. It is the direct expression of the character of the individual and is often the window by which people understand the personal character of the leader (Zenger \& Folkman, 2002, p. 14).

The fifth tent pole and final competency is Leading Organizational Change. It is the ability to produce and lead change within an organization (Zenger \& Folkman, 2002, p. 14). Zenger/Folkman note that for many leadership roles, the first four tent poles may be all that are required. It is not until a person needs to lead a broad, strategic change that the fifth and final tent pole is required (Zenger \& Folkman, 2002, p. 15).

In addition to the Leadership Tent Model Zenger/Folkman's research led them to what they refer to as 20 insights which are presented in Table 2. It is their conclusion that these 20 insights make the difference between developing great leaders and leadership development.

While each of the authors presented has conducted research which led to different evidence-based theories, illustrated their theories using a variety of conceptual models, and developed innovative ways to remember their models they all agree on the basics: great leaders pay attention, continue to learn, take action, are accountable, and model the ideal behavior. Without great leaders an organization cannot achieve excellence. Maybe that is why leadership lies at the beginning of the list of the Baldrige criteria. Now on to criteria number two: strategic planning.

\section{Baldrige Criterion Two: Strategic Planning}

Strategic planning is the systematic process of envisioning a desired future, and translating this vision into broadly defined goals or objectives and a sequence of steps to achieve them. In contrast to long-term planning (which begins with the current status and lays down a path to meet estimated future needs), strategic planning begins with the desired- 
Table 2. The 20 Insights of Developing Great Leaders

\begin{tabular}{|c|c|}
\hline \multicolumn{2}{|r|}{ The 20 Insights of Developing Great Leaders } \\
\hline Insight 1 & Great leaders make a huge difference, when compared to merely good leaders \\
\hline Insight 2 & One organızation can have many great leaders \\
\hline Insight 3 & We have been aiming too low in our leadership development activities \\
\hline Insight 4 & $\begin{array}{l}\text { The relationship between improved leadership and increased performance outcomes is neither } \\
\text { precisely incremental not is it linear }\end{array}$ \\
\hline Insight 5 & $\begin{array}{l}\text { Great leadership consists of possessing several "bullding blocks" of capabilities, each } \\
\text { complementıng the others }\end{array}$ \\
\hline Insight 6 & Leadershıp culmınates in championıng change \\
\hline Insight 7 & $\begin{array}{l}\text { All competencies are not equal Some differentiate good from great leaders, while others do } \\
\text { not }\end{array}$ \\
\hline Insight 8 & Leadership competencies are linked closely together \\
\hline Insight 9 & Effective leaders have widely different personal styles There is no one right way to lead \\
\hline Insight 10 & Effective leadership practices are specific to an organization \\
\hline Insight 11 & The key to developing great leadershıp is to build strengths \\
\hline Insight 12 & Powerful combinations produce nearly exponential results \\
\hline Insight 13 & Greatness is not caused by the absence of weakness \\
\hline Insight 14 & Great leaders are not perceived as having major weaknesses \\
\hline Insight 15 & Fatal flaws must be fixed \\
\hline Insight 16 & Leadershıp attrıbutes are often developed in non obvious ways \\
\hline Insight 17 & Leaders are made, not born \\
\hline Insight 18 & Leaders can improve their leadershıp effectıveness through self-development \\
\hline Insight 19 & $\begin{array}{l}\text { The organization, with a person's immediate boss, provides significant assistance in } \\
\text { developıng leadershıp }\end{array}$ \\
\hline Insight 20 & The quality of leadership is an organization seldom exceeds that of the person at the top \\
\hline
\end{tabular}


end and works backward to the current status (Business Dictionary, n.d.). In other words strategic planning is how we move the organization down the yellow brick road to $\mathrm{Oz}$.

The roots of strategic planning can be traced back to the industrialists of the early 1900s with the publication of Fredrick W. Taylor's The Principles of Scientific Management (1911). Broad-based formal strategic planning became common practice in the 1950 s, driven by the demands of mass reindustrialization following World War II. Dr. Igor Ansoff, considered by many to be the father of strategic management (and planning), developed a very sophisticated and detailed process model that focused on a firm's present and potential products and markets (Dolence, 2004).

His matrix (Figure 4) shows four different growth strategies: market penetration is when a firm seeks to increase growth with existing products within their existing market by improving market share; market development is the strategy of obtaining growth by selling its current products to new target markets; product development is the strategy of growth by developing new products for an existing market and the last growth strategy is diversification which is growth obtained by entering into new businesses and developing new products for new markets (QuickMBA, n.d.).

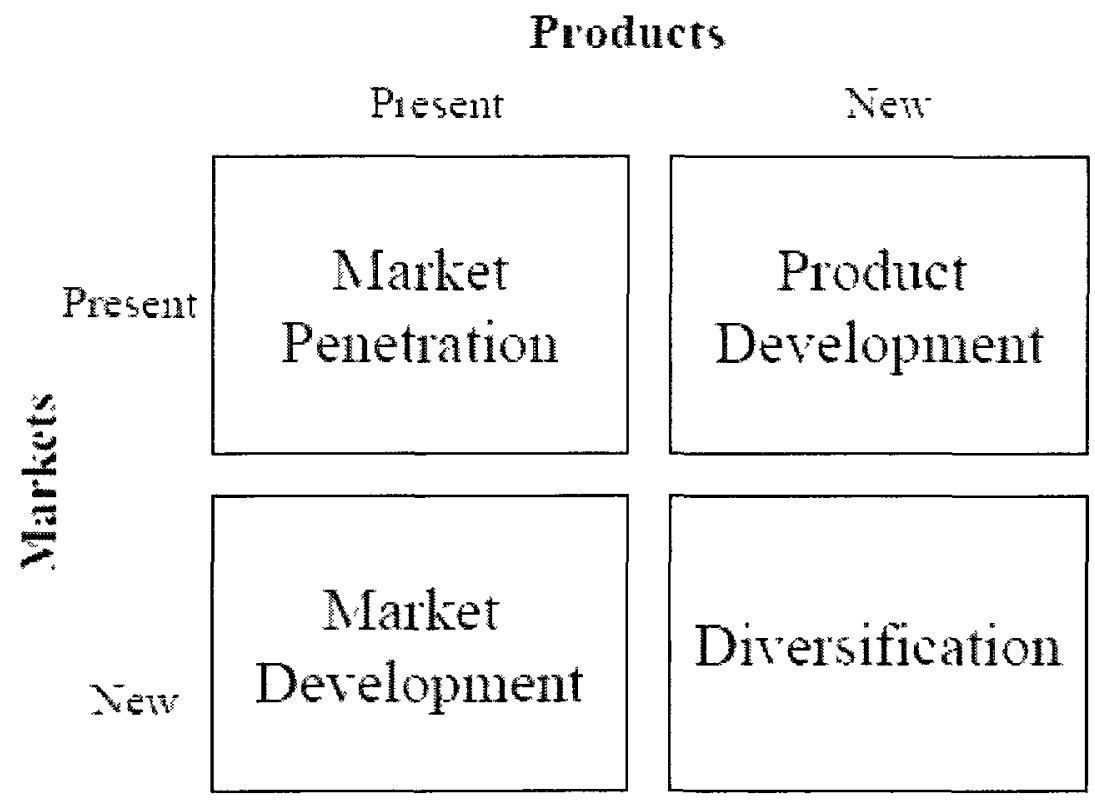

Figure 4. Ansoff matrix. Source: Tradekey Community. (n.d.). Ansoff matrix. Retrieved from www.community.tradekey.com 
Strategic planning was simplified and further popularized by George Steiner in his book Strategic Planning: What Every Manager Must Know (1969). According to Steiner strategic planning consists of linking four distinct points of view: (1) evaluating the futurity of current decisions (looking at the chain of cause and effect consequences over time of an actual or intended decision that will be made); (2) a process of setting organizational aims, defining strategies and policies to achieve them and developing detailed plans to make sure the strategies are implemented; (3) a philosophy or a dedication to contemplating the future, a determination to plan constantly and systematically; and (4) a structured linkage between long- medium and immediate range financial, human resource, product, operating plans, etc (Steiner, 1969, p. 13-17).

Probably the most influential strategist since the 1980's is Michael Porter. He introduced many new concepts including: 5 forces analysis, generic strategies, the value chain, strategic groups, and clusters. In 5 forces analysis Porter identifies the forces that shape a firm's strategic environment. Porter's model (Figure 5) shows how a firm can use these forces to obtain a sustainable competitive advantage.

\section{Porter's Five Forces Model of Competition}

\begin{tabular}{|l|}
\hline Determinants of Supplier Power \\
Supplier concentration \\
Auallability of substitute inpuis \\
importance of suppliers input to buyer \\
Suppliers product differentiation \\
importance of industry to suppliers \\
Buyers switching cost to other input \\
Suppliers' threat of forward inte gration \\
Buyers threat of backward integration \\
\end{tabular}
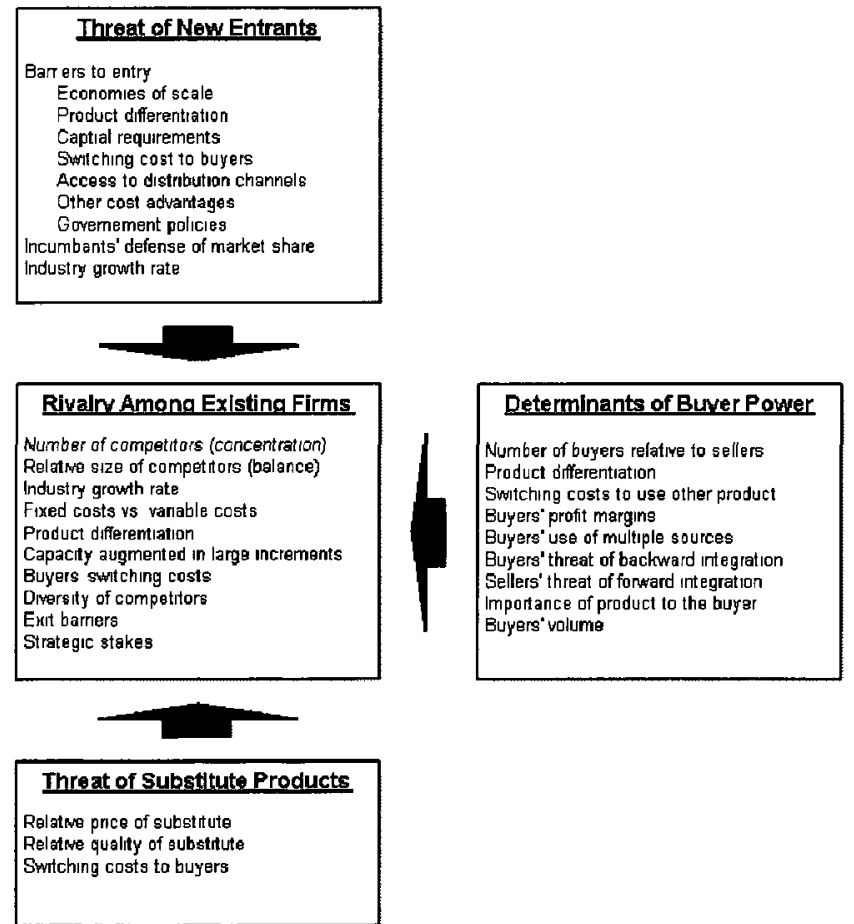

Determinants of Buver Power

Number of buyers relatiye to sellers Product differentiation Swytching costs to use other product Buyers' threat of backward integration Importance of product to the buyer Buyers" volume Sellers' threat of fonward integration

Figure 5. Porter's five forces model of competition. Source: Smartcode. (n.d.). Porter's five forces model of competition. Retrieved from http://software--porter-five-forces.smartcode.com 
Porter's generic strategies model (Figure 6) details the interaction between cost minimization strategies, product differentiation strategies, and market focus strategies. Although he did not introduce these terms, he showed the importance of choosing one of them rather than trying to position a company between them.

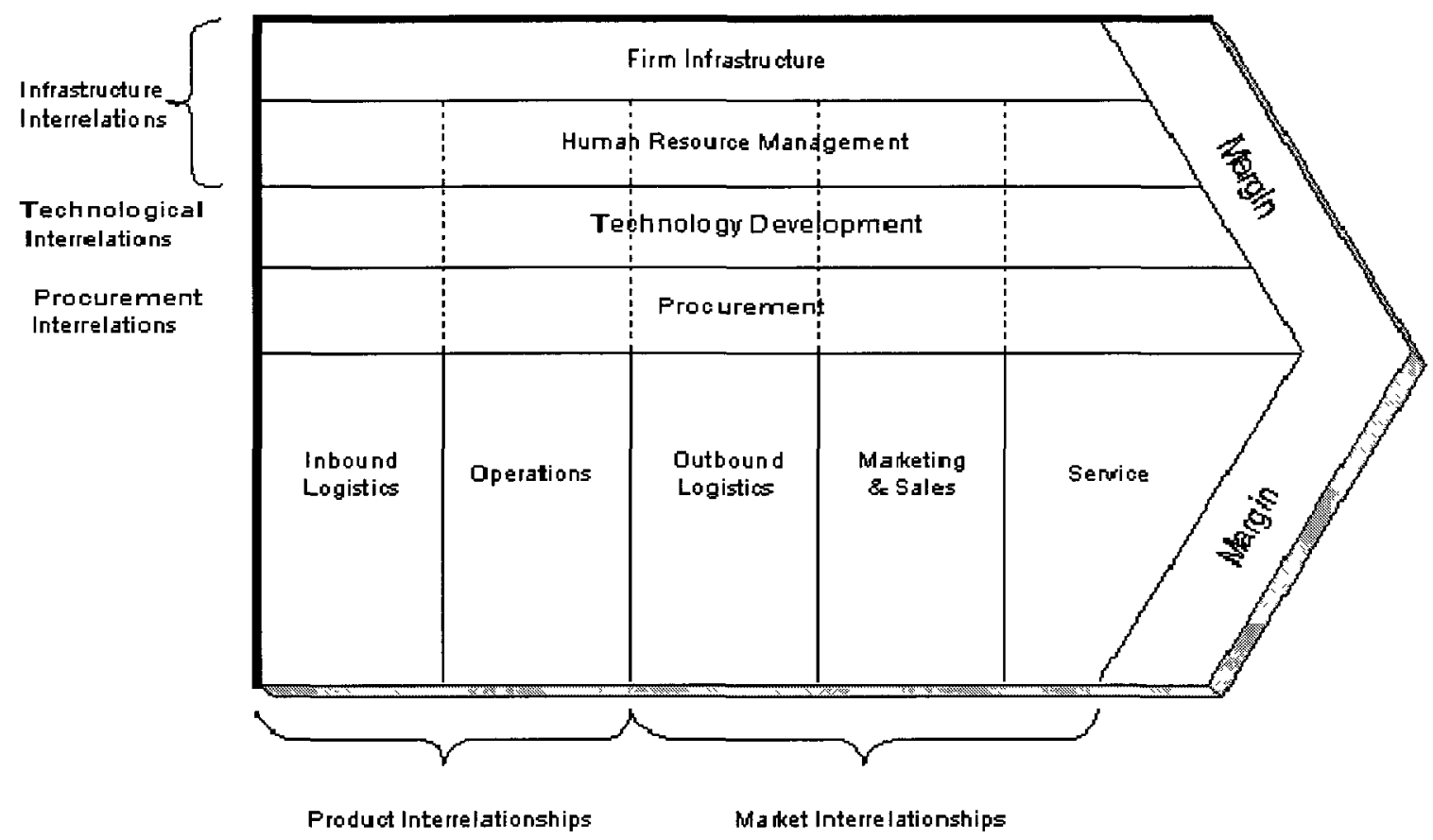

Figure 6. Michael Porter's value chain. Source: Learn Marketing. (n.d.). Michael Porter's value chain. Retrieved from http://www.learnmarketing.net/valuechain.htm

He also challenged managers to see their industry in terms of a value chain. A firm will be successful only to the extent that it contributes to the industry's value chain. This idea forced management to look at its operations from the customer's point of view. Porter believes every operation should be examined in terms of what value it adds in the eyes of the final customer (Porter, 1985).

Another value based model was introduced by Robert Kaplan and David Norton in their 2004 book Strategy Maps: Converting Intangible Assets into Tangible Outcomes. Kaplan and Norton (2004) posit that an organization's strategy should describe how it intends to create value for its shareholders, customers, and citizens. If an organization's intangible assets represent more than 75 percent of its value then its strategy formulation and 
execution need to explicitly address the mobilization and alignment of its intangible assets (Kaplan \& Norton, 2004, p. 5).

Their strategy map is a diagram that describes how an organization creates value by connecting strategic objectives in explicit cause-and-effect relationships with each other in Kaplan and Norton's four Balanced Scorecard objectives: financial, customer, processes, and learning and growth. Figure 7 shows simplified versions of strategy maps for both private and public organizations.
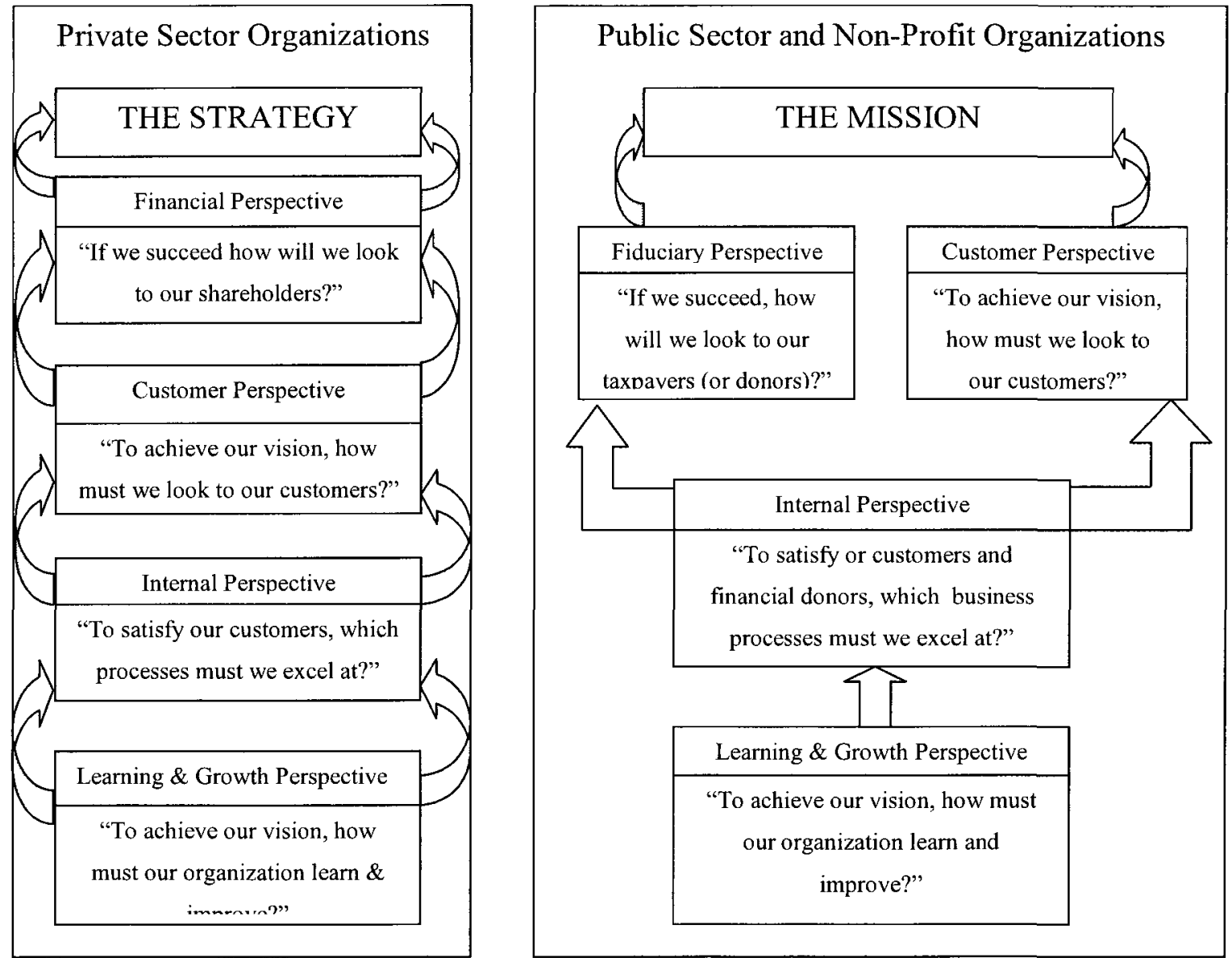

Figure 7. Strategy maps: The simple model of value creation. Source: Kaplan, R., \& Norton, D. (2004). Strategy maps: Converting intangible assets into tangible outcomes. Boston, MA: Harvard Business School. Adapted from their Figure 1: 2 Strategy maps: The simple model of value creation.

As illustrated in the models presented here adopting a formal strategic planning process requires an organization to take a realistic look at its vision in relationship to its internal resources and the external environment in which it operates. The experts presented 
here would agree that the process can help map out the road to $\mathrm{Oz}$ but according to an article in the MITSloan Management Review the real value of strategic planning doesn't lie so much in the formal process as it lies in using the process as a learning tool to create "prepared minds" within their management teams (Kaplan \& Beinhocker, 2003). Preparing the minds of the management team has its benefits when dealing with the flying monkeys of the future.

\section{Baldrige Criterion Three: Customer Focus}

The third criterion used by the Baldrige is customer focus. While the previous section on strategic planning presented several models requiring an organization to consider the customer there are other tools marketers use to understand the consumer's needs and expectations. This section will examine some of those tools.

Marketing, the business school discipline that studies the customer's wants and needs is a very misunderstood, and often maligned, discipline. Considered by many to be only about selling a product or service, marketing guru Philip Kotler defines marketing as the science and art of exploring, creating, and delivering value to satisfy the needs of a target market at a profit. Marketing identifies unfulfilled needs and desires. It defines, measures, and quantifies the size of the identified market and the profit potential. It pinpoints which segments the company is capable of serving best and it designs and promotes the appropriate products and services (Kotler, n.d.).

According to Kotler, marketing's key processes are: (1) opportunity identification, (2) new product development, (3) customer attraction, (4) customer retention and loyalty building, and (5) order fulfillment (Kotler, n.d.). One tool marketers use to help manage these key processes is conducting a SWOT analysis. Even though there has been much discussion about who should receive credit for developing this widely used tool which includes such notables as Stanford University's Albert Humphrey, various Harvard academics, and Igor Ansoff, there is no documented creator of the SWOT analysis (Friesner, 2011).

A SWOT analysis examines an organization by looking at its internal strengths and weaknesses as well as its external opportunities and threats. Conducting a SWOT analysis 
can be a very effective tool in helping an organization understand the relationship between product and customer Table 3 illustrates a SWOT analysis for a regional airport.

Table 3. SWOT Analysis

\begin{tabular}{|l|l|}
\hline \multicolumn{1}{|c|}{ INTERNAL } & \multicolumn{1}{c|}{ EXTERNAL } \\
\hline Strengths & Opportunities \\
Centrally located, near business district and hotels & $\begin{array}{l}\text { With the addition of 10 new gates can attract new } \\
\text { routes into San Diego }\end{array}$ \\
$\begin{array}{l}\text { Largest Airport Ambassador program in the United } \\
\text { terminal information booths to help answer } \\
\text { passengers' questions }\end{array}$ & $\begin{array}{l}\text { New concessions program will enable the Authority to } \\
\text { place requested services addressing customer requests }\end{array}$ \\
$\begin{array}{l}\text { Weaknesses } \\
\text { construction of new gates may cause traffic }\end{array}$ & $\begin{array}{l}\text { Threats } \\
\text { Depressed economy has impacted travel which has } \\
\text { decreased Authority revenue }\end{array}$ \\
$\begin{array}{l}\text { Hiring freeze may leave important positions vacant } \\
\text { which places stress on current staff }\end{array}$ & $\begin{array}{l}\text { Additional service charges by Airlines and new TSA } \\
\text { body scanners are causing greater customer anxiety. }\end{array}$ \\
\hline
\end{tabular}

Created by C Lew1s using http //www businessballs com/swotanalysisfreetemplate.htm June 2010.

Analyzing an organization's internal strengths and weaknesses and external opportunities and threats helps the organization's leaders make better long term decisions. Another tool used by marketers to align service/product offerings with customer expectations is a marketing mix assessment.

The marketing mix is a general phrase used to describe the different kinds of choices organizations have to make in the whole process of bringing a product or service to market. The 4 Ps is one way - probably the best-known way - of defining the marketing mix, and was first expressed in 1960 by E.J. McCarthy (Mindtools, n.d.).

The components of the marketing mix are the product/service, price, place (distribution method), and promotion of a product or service. Asking questions regarding the marketing mix variables in relationship to the target customer are important to the success of any organization offering a product or service.

Marketing mix questions regarding products or services an organization might ask are: What does the customer want from the product/service? What needs does it satisfy? How 
and where will the customer use it? What size(s), color(s), and so on, should it be? (Mindtools, n.d).

Questions regarding price might be: What is the value of the product or service to the buyer? Is the customer price sensitive? Will a small decrease in price gain you extra market share or will a small increase be indiscernible, and gain you extra profit margin? (Mindtools, n.d).

Place questions examine the best distribution method for the customer. They might include the following: Where do buyers look for your product or service? What kind of store: A specialist boutique or in a supermarket, or both? Will they expect to find it online? (Mindtools, n.d).

The final marketing mix questions revolve around promotion and how best to attract the attention of the intended customer. These questions could look like the following: Where and when can you get across your marketing messages to your target market? Will you reach your audience by advertising in the press, or on TV, or radio, or on billboards? Is the best promotion strategy by using direct marketing, through PR, or on the Internet? (Mindtools, n.d).

Understanding your customer is an essential element in achieving organizational excellence. As the master of customer focus, Walt Disney once said, "You don't build the product for yourself. You need to know what the people want and build it for them." (Capodagli \& Jackson, 1999).

\section{Baldrige Criterion Four: Measurement, Analysis, and Knowledge Management}

The fourth Baldrige criterion examines how an organization measures, analyzes, and improves its performance, as well as how it builds and manages its knowledge assets. This section will take a look at performance measurement systems and knowledge management processes.

In an article written in 1995 by Andy Neely, Mike Gregory and Ken Platts and published in the International Journal of Operations \& Production Management performance measurement is defined as the process of quantifying action, where measurement is the process of quantification and action leads to performance (p. 80). 
According to Neely, Gregory, and Platts the level of performance a business attains is a function of the efficiency and effectiveness of the actions it undertakes and therefore can be examined at three different levels: (1) the individual performance measures, e.g., quality, time, cost, and flexibility; (2) the performance measurement system as an entity, e.g., Kaplan and Norton's (1992) Balanced Scorecard, Keegan, Eiler and Jones' (1989) Performance Measurement Matrix, and Dixon, Nanni and Vollman's (1990) Performance Measurement Questionnaire; and (3) the relationship between the performance measurement system and the environment within which it operates, e.g., Richardson and Gordon's (1980) work on linking changing performance measures to products as they move through their life cycle and Crawford and Cox's (1990) guidelines for developing a performance measurement system for just-in-time manufacturing (Neely et al., 1995, p. 81-104).

A technique for measuring performance that is of interest to both academics and consultants is known as benchmarking. Benchmarking allows an organization to compare its performance with those of its competitor.

The recognized authority on benchmarking is Robert Camp who has written three books on the subject since his first in 1989. Camp defines benchmarking as the search for industry best practices that lead to superior performance. To better explain his thoughts he draws a parallel to waging war:

In the year 500 B.C., Sun Tzu, a Chinese general wrote, "If you know your enemy, and know yourself, you need not fear the result of a hundred battles." Sun Tzu's words could just as well show the way to success in all kinds of business situations. Solving ordinary business problems, conducting management battles, and surviving in the marketplace are all forms of war, fought by the same rules Sun Tzu's rules (Camp, 1989, p. 3).

Camp organized his benchmarking process steps into four categories: planning, analysis, integration, and action. Each category contains one or more of the 10 process steps. The planning category contains process steps one through three, they are: identify what is to be benchmarked; identify comparative companies; determine data collection method and collect data (Camp, 1989). The analysis category is home to steps four and five: determine current performance gap and project future performance levels (Camp, 1989). Steps six and seven are included in the integration category, they are: communicate benchmark findings and gain acceptance and establish functional goals (Camp, 1989). The final three steps are part of the action category, they are: develop action plans; implement specific actions and 
monitor progress; and recalibrate benchmarks (Camp, 1989). Once all steps have been completed Camp believes a leadership position is attained and the benchmarking practices are fully integrated into processes. He calls this maturity (Camp, 1989).

In addition to developing a benchmarking process Camp identifies four basic types of benchmarking. The first type is called internal and is a comparison of internal operations. The second type is competitive, specific competitor-to-competitor comparisons for the product or function of interest. Functional benchmarking is the third type and compares similar functions within the same broad industry or to industry leaders. The fourth and final type is generic. Generic benchmarking is a comparison of business functions or processes that are the same regardless of industry, e.g., invoicing (Camp, 1989).

Benchmarking is an excellent method for gathering information about an organization whether it's internal or external to the organization. The difference between a successful organization and one that struggles is what they do with that information.

Knowledge management is the process of systematically and actively managing and leveraging the stores of knowledge in an organization. It is the process of transforming information and intellectual assets into enduring value (University of South Australia, n.d.).

Thomas Stewart (1999) calls it Intellectual Capital and in his book of the same name defines it as:

... the sum of everything everybody in a company knows that gives it a competitive edge. Unlike the assets with which business people and accountants are familiar - land, factories, equipment, cash - intellectual capital is intangible. It is the knowledge of a workforce: the training and intuition of a team of chemists who discover a billion-dollar new drug or the know-how of workmen who come up with a thousand different ways to improve the efficiency of a factory. It is the electronic network that transports information at light speed through a company, so that it can react to the market faster than its rival. It is the collaboration-the shared learning-between a company and its customers, which forges a bond between them that brings the customer back again and again. In a sentence: Intellectual capital is intellectual material - knowledge, information, intellectual property, experience - that can be put to use to create wealth. It is collective brainpower (p. ix-xx).

Stewart (1999) illustrates the dollar value of intellectual capital in one very simple example. Comparing a \$100 (1996 dollars) investment in either Microsoft or IBM, Stewart explains that for every $\$ 100$ invested in IBM, the investment bought $\$ 23$ of fixed assets: 
property, plant, and equipment while every $\$ 100$ invested in Microsoft bought fixed assets worth just over a dollar (p. 33).

Stewart (1999) also offers several methods for measuring and managing intellectual capital. He has grouped them in four areas: ways to measure the overall value of intangible assets, e.g., market-to-book ratios; structural capital measurements, e.g., working capital turns which substitute information for inventory; customer capital measurement such as customer satisfaction surveys; and human capital measurements such as employee opinion surveys (Stewart, 1999, p. 225-244).

The most important asset according to Stewart (1999) is the human element or as he puts it human capital (p. 84). He describes human capital metaphorically as follows:

Human capital is, to quote Yeats out of context, the place where all the ladders start: the wellspring of innovation, the home page of insight. If intellectual capital is a tree (one of Leif Edvinsson's metaphors), then human beings are the sap - in some companies, the saps- that make it grow (p. 86).

The human capital dimension is next on the Baldrige list.

\section{Baldrige Criterion Five: Workforce Focus}

How an organization engages, develops, and assesses the satisfaction of its workforce is the focus of the fifth criterion of the Baldrige. This section will explore some of the current literature on engagement and methods of assessing satisfaction through employee opinion surveys (EOS). A thorough examination of workforce development is presented in the second part of this chapter on the criteria used by the ASTD to determine BEST award recipients.

Defining employee engagement is similar to playing a game of Whack-a-Mole, when one definition pops up, another is soon to follow. To bring some sort of order to this mish mash of information The Conference Board published Employee Engagement: A Review of Current Research and Its Implications in 2006 that attempted to synthesize the conclusions of twelve major studies on this topic (Soldati, 2007).

The Conference Board looked at data from research conducted by groups such Gallup, Towers Perrin, Blessing White, and the Corporate Leadership Council and came up with a blended definition of employee engagement and eight key themes that crossed all of the studies (Soldati, 2007). 
The definition of employee engagement developed by the Conference Board is "a heightened emotional connection that an employee feels for his or her organization, that influences him or her to exert greater discretionary effort to his or her work" (Soldati, 2007).

The eight key drivers they identified are: (1) Trust and integrity - how well managers communicate and 'walk the talk'; (2) Nature of the job - is it mentally stimulating day-to-day; (3) Line of sight between employee performance and company performance - does the employee understand how their work contributes to the company's performance; (4) Career Growth opportunities -are there future opportunities for growth: (5) Pride about the company - how much self-esteem does the employee feel by being associated with their company; (6) Coworkers/team members - significantly influence one's level of engagement; (7) Employee development - is the company making an effort to develop the employee's skills; and (8) Relationship with one's manager - does the employee value his or her relationship with his or her manager; which in their final analysis turned out to be the strongest driver of all (Soldati, 2007).

Another study examining the impact of employee engagement on an organization's bottom line was the August 2009 Gallup Employee Engagement Index. The findings of this study reported that only 33 percent of workers are engaged in their jobs, 49 percent are not engaged, and 18 percent are actively disengaged (Fox, 2010 ).

The Gallup Organization defines the categories as follows: Engaged employees work with passion and feel a profound connection to their company. They drive innovation and move the organization forward. Non-engaged employees have essentially "checked out." They sleepwalk through workdays. They put in time but don't approach their work with energy or passion. Actively disengaged employees aren't just unhappy at work; they're busy acting out their unhappiness. Every day, these workers undermine what engaged co-workers accomplish (Fox, 2010).

Gallup researchers, who base the Employee Engagement Index on a survey of nearly 42,000 randomly selected adults, estimate that disengaged workers cost U.S. businesses as much as $\$ 350$ billion a year (Fox, 2010).

In a subsequent study in January of 2010, Gallup researchers found that companies in the top 10 percent on employee engagement bested their competition by 72 percent in 
earnings per share during 2007-08. For companies that scored beneath the top quartile, earnings fell 9.4 percent below their competition (Fox, 2010).

An interesting study by Harvard Business School management professor, Teresa Amabile, sought to identify what drives employee engagement. Her research found a big disconnect between manager and employee perceptions regarding drivers of employee engagement (Fox, 2010).

In 2009 Amabile asked 600 managers to rank workplace factors that they thought engaged employees. "Recognition for good work" topped the list; "progress" came in dead last (Fox, 2010).

Amabile then compared the managers' rankings to what she had concluded from a multiyear study tracking day-to-day activities, emotions and motivations of hundreds of knowledge workers in a variety of settings. Her findings concluded that progress ranked No. 1 on the list of engagement factors related to performance (Fox, 2010).

Analyzing 120,000 journal entries, Amabile found that workers reported feeling most engaged on days when they made headway or received support to overcome obstacles in their jobs. They reported feeling least engaged when they hit brick walls. Small dents in work meant as much as large achievements (Fox, 2010).

Daniel Pink, author of Drive: The Surprising Truth About What Motivates Us (2009) concurs. Pink says many employees feel they aren't making a contribution. "They are working hard, but they don't understand or see how their work drives the business, that is a form of disengagement" (Fox, 2010).

One interesting outcome of Gallup's research was finding out that pay does not drive employee engagement. From July 2008 to March 2009, during an economic recession, Gallup found only slight changes in overall engagement. In July 2008, 31 percent of employees were engaged, 51 percent were not engaged, and 17 percent were actively disengaged. By March 2009, the results changed to 30 percent, 52 percent and 18 percent, respectively (Fox, 2010). Had pay been an engagement factor, the figures for March 2009 would have declined dramatically.

Other factors that do have a positive impact on engagement according to Gallup are: empowerment - the ability to solve problems without going through a chain-of-command; self-direction - the encouragement to develop new products/services or to comment on ways 
to improve current products/services; and development through skill building training (Fox, 2010).

Understanding what factors influence workforce engagement is typically accomplished through an employee opinion survey (EOS). Benjamin Schneider, senior research fellow with Chicago-based HR consulting firm Valtera and a professor emeritus at the University of Maryland cautions EOS developers to be clear about what factors an organization wants to understand, satisfaction or engagement. He states, "Satisfaction is largely about stuff over which the larger company has control-pay, benefits-but engagement is mostly under the control of the local supervisor, through job assignments, trust and so on" (Rivenbark, 2010).

Laura Lea Clinton, director of HR business partnerships at CARE, an international humanitarian organization agrees,

Engagement surveys aren't opinion surveys. Opinion surveys ask how the organization is doing on broad initiatives leaders identify as important, such as diversity, but engagement surveys focus on "the extent you are personally connected to the organization ... your daily work, your supervisor, the probability you want to stay with the organization" and how all of that affects productivity (Rivenbark, 2010, p. 48).

Researchers and practitioners agree that there is value in determining how engaged the workforce is and offer some basic points to consider when developing an employee engagement survey. First on the list is to figure out what to do with the results. An organization unable or unwilling to act on the results of their survey loses respect and trust in the eyes of their workforce (Grensing-Pophal, 2009). Next is to decide who gets to contribute. Schneider recommends involving workers upfront. Employee focus groups are a good way of alerting employers to issues that should be covered in survey questions (Rivenbark, 2010).

Next on the list is the structure of the questions. Brad Federman, author of Employee Engagement: A Roadmap for Creating Profits, Optimizing Performance, and Increasing Loyalty (2009), outlines two types of engagement questions. One type covers what he calls "core engagement issues, or 'Do I have what I need to do my job?' questions." The other covers "enriching engagement issues, or 'Do you believe in the mission of the organization?' questions." Federman warns HR professionals tempted to stick to broad questions about mission should realize that core issues of day-to-day resources are vital to employee 
engagement, he explains that if an employee doesn't have a computer to do his/her work, they are not thinking about the mission of the organization (Rivenbark, 2010).

Other items on the list are using neutral language, keeping the survey to a reasonable length, considering conducting more than one type of survey, and getting feedback at every level of the organization (Rivenbark, 2010).

An employee opinion survey is just one of many methods an organization uses to track and measure its success or failure. How the work is structured and the designs used in this effort make up criterion 6 of the Baldrige. The next section will examine Process Management.

\section{Baldrige Criterion Six: Process Management}

In his book The Agenda (2001), Michael Hammer defines process as "an organized group of related activities that work together to transform one or more kinds of input into outputs that are of value to the customer." Hammer's definition communicates several key ideas: (1) A process is a group of activities, not just one; (2) The activities that make up a process are not random or ad hoc; they are related and organized; (3) All the activities in a process must work together toward a common goal; and (4) Processes exist to create results your customers - whether they're internal (within your organization, such as a department) or external (outside your organization, such as paying customers) - care about (American Society for Quality [ASQ], n.d.-a).

A process can also be viewed as a "value chain," in which each activity or step contributes to the end result. Some activities directly contribute value, while others may not.

All activities consume enterprise resources, however. The challenge for managers is to eliminate steps that do not add value and to improve the efficiency of those that do. Figure 8 illustrates a model for a simple process.

Organizations use different types of processes to conduct work. In his book The Process Centered Enterprise: The Power of Commitments (2000), Gabriel Pall recognizes three important types of process: Management processes which provide direction and governance for an enterprise. They are generally conducted by senior leaders to set organizational goals, develop and deploy strategy to attain goals, establish and manage 


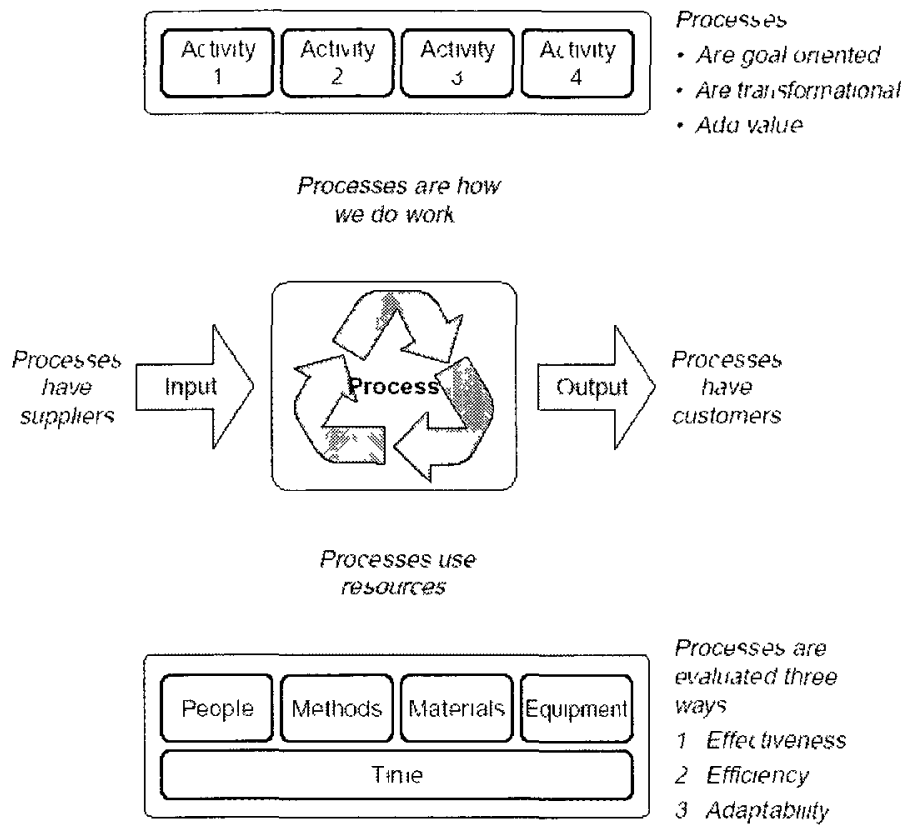

Figure 8. A simple process model. Source: American Society for Quality. (n.d.-a). Basic concepts: Process view of work. Retrieved from http://asq.org/learn-about-quality/process-viewof-work/overview/overview.html

organization designs and manage performance goals. Management processes also shape and manage the business and support processes used by the enterprise (ASQ, n.d.-a).

Business processes are a second form and are the processes that reflect the unique competencies of the enterprise and are mission-critical. They tend to lie on, or close to, the core value-creating activities of the enterprise and are the processes that are seen and experienced by external customers. Value-creating business processes begin and end with the external customer, tend to be large in scope, and commonly span multiple organizational components as illustrated in Figure 9. While organizations may have hundreds of work processes, they usually have very few business processes (typically five to seven). Since this group of processes represents the core competencies of the organization, this is where performance improvement work should be focused (ASQ, .n.d.-a).

Support processes exist to sustain the enterprise. Since the support needs of business organizations are similar, these processes tend to be fairly standard and are frequent candidates for outsourcing. The customers of support processes are internal customers within the organization (ASQ, .n.d.-a). 

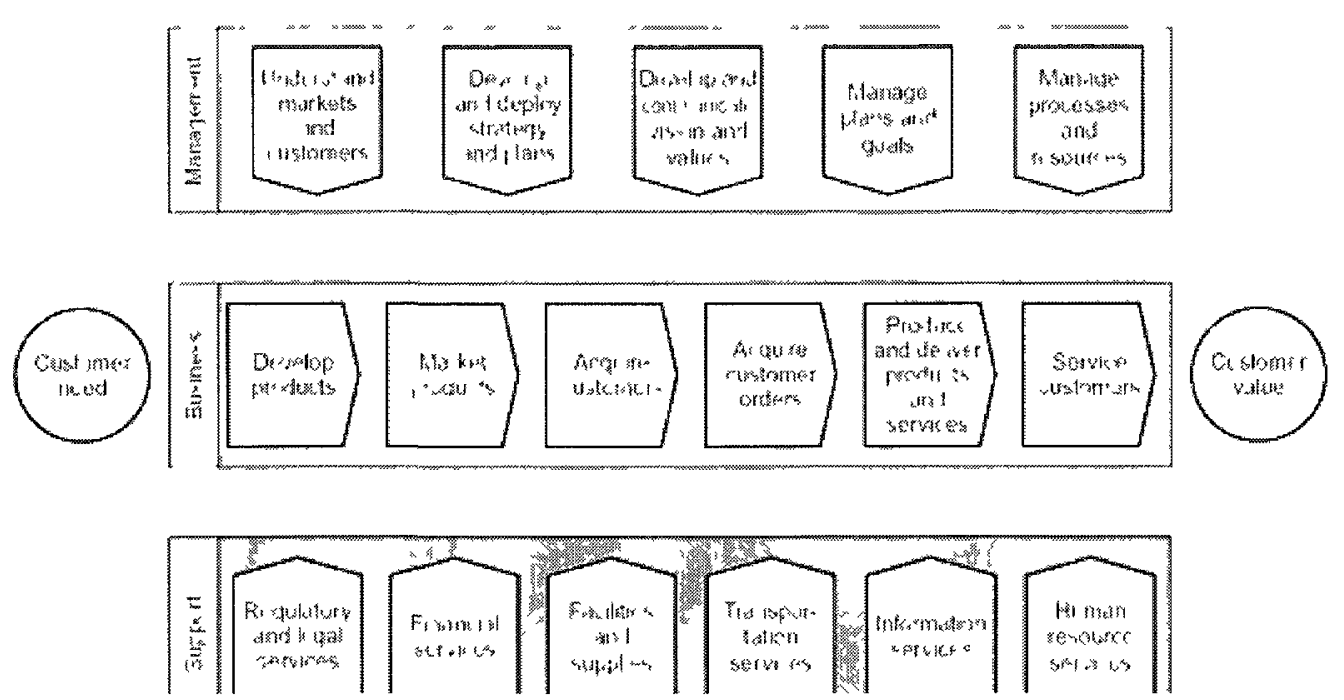

Figure 9. Types of enterprise processes. Source: American Society for Quality. (n.d.-a). Basic concepts: Process view of work. Retrieved from http://asq.org/learn-about-quality/process-view-of-work/overview/ overview.html

While these three categories play significantly different roles, they must be aligned and integrated to enable effective performance of the total system. Effective and sustained performance improvement must consider the management and support processes as well as the core business processes.

There are several tools available for use to help manage specific work processes such as the fishbone diagram, and Pareto chart to problem solve; there are affinity diagrams and brainstorming for idea generation and there are other tools that take an organizational wide approach to quality process management. Two of the approaches widely used in the manufacturing industry are Six Sigma and Lean.

Six Sigma is a fact-based, data-driven philosophy of quality improvement that values defect prevention over defect detection. It drives customer satisfaction and bottom-line results by reducing variation and waste, thereby promoting a competitive advantage. It applies anywhere variation and waste exist, and every employee should be involved. In simple terms, Six Sigma quality performance means no more than 3.4 defects per million opportunities (ASQ, n.d.-c).

There are differing opinions on the definition of Six Sigma, some see Six Sigma as a philosophy. This perspective views all work as processes that can be defined, measured, 
analyzed, improved and controlled. Processes require inputs (x) and produce outputs (y). The theory goes if you control the inputs, you will control the outputs. Others see Six Sigma as a set of qualitative and quantitative techniques used to drive process improvement and still others see Six Sigma as a methodology. This view of Six Sigma recognizes the underlying and rigorous approach known as DMAIC (define, measure, analyze, improve and control). DMAIC defines the steps a Six Sigma practitioner is expected to follow, starting with identifying the problem and ending with the implementation of long-lasting solutions. While DMAIC is not the only Six Sigma methodology in use, it is certainly the most widely adopted and recognized (ASQ, n.d.-c).

While several different definitions have been proposed for Six Sigma, they all share some common themes. First is the use of teams that are assigned well-defined projects and that have direct impact on the organization's bottom line. Secondly, training is "statistical thinking" at all levels of the organization and providing key people with extensive training in advanced statistics and project management. Next emphasis on the DMAIC approach to problem solving, and finally develop a management environment that supports these initiatives as a business strategy (ASQ, n.d.-c).

Another organizational approach to process management is the Lean concept. Lean manufacturing is a system of techniques and activities for running a manufacturing or service operation. The techniques and activities differ according to the application at hand but they have the same underlying principle: the elimination of all non-value-adding activities and waste from the business (ASQ, n.d.-b).

Lean enterprise extends this concept through the entire value stream or supply chain: The leanest factory cannot achieve its full potential if it has to work with non-lean suppliers and subcontractors. Types of waste a Lean approach hopes to eliminate are: overproduction, waiting time in queue, transportation, non-value-adding processes, inventory, motion, and costs of quality: scrap, rework and inspection (ASQ, n.d.-b).

The success of quality management processes such as Six Sigma, Lean, and even the Baldrige criteria can in part be attributed to the work of W. Edwards Deming. Deming was an American statistician who is credited with the rise of Japan as a manufacturing nation. Deming went to Japan just after World War II to help set up a census of the Japanese population. While there, he taught statistical process control to Japanese engineers - a set of 
techniques which allowed them to manufacture high-quality goods without expensive machinery (Cohen, n.d.).

Deming returned to the US and spent some years in obscurity before the publication of his book Out of the Crisis (1982). In this book, Deming set out 14 points (Table 4) which, if applied to US manufacturing industry, would, he believed, save the US from industrial doom at the hands of the Japanese (Cohen, n.d.).

Table 4. Deming's 14 Points

\begin{tabular}{|l|l|}
\hline \multicolumn{2}{|c|}{ Deming's 14 Points } \\
\hline Create constancy of purpose towards improvement & Drive out fear \\
\hline Adopt the new philosophy & Elımınate boundarıes \\
\hline Cease inspection, require evidence & Elımınate the use of slogans \\
\hline Improve the quality of supplies & Elımınate numerical standards \\
\hline Contınuously improve production & Let people be proud of their work \\
\hline Train and educate all employees & Encourage self-improvement \\
\hline Supervisors must help people & Commit to ever improving quality \\
\hline
\end{tabular}

Source. 1000advices. (n d ). Deming's 14 point plan for total quality management Retrieved from

http://www.1000advices.com/guru/quality_tqm_14points_deming.html

Deming believed that variation in product development must be controlled. He saw variation as the disease that threatened US manufacturing. The more variation in the uniformity of parts, in delivery times, in prices, in work practices - the more waste, he reasoned (Cohen, n.d.).

\section{Baldrige Criterion Seven: Results}

The Results Category is the only category in the Baldrige Criteria that examines an organization's performance and improvement and any indicators as to how the organization may perform in the future. An interesting article on the Baldrige.com site by Steve George titled Interpreting Results (2009) uses an intriguing "organization" to illustrate valid indicators of future performance by the organization. Consider the chart in Figure 10.

It shows current levels of performance and a trend over a longer period of time than most organizations display. When performance shows this kind of variability, some organizations include a trend line (Figure 11) to clarify the direction this measure is heading, although, in this case, the direction is pretty clear (George, 2009).

The "organization" in this chart happens to be Earth, with temperature data from the National Climatic Data Center. "Normal" is the average temperature from 1901 to 2000 . As 


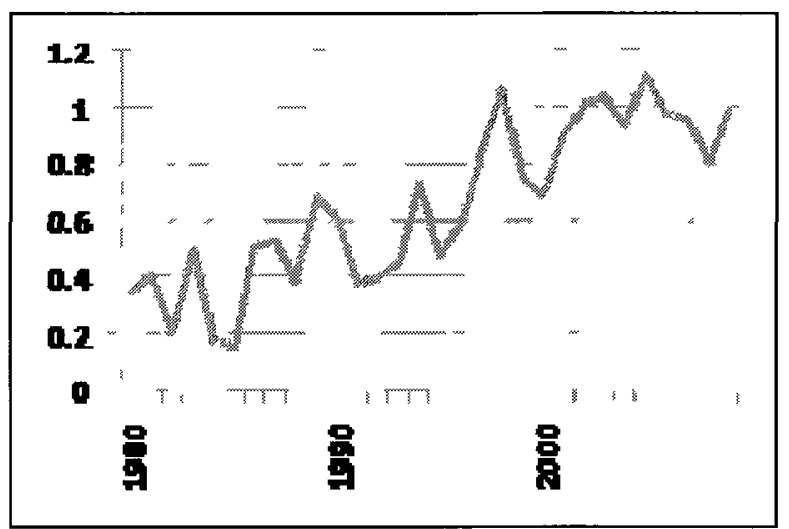

Figure 10. Levels of performance. Source: George, S. (2009). Interpreting results. Retrieved from http://www.baldrige.com/ criteria_results/interpreting-results/

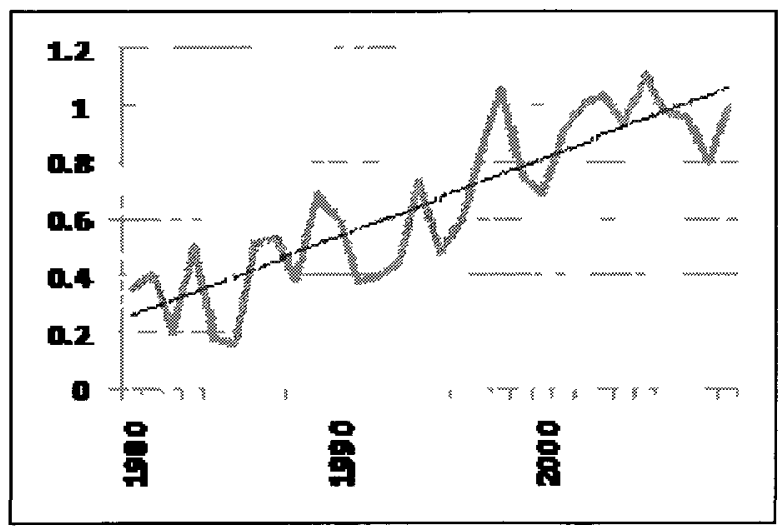

Figure 11. Trend line. Source: George, S. (2009). Interpreting results. Retrieved from http://www.baldrige.com/criteria_results/ interpreting-results/

Deke Arndt, NOAA climate monitoring chief, said, "The last 10 years are the warmest 10year period of the modern record." And it's getting warmer, not cooler, which is a valid indicator of future performance unless we act to stop the trend (George, 2009).

More common types of results would show improvement in the workforce, customer or management process categories. The following are actual examples of results achieved by recipients of the Baldrige award: error-free delivery rate of $99 \%$ or better from 2005 to 2008; achieved overall Lean/Six Sigma improvements in quality (91\%), cost (70\%), schedule $(67 \%)$, and risk (84\%) with an overall cost avoidance of $\$ 3.22$ billion since 2001; staff turnover declined from $13.5 \%$ to $7.5 \%$ in five years; named one of "America's 100 Best 
Places to Work in Healthcare" with employee satisfaction ranked in the $97^{\text {th }}$ percentile nationally; named the best healthcare provider in the region; and increased revenue by $56 \%$ from 2001 to 2006 (NIST, 2009a).

Each category presented above provides a stepping stone to organizational excellence. While each category is vital in the pursuit of that goal there is one that addresses the learning function within the organization. Nestled in the workforce focus category are questions regarding workforce and leader development, e.g. how are learning and development needs established; how is the transfer of knowledge of retiring employees handled; what is the breadth of learning and development opportunities; etc.

Achieving excellence in the workplace learning function is critical to the success of the ultimate goal of receiving the Baldrige award but how does one determine excellence in workplace learning? The ASTD has established a set of criteria for just this purpose and each year presents its BEST award to those organizations they believe have achieved excellence in workplace learning.

\section{THE AMERICAN SOCIETY OF TRAINING AND DEVELOPMENT'S BEST AWARD}

Introduced in 2002, the BEST Awards program recognizes organizations that demonstrate a clear link between learning and performance across the organization. The recipients must show evidence of excellence in three areas: a link between learning and performance, the presence of innovative learning initiatives, and that learning has value in the culture (ASTD, 2009a).

BEST factors examined in this study in support of the Baldrige criteria are strategic alignment of training initiatives with organizational goals and objectives, measurement of training effectiveness, workplace learning delivery methods, and the perceived value of workplace learning at the executive level.

\section{BEST Criterion One: Strategic Alignment with Organizational Goals}

Unless you align corporate training to organizational goals, any returns you realize from the training investment will be by chance alone (Clark \& Kwinn, 2005). A strong 
tatement but true according to Ruth Clark and Ann Kwinn who have developed seven "routes" designed to help workplace learning professionals align training programs to business goals. Route 1: Determine the organization's goals - which must be bottom-line and specific- and define how the CEO measures progress toward those goals Frank Nguyen, then senior learning technologist with Intel Corporation and former Assistant Professor of Educational Technology at San Diego State University, recommends "placing the training function within specific business units to closely align with the bottom line" (Clark \& Kwinn, 2005, p. 34).

Route 2: Identify management's greatest areas of pain then provide training solutions that will help alleviate them (Clark \& Kwinn, 2005, p. 35). Route 3: Find out what the biggest corporate resource constraints are, e.g., tight deadlines, reduced budgets, loss of subject matter experts and figure out how these constraints will affect departments such as training. Factor these constraints in to training solutions (Clark \& Kwinn, 2005, p. 35). Route 4: Turn constraints into opportunities. For example take a shrinking training budget and turn some instructor led classes into computer based courses. Doing so helps business units to eliminate travel and time away from work site (Clark \& Kwinn, 2005, p. 36).

Route 5: Identify and document effective processes and procedures within your organization and share them with the entire organization. Intel has developed a program entitled, Copy Exactly! which requires a new manufacturing facility to duplicate the best methods used in existing factories. The result has been bringing high-volume factories online quickly, decreasing time to market and increasing yields. By distributing best practices throughout the organization expertise residing in a few now belongs to many (Clark \& Kwinn, 2005, p. 36).

Route 6: Be aware of industry-specific events outside of your organization that impact how your organization does business (Clark \& Kwinn, 2005, p. 38). Route 7: Partner with management in ways that integrate the training professional into the business. Helping management achieve their goals positions workplace learning as a critical service provider (Clark \& Kwinn, 2005, p. 39)

Kevin Wheeler, president and founder of Global Resources, a human capital consulting firm in San Francisco, echoes the importance of repositioning the workplace learning function throughout the organization. 
Moving training out of an administrative thought process into the strategic thought process is difficult for many people to do. It is a tough leap. You are not putting courses together, you are not organizing training, and you are not spending a training budget. You are helping to give people the skills they need to achieve a business goal (Ellis, 2005, p. 40).

Wheeler recommends specifying the elements of learning and how they fulfill a stated business goal. Success in achieving the objective will demonstrate to all involved the strategic value of learning and help embed the link throughout the organization (Ellis, 2005).

Tony Bingham and Tony Jeary in an article for $T \& D$ titled "Communicating the Value of Learning" (2007) agree that aligning learning with organizational goals is very important and suggest the best way to do this is by making a persuasive case for learning's overall strategic impact on an organization (p. 80).

They believe that too often an organization's strategies and objectives are communicated in vague, hollow language making it hard if not impossible for rank-and-file employees to understand (Bingham \& Jeary, 2007, p. 81). For example the understanding of an organization's mission statement is filtered through each department within the organization and as a result can mean different things to different employees (Bingham \& Jeary, 2007, p. 81). Bingham and Jeary suggest that it is the responsibility of the learning professional to understand the reasons behind the mission statement and to be able to communicate its relevance to each department, business unit, division, etc. within the organization (Bingham \& Jeary, 2007, p. 81).

The opportunities for learning professionals to communicate within an organization are numerous. Aside from the obvious training sessions; conversations with co-workers and colleagues, purposeful interviews, and day-to-day experience provide opportunities to learn as much as possible about the way in which information travels through the organization.

The astute learning professional should be looking for ways learning can be used to leverage the strengths and shore up the weaknesses of the organization, and for ways learning can add value to the organization (Bingham \& Jeary, 2007, p. 84).

\section{BEST Criterion Two: Measurement of Workplace Learning Effectiveness}

Any review on measurement of workplace learning effectiveness would be remiss if the work of Robert O. Brinkerhoff, Professor Emeritus of Western Michigan University and 
Donald L. Kirkpatrick, Professor Emeritus of the University of Wisconsin and a past president of the ASTD were not discussed.

In 2003 Robert Brinkerhoff published his book The Success Case Method: Find Out Quickly What's Working and What's Not and that same year presented his model at the ASTD's International Conference in San Diego, CA.

The purpose of a Success Case study is to find out how well an organizational initiative (e.g., a training program, a new work method) is working. A Success Case study also identifies and explains the contextual factors that differentiate successful from unsuccessful adopters of new initiatives (Brinkerhoff, 2003).

The Success Case study process has two fundamental parts. First, the evaluator identifies the few program participants who were the most, and least, successful usually through a brief 3-5 item survey. All participants, self report, to what extent they are using the new methods and tools a new initiative intended them to use, and what results, if any, they are accomplishing (Brinkerhoff, 2003).

Survey respondents are sorted into those few that are most and least successful. A random sample is then selected from the most and least successful followed by a telephone interview intended to "dig deep" into the participant's. The evaluator seeks to discover: exactly what they used, when they used it, how they used it, what results they accomplished, how valuable the results were (e.g., in dollars), what environmental factors enabled their application and results (Brinkerhoff, 2003).

Unsuccessful persons are interviewed to determine why they were unable to use or benefit from the program. Specifically, they are asked what got in the way, what factors kept them from being successful, and so forth (Brinkerhoff, 2003).

The results of the Success Case study are then communicated in "story" form. That is, the evaluator finds the most compelling and descriptive examples of success the program has achieved, then documents these examples in a few brief but richly detailed stories. Comparing these stories with the stories of unsuccessful participants allows the investigator to pinpoint the several key performance system factors that enabled some to make very successful use of the program, while others were not nearly so successful (Brinkerhoff, 2003). 
The Success Case Method differs from typical more quantitative methods in that it does not seek to learn about the "average" or modal participant in an initiative. It intentionally seeks the very best that a program is producing, to help determine if the value a program is capable of producing is worthwhile, and whether it is likely that it can be leveraged to a greater number of participants (Brinkerhoff, 2003).

Donald L. Kirkpatrick is best known for creating a four-level model for training evaluation. Kirkpatrick's ideas were first published in 1959, in a series of articles in the US Training and Development Journal but are better known from a book he published in 1975 entitled, Evaluating Training Programs. Kirkpatrick's four-levels of evaluation work is based on the 1956 Hierarchy of Steps work produced by Raymond Katzell, Professor Emeritus of NYU (Smith, 2008). Table 5 provides a quick at-a-glance comparison of the two models.

Table 5. Comparison of Katzell's and Kirkpatrick's Evaluation Models

\begin{tabular}{|c|c|}
\hline Donald Kırkpatrıck's - 1959 & Raymond Katzell's - 1956 \\
\hline Four Levels of Evaluation Model & Hierarchy of Steps Model \\
\hline $\begin{array}{l}\text { Level 1. Reactions - How well they liked the } \\
\text { training. }\end{array}$ & $\begin{array}{l}\text { Step One. To determine how trainees feel about } \\
\text { the program }\end{array}$ \\
\hline Level 2: Learnıng - How much they learned & $\begin{array}{l}\text { Step Two. To determine how much the trainees } \\
\text { learn in the form of increased knowledge and } \\
\text { understanding. }\end{array}$ \\
\hline $\begin{array}{l}\text { Level 3: Behavior - How well they applied the } \\
\text { learnıng to work. }\end{array}$ & $\begin{array}{l}\text { Step Three. To measure the changes in the on-the- } \\
\text { job behavior of the trainees. }\end{array}$ \\
\hline $\begin{array}{l}\text { Level 4: Results - What return the trainıng } \\
\text { investment yielded. }\end{array}$ & $\begin{array}{l}\text { Step Four. To determine the effects of these } \\
\text { behavioral changes an objectıve criteria such as } \\
\text { production, turnover, absenteeısm, and waste. }\end{array}$ \\
\hline
\end{tabular}

Source Smith, S. (2008). Why follow levels when you can build bndges? Training + Development, 62(9), 5862; Parry, S. (1997) Evaluating the impact of training Alexandria, VA: ASTD Press.

In a 1996 article titled "Measuring ROI: The Fifth Level of Evaluation," published in Technical and Skills Training, Jack Phillips suggested adding a fifth level to Kirkpatrick's Four Level Model (p. 10). Phillips fifth level is called return on investment (ROI) and asks the question, did the monetary value of the results exceed the cost for the program. Phillip's fifth level requires the calculation of ROI using the following formula: 


$$
\text { ROI }(\%)=\frac{\text { Benefits }- \text { Costs } \times 100}{\text { Costs }}
$$

Although Brinkerhoff's Success Case approach to evaluation can provide some very valuable, deep, rich information regarding training initiatives, it is Kirkpatrick/Phillips's model that has been more widely accepted and used in the workplace.

In the 2009 research study: The Value of Evaluation: Making Training Evaluations More Effective ASTD along with The Institute for Corporate Productivity (i4cp) published the results of a survey sent to business, HR, and learning professional contacts from ASTD and i4cp to find out how and if organizations were evaluating their workplace learning initiatives (ASTD, 2009b). In total, 704 people, representing a variety of organizational sizes and industries, responded to the survey.

Respondents were asked first if they used the Kirkpatrick/Phillips Model to evaluate workplace learning and then to identify which levels of the Kirkpatrick/Phillips Model they used as measurement and finally how valuable they felt the level was to measuring effectiveness of their training initiatives.

Figure 12 shows the responses of only those who actually use the Kirkpatrick/Phillips Model. The chart shows the percentage that use the level as measurement compared to the value they assign to the level with regard to measuring the effectiveness of their training initiatives. Although Level 1 is the most commonly measured type of evaluation, it is not considered to have high or very high value. In fact, only 35.9 percent of respondents whose companies use Level 1 evaluation believed it had high or very high value. By comparison, 54.9 percent said Level 2 had high or very high value, and 75 percent said the same about Level 3 and Level 4. Phillips' ROI-based Level 5 was seen as having high or very high value by 59.4 percent of respondents (ASTD, 2009b). This puts Level 1 at the bottom of the value chain for the four Kirkpatrick levels.

Allison Rossett, Professor Emerita at San Diego State University cautions against rushing to judgment against lowly Level 1. Rossett says that although Level 1 is not considered as valuable as other levels, employees must see the value in the assets that surround them. Appreciation is a perquisite to voluntary participation (Rossett, 2007). Level 1 evaluation, used correctly, has a significant place in understanding the satisfaction of the learner. Immediate feedback helps the facilitator organization make needed adjustments to the program. Level 1 is so much more than a smile sheet (Lopker \& Askeland, 2009). 


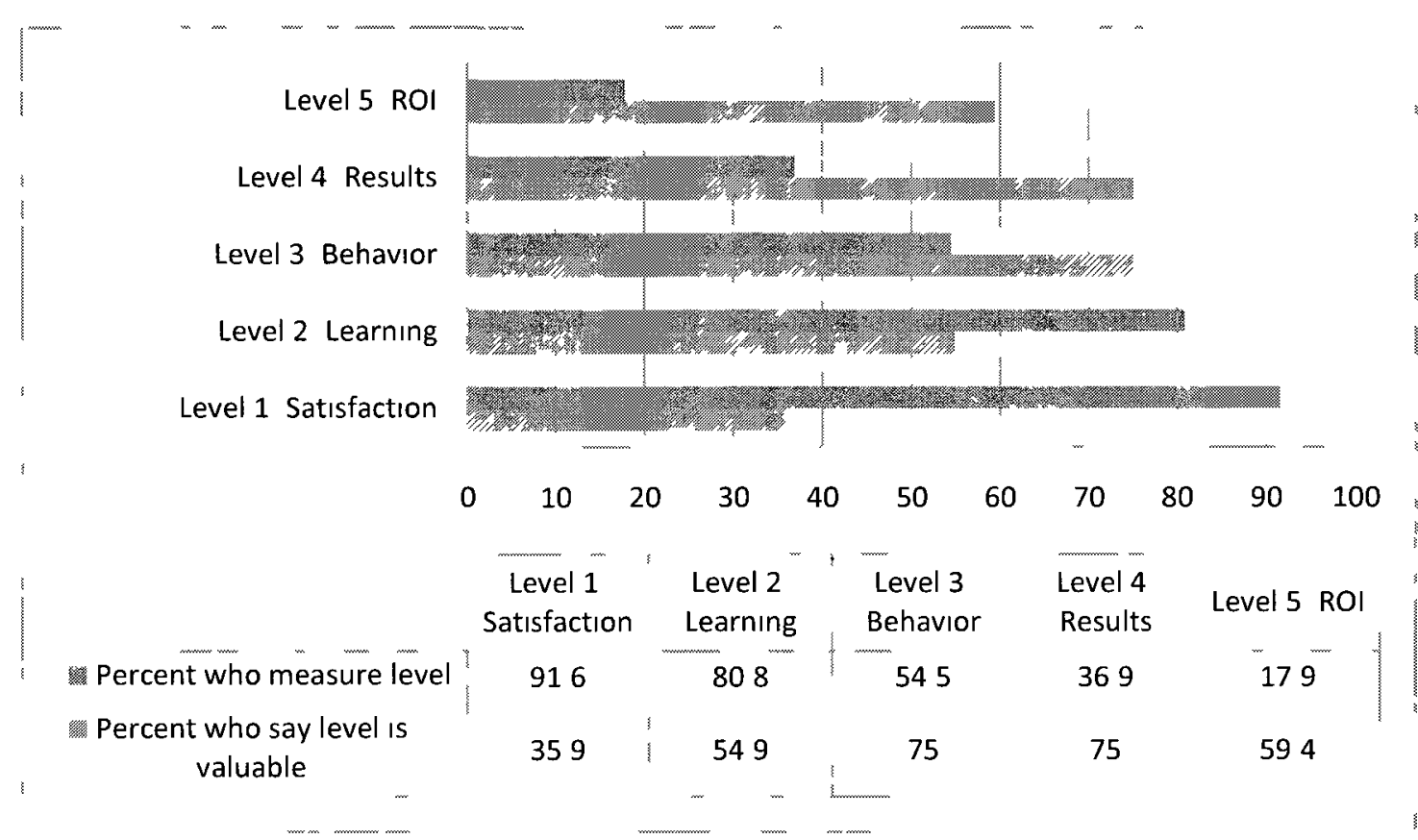

Figure 12. The value of evaluation. Source: American Society for Training \& Development. (2009b). The value of evaluation: Making training evaluations more effective. Alexandria, VA: Author.

Level 2 typically measures the learning achieved during the training event. The most successful measurement of Level 2 occurs when training practitioners have done some homework and design the course around a specific need. If the test results show that the participants have not learned the key lessons, it is time to redesign the experience (Withers, 2009).

Much of the recent literature on the Kirkpatrick/Phillips Model focuses on levels three through five. Some articles examine the how-to of gaining learning transfer and results (Kirkpatrick, 2005; Vellios, 2008; Weinstein, 2007a). Some are compelled to remind us of the value of each level (Kirkpatrick, 2007). Some present the challenges and opportunities of applying the Kirkpatrick/Phillips Model to e-learning (Horton, 2005; Rossett, 2007). And, finally ROI disciples, most notably Jack Phillips, make a case for Level 5 by answering questions about the complexity of figuring ROI (Phillips, 2007) or explain the predictive ability of the measurement (Smith, 2008).

As evidenced by the data presented in the ASTD/i4cp study there seems to be a contradiction. If the higher levels of three, four and five are believed to be more valuable to an organization, then why are they not measured with as much frequency as levels one and 
two. Some of the explanation may lie in what the respondents reported as barriers to assessment as seen in Figure 13.

\section{Percentage who see these as barriers to a high or very high extent}

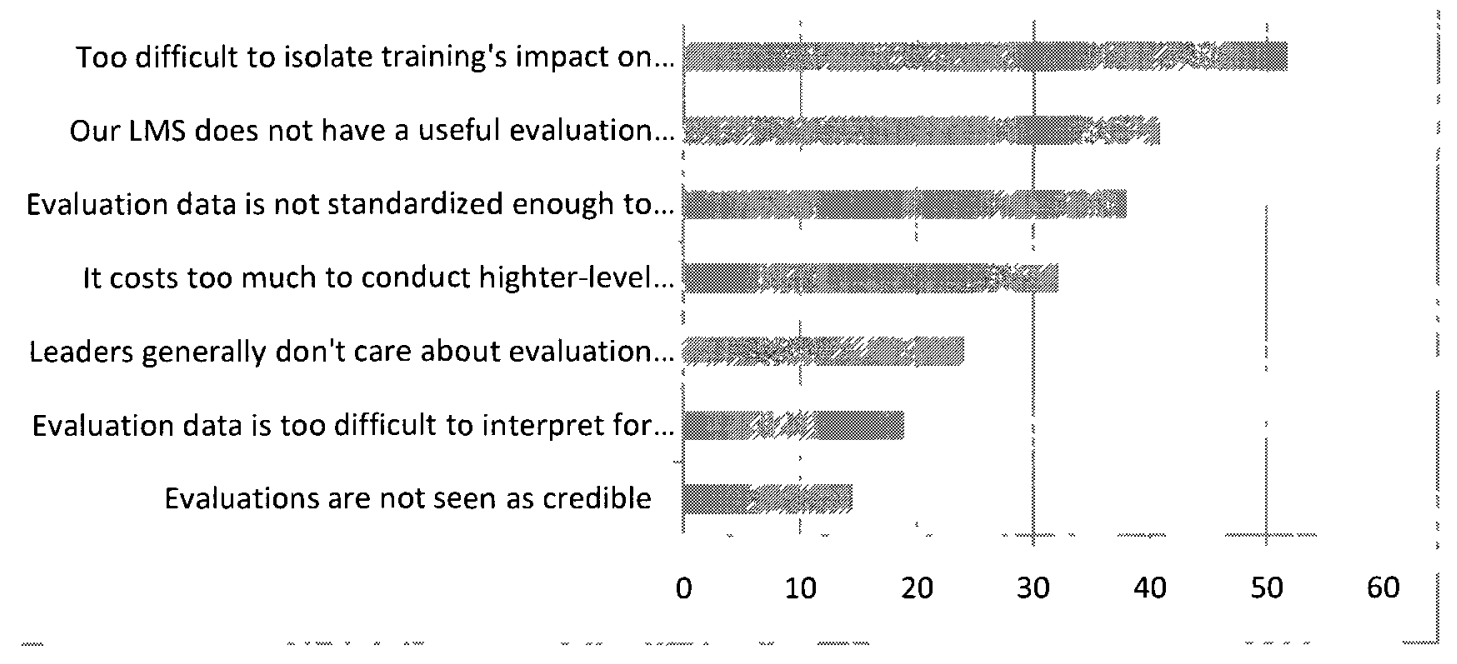

Figure 13. Barriers to assessment. Source: American Society for Training \& Development. (2009b). The value of evaluation: Making training evaluations more effective. Alexandria, VA: Author.

At the May 26, 2010 local chapter meeting of ASTD members, the topic was evaluation. The title of the evening's discussion was The Realities and Myths About Learning Measurement. When audience members were asked to call out reasons why measurement beyond Level 2 was problematic for their organization the issues of perceived value, cost, and time prevailed. Even this very informal gathering of data supported the findings of the ASTD/i4cp survey.

The survey also asked respondents about the evaluation of Successful Cases. It specifically asked if respondent's organizations conducted evaluation studies or interviews with successful trainees, though they did not name the Brinkerhoff Success Case Method. The study found that almost half of respondents said they did, with several more using an "other" selection as a chance to write in "Brinkerhoff" or "Success Case Method" (ASTD, 2009b, p. 16). 
The study found that, among those who said their organization has conducted an evaluation interview with successful trainees, just three-quarters said the interviews have helped them develop more effective learning services, only 59.7 percent said they disseminate the positive stories throughout the company, and only a little more than a third use the studies to identify factors that enhance or impede business impact (ASTD, 2009b, p. 17). Figure 14 shows the ratio of organizations who reported using a Successful Case evaluation.

\section{HAS YOUR ORGANIZATION EVER CONDUCTED AN EVALUTION STUDY (E.G., INTERVIEWS) WITH SUCCESSFUL TRAINEES?}

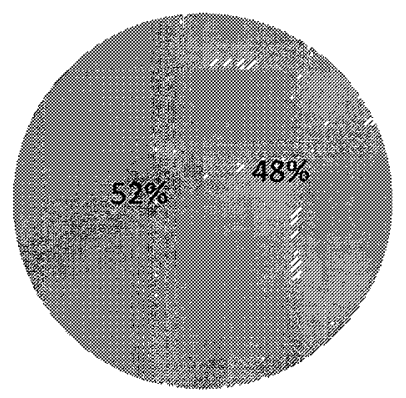

Figure 14. Ratio of organization who reported using a Successful Case evaluation. Source: American Society for Training \& Development. (2009b). The value of evaluation: Making training evaluations more effective. Alexandria, VA: Author.

The remainder of this section will look at other ways organizations evaluate workplace learning. One method that is drawing attention and gaining in popularity is the use of metrics, the heuristics designed for the purpose of guiding organizational decisionmaking. Unlike other evaluation methods devoted to measuring workplace learning initiatives after-the-fact and then leveraging the information to justify the investment, metrics takes a front end approach (Davenport, 2006).

Allison Rossett in the March 2010 T\&D article "Metrics Matter" describes the process from a technological point of view by focusing on a dozen key purposes Figure 15 


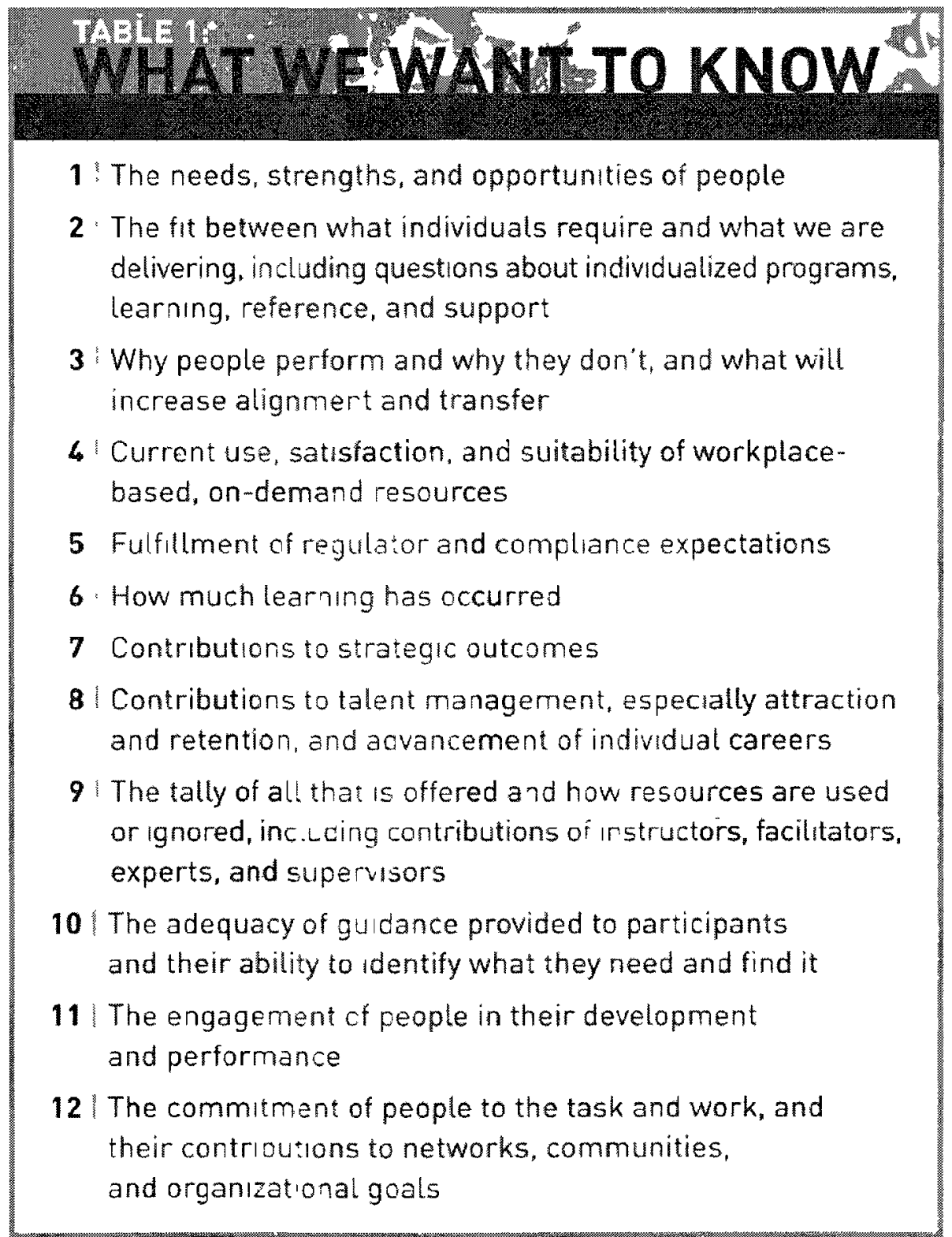

Figure 15. What we want to know. Source: Rossett, A. (2010). Metrics matters. Training + Development, 64(3), 64-69.

while advancing four goals: (1). Examining what matters to line leaders and their organization; (2). Capturing what matters to learning leaders; (3). Using the data in three ways: to plan, report, and improve, and 4). Matching the metrics to the changes (Rossett, 2010, p. 66).

Rossett (2010) suggests several methods to find out "what we want to know." For example for item number 6 (from Figure 14) she suggests the following techniques: 
Assessments, tests, observations, checklists, checking for speed, accuracy, and errors (Rossett, 2010, p. 67). To illustrate metrics in action she offers the following example (pay attention to plan, report, and improve):

Imagine a community college professor needs to provide data about her students' learning (number 6 from Figure 12), she asks them to criticize 10 graphical treatments using the criteria taught in class. The professor then measures the class on their ratings and rationale, comparing their efforts to those of a panel of experts. That data has implications for planning a short prerequisite offering for the class such that students will enter with shared skills and knowledge. She also reviews their performance, makes improvements to the class for the next time she offers it, and reports results on the exercise to each student (Rossett, 2010, p. 66).

Jack Zenger, Joe Folkman, and Robert Sherwin (2005) cofounders of Zenger/Folkman look at learning and development and segment the process into three phases: Phase 1 consists of all the activities that happen prior to someone physically attending a session. That includes articles and books to read, questionnaires to be completed, or data to be collected. Phase 2 describes the learning event itself. The event may be two hours in length or three months long. It may involve participants congregating in the same room or participants communicating via video-conferencing or some other form of distance learning. Phase 3 begins after the learning event. It includes the subsequent activities that are designed to reinforce and strengthen the application of the learning (Zenger, Folkman \& Sherwin, 2005).

They suggest the power of the segmentation lies in Phase 3 because it is at this phase the investment made in Phase 2 is leveraged. They offer several methods to insure Phase 3 success: space learning events over time, create buddy systems or support groups, coach online or by telephone, encourage mentorships, and have managers and supervisors regularly provide reminders to their direct reports to practice new behaviors learned in Phase 2 (Zenger et al., 2005).

While ROI receives the majority of press another method receiving little research but is thought to be more broadly applied is return-on-expectations (ROE). Proponents suggest that workplace learning programs should be evaluated in terms of the agreed-upon expectations and how well the program accomplished those objectives. They offer three key questions: What is the solution intended to change?, Is it realistic to assume that the solution can produce the change?, and Can we objectively isolate and measure the impact of the 
solution. All three questions must be answered with a yes before the perspective solution will be moved forward (Bernthal, 2005).

The final subject with regard to workplace learning evaluation is the heretical question of, "Do we even need to evaluate?" Martyn Sloman, advisor for the Chartered Institute of Personnel and Development in the United Kingdom offers this observation: Evaluation does not receive the attention that orthodoxy demands because it's not necessarily important in determining the allocation of resources to training and learning in organizations. We have reached the stage at which we should come clean and say that this precise evaluation isn't necessarily what organizations want or welcome (Sloman, 2004).

At the previously mentioned local ASTD chapter meeting on learning evaluation, two chief learning officers (CLO) were members of the panel. Each CLO represented a very large global organization each with over 50,000 employees and they concurred with $\mathrm{Mr}$. Sloman. Both agreed that it is unnecessary to measure every training or to rationalize a training program's existence. They believed the executives at the C-level trusted their abilities and were most interested in seeing improvements in employee and customer scores, employee retention rates, or sales increases. The executives used these variables as indicators of training success.

\section{BEST Criterion Three: Delivery Methods}

ASTD started asking its members how their companies delivered training in 2001. Before that time it was assumed that most if not all workplace learning was conducted in an instructor led classroom format.

According to the ASTD's 2009 State of the Industry Repost computer based delivery of formal learning declined in 2008 after two years of increases while the consolidated average for all instructor-led formal learning was 71.5 percent in 2008 , up slightly from 70.5 percent in 2007.

Curious about the actual use of e-learning by workplace learning professionals, Allison Rossett, Professor Emirita at San Diego State University (SDSU) and James Marshall a faculty member at SDSU in Educational Technology polled practitioners in corporations, government, military and higher education in 2009 and asked them to share what they were currently doing and when they were using e-learning (Rossett \& Marshall, 2010). 
Interestingly enough Rossett and Marshall found that contrary to what evangelists of Web 2.0 preach there is little evidence of technology driven collaborative and user-centered approaches in corporate and government settings (Rossett \& Marshall, 2010, p. 37).

According to Rossett and Marshall (2010) the most frequently occurring e-learning practice in the corporate and governmental workplace is the testing of skills and knowledge (p. 36).

So how should workplace learning professionals react to this information? For some, comfortable with the instructor led classroom form of workplace learning, maybe an "I told you so" wink and a sigh of relief. For others hoping for more evidence that technology is taking over maybe handwringing and gnashing of teeth.

Allison Rossett and James Marshall have issued a challenge and are asking workplace learning professionals this question, "Should we lament that the habits identified are not much different in 2009 than they were in 1989? Is this good news or bad? And most important, what do you intend to do about it (Rossett \& Marshall, 2010, p. 38)?

Although recent evidence indicates a decline in technologically delivered workplace learning the future seems bright. As the Gen Y cohort enters the workforce they will bring with them an expectation to receive or at least be offered a choice for technologically delivered workplace learning. Some methods they may expect are: web-based courses, games, simulations and virtual worlds, social media, and mobile devices.

Web-based courses also referred to as computer based courses usually come in two forms: synchronous and asynchronous. Synchronous which literally means, at the same time, involves interacting with an instructor and other students in real time. Participants attend the class at the same time and place (in this case link) just as one would in a traditional instructor led physical classroom. The advantages to synchronous courses are also similar to those found in the traditional classroom. Real time exchange with instructor and other students allows for robust dialog, sharing of ideas, and the immediacy of clearing up fuzzy or confusing concepts. The disadvantages include having to schedule their time around the predetermined plan of the instructor. This can be a distinct disadvantage to employees that are dispersed globally (Giguere \& Minotti, 2005).

An asynchronous course, which means not at the same time, allows a participant to attend and complete the course at any time without an instructor or interaction with other 
participants. This form of web based course is the most popular in the workplace because this format offers the most flexibility for employees. Participants log on and complete a course whenever their schedule permits. This option also allows participants, spread across the globe, to complete a course without having concerns over attending a class scheduled during the work day for an instructor but in the dead of night for a participant (Giguere \& Minotti, 2005).

One of the problems encountered by organizations initiating a web based course program is the belief that all classroom content can be converted to the web. Web based courses are most successful when they encourage participants to strive toward new levels of self-directedness and competency. Initiating a web based program also takes a great deal of time, talent, training, and money to develop. An organization must have skilled designers and facilitators to design, create, monitor, and evaluate the training courses (Giguere \& Minotti, 2005).

Web based courses are not suitable for all trainers and participants. Members of both groups have varying levels of comfort with technology. Some trainers are excellent in the classroom but are not effective online. Without a live audience they have trouble delivering the material in an effective way. Participants have different learning styles and varying degrees to which they need and seek assistance (Giguere \& Minotti, 2005).

Games, simulations, and virtual worlds training proponents say immersive learning and other Web 3D technologies represent the biggest communications advance since the Internet was formed, and promise they will revolutionize how people learn and interact (Harris, 2009).

Although the terms are used interchangeably there are differences between games, simulations and virtual worlds. Games are immersive learning simulations that are easy to access and are especially useful in situations when an employee needs to learn a skill through repetition (Aldrich, 2007).

Simulations mirror everyday situations participants encounter in their work. Nowhere is that more true than in training emergency personnel, where lecturing trainees on how to handle a crisis situation is a far cry from participating in an actual event (Laff, 2007b). 
Virtual worlds immerse avatars into an environment that allows a participant to collaborate with others and to create their own experience. One of the biggest names in virtual worlds is Second Life. Joe Miller, vice president of platform and technology development at Linden Lab, which operates Second Life, describes Second Life as “ ... a collaborative environment where you really feel like you're physically with other people" (Gronstedt, 2007).

Visitors to Second Life appear in the form of an avatar, a digital representation of themselves, in a three-dimensional world. Avatars move about an environment created by the site's users. An increasing number of corporate heavy hitters like Sun, Dell, British Petroleum (uh oh), and IBM are transferring their training programs to Second Life's virtual "metaverse" (Gronstedt, 2007).

The experts generally agree that games, simulations, and some virtual world activities boost learning retention rates dramatically. An often-cited study conducted by the National Training Laboratory (NTL) Institute for Applied Behavioral Sciences in Alexandria, VA., found that on average, students retain 5 percent of what they hear in lectures, 10 percent of what they read, and 20 percent of what they see and hear in audiovisual presentation. But add "practice by doing" and "teach others/immediate use" to the mix - two learning techniques that simulations possess - and retention rates shoot up to 75 and 80 percent, respectively (Boehle, 2005).

Some also credit simulations with accelerating the learning curve. According to James Lundy, vice president of Gartner, the Stamford, Connecticut, research firm, students learning via simulation - based training become proficient more quickly than those learning the same skill on the job (Boehle, 2005; Weinstein, 2008).

Proponents also point out that simulations allow students to practice newly acquired skills and apply new knowledge in a realistic, yet risk-free, environment. Students can experiment and explore the cause-and-effect relationships between operating decisions and business outcomes without facing real-world consequences (Boehle, 2005; Dolezalek, 2007).

The ability to gather team members around the world to collaborate at any time, in a realistic setting is one of the biggest advantages to virtual worlds. Not only do organizations save thousands of dollars in travel expenses but employees can address issues as they arise (Harris, 2009). 
One of the more interesting applications of virtual worlds is being used by IBM. Retired IBMers enter a virtual room to chat about issues of the day and share institutional knowledge with current employees (Galagan, 2008).

Other advantages are the ability to engage and empower employees in ways that accommodate digital and mobile lifestyles and the ease of adapting to individual learning needs (Gronstedt, 2007).

There are also several obstacles to widespread adoption of these technologies in the workplace. Chief among them are the IT issues such as getting around corporate firewalls and the hardware and infrastructure requirements to handle the amount of data driven by these technologies (Gronstedt, 2007). In addition the cost to conduct research and develop modules is a big obstacle in the corporate world (Harris, 2009; Laff, 2007b).

Another obstacle is preparing instructors for virtual classroom delivery. Some organizations have found that the differences in the virtual classroom compared to the instructor led class were so significant that every instructor (experienced or inexperienced) had problems adjusting to the virtual classroom environment (Clark, 2005).

The comfort level of participants also stands in the way. While younger workers falling into the Gen $Y$ and Gen X generational cohorts feel very comfortable using this technology, Baby Boomers and Traditionalists may have a harder time embracing this idea (Weinstein, 2008).

There is also a public relations issue. For many there is an inbred prejudice against paying employees to have fun (Harris, 2009). Henry Kelly, president of the Federation of American Scientists offered this explanation,

Some people may think that if you use a game and have fun then you can't be learning. The Department of Defense has been using war games forever. If you were to call it simulation-based instructional technology, people wouldn't understand you. The concept of games brings to mind a vivid image. It's a powerful way to communicate (Laff, 2007b, p. 55).

Workplace learning delivery via social media includes various online technology tools that enable people to communicate easily via the internet to share information and resources. Some familiar brands of social media are: Twitter, Facebook, and YouTube. Other social media methods include blogs and podcasts. Jane Hart, a social media and learning consultant, classifies Twitter and other micro-blogs as tools for personal and informal learning (Galagan, 2009). 
Employees like Twitter because they believe it accelerates their learning curve, helps with personal learning, and expands their circle (Galagan, 2009). They believe it helps their organization be smarter, more nimble, and more personal. One employee said "It makes a 28,000 person company feel like a 280 person company (Conner, 2009).

A blog is an online journal. Blogging is also a significant learning and networking tool that can help individuals, groups, and organizations learn in new and interesting ways (Karrer, 2007). Blogs are used to share information among knowledge workers within a team or across an organization. Work teams can use blogs as a means to collaborate on research tasks and they are a wonderful way to capture lessons learned. Blogs also promote a culture of productive disagreement, discourse, and problems resolution (Karrer, 2007).

Because blogging is a bottom-up activity driven by individuals, it presents challenges to workplace learning professionals about the best way to support it. Providing easy access to tools, information on blogs and models of best practices in addition to developing a policy for blog use are good starting points (Karrer, 2007).

Mobile learning is the exploitation of ubiquitous handheld technologies, together with wireless and mobile phone networks to facilitate, support, enhance and extend the reach of teaching and learning (Brown, 2010). Mobile devices used for mobile learning are pocket size computing devices. IPods, IPhones, and BlackBerries, are all brand names for these mobile devices.

Advocates of mobile learning believe that effective usage can bring us closer to improved personalized learning by delivering the right materials to the right person at the right time and place (Brown, 2010).

While there seems to be many benefits and much enthusiasm from those organizations using mobile devices for learning there are still some hurdles for others to overcome before entering into the mobile learning arena. It is highly unusual for companies to record their own podcasts or to provide workers the devices required to listen to the program. Providing mobile devices to every employee, or a select group, can be very expensive (Weinstein, 2007b).

Anders Groenstedt (2007), whose firm the Groenstedt Group specializes in computerbased simulations to train sales and service organizations, cautions, simply recording lectures, digitizing them, and distributing them via the web is a sure road to failure. There is 
a fundamental difference between what holds the interest of students in a classroom and those listening on an iPod. You have to model podcasts in ways familiar to audiences of aural media (Sussman, 2005).

There is also a "slacker stigma" associated with the on-the-job use of these devices in some work cultures. Providing cultural change work prior to introducing mobile learning initiatives would be necessary. Also developing policy for monitoring how sensitive or proprietary information is distributed and how employees use these devices, e.g., downloading music instead of training, are all major considerations (Boehle, 2009).

Mobile learning will be an interesting trend to watch. At a recent event at Massachusetts Institute of Technology, Google CEO Eric Schmidt asked the question, "Why do we teach the old way since all the world's information is literally on this phone or equivalent to a phone device that you carry around with you" (Brown, 2010)?

\section{BEST Criterion Four: Perceived Value of Workplace Learning Within the Organization}

At the previously mentioned ASTD chapter meeting the Chief Learning Officer for a large multi-national corporation claimed "The learning function is the only function in an organization asked to prove its worth."

It is true that workplace learning leaders spend large amounts of time pointing to past learning and performance improvement initiatives trying to show a direct cause and effect link to the success of a business venture or a positive change in some critical business indicator.

Much of the recent literature on valuing the learning function focuses on the how-to and importance of preparing return-on-investment data as a way of convincing executives that learning has a quantitative value (Natchez, 2008; Phillips, 2007; Phillips \& Phillips, 2009, 2010; Weinstein, 2009). In fact there are 31 case studies in ASTD's In Action Series: Measuring Return on Investment edited by Jack (father of the Kirkpatrick/Phillips Level 5) and Patti Phillips on this very topic (Sugrue, 2004).

Other research links learning to employee development through a larger set of human resources practices. One such study is Mark A. Huselid's (1995) article on the impact of HR practices on turnover and productivity. Another study by ASTD, "Profiting From Learning: Do Firms' Investments in Education and Training Pay Off?" found that training expenditure 
per employee in 1996, 1997, and 1998 predicted company stock price the following year (Bassi, Ludwig, McMurrer, \& Van Buren, 2009; Sugrue, 2004).

Theresa Seagraves in an article published in the February $2005 T \& D$ titled "The Inside Pitch" recommends communicating workplace learning value through the language of finance Ms. Seagraves offers a 12 step approach she claims will help workplace learning professionals master the basics of the language of finance. Using terms such return on assets, cash flow from operations, or net profit or loss and understanding what numbers "keep your executives up at night" will help you gain their attention and earn their respect (Seagraves, 2005, p. 42).

While learning to figure ROI or tying learning to a metric such as employee retention have their place, financial considerations are certainly not the whole picture. Jack and Patti Phillips (2009) expanded their research beyond ROI measurement and took a very interesting look at the relationship the person in charge of the learning function has to the CEO. In a study of Fortune 500 executives the Phillips asked only CEOs how many reporting levels there were between themselves and the person in charge of learning. Ninety six responded to the request. In the study, a " 1 " indicated that the person in charge of learning reported directly to the CEO. A " 2 " meant that there were two levels between them, and a " 3 " meant that there were three levels between them. The average was 3.2 which meant that the CEO is at least three levels above the person in charge of learning (Phillips \& Phillips, 2009).

The findings were disturbing given the amount of effort focused on pushing the learning function to a higher level within an organization (at least by the learning community) over the past few years. The Phillips' believed that one factor contributing to their findings is the lack of interaction between the CEO and the person in charge of learning. Senior executives have limited time and they spend it in those areas they perceive to be critical, important, and central to the organization's success (Phillips \& Phillips, 2009).

Another non ROI factor pointing to perceived value of the learning function is the number of senior executives participating in training courses themselves. When HR and learning leaders were asked which category of employee receives the most training in their organizations, 90 percent reported frontline managers. Senior level executives rated the lowest (Laff, 2007a). 
Whether the lack of senior level participation in workplace learning initiative is reflective of other demands on their time or the belief that senior executives don't need training is uncertain. What is certain is the organizational commitment to learning must be led from the top.

\section{RELATIONSHIP BETWEEN ORGANIZATIONAL Excellence ANd WorkPlace Learning Practices}

This review of the literature has explored organizational excellence through the lens of the Malcolm Baldrige National Quality Award criteria which draws a connection to the value and contribution workplace learning has to the pursuit of organizational excellence. It has also examined workplace learning practices from the criteria used by the ASTD to determine BEST award recipients. While the literature directly linking workplace learning practices to organizational excellence is limited, there are references to the value of workplace learning practices in relationship to establishing corporate values of excellence, as a method of disseminating knowledge throughout the organization, and its role in building a learning organization culture.

In their book The Disney Way (1999) Capodagli and Jackson state that a company claiming the corporate value of excellence must establish a specific ongoing process to transmit knowledge and, in turn, improve employees' skills (p. 140).

For many, the process of disseminating knowledge throughout an organization begins with developing the leaders who in turn act as role models and stimulate learning organization-wide (Bennis \& Nanus, 1985; Kouzes \& Posner, 2002, 2010; Studer, 2003; Ulrich et al, 2008; Zenger \& Folkman, 2002).

Peter Senge, faculty member at the Massachusetts Institute of Technology (MIT), founding chairman of the Society for Organizational Learning (SoL), and author of The Fifth Discipline: The Art and Practice of the Learning Organization (1990) disagrees with the notion that transmitting knowledge throughout an organization begins at the top. In his 1995 chapter Leading Learning Organizations: The Bold, the Powerful, and the Invisible, from the book The Leader of the Future, Senge suggests that true organizational learning is not a top down practice but comes from many places within an organization (Senge, 1995).

He identifies three different types of learning leaders: local line leaders, executive leaders, and internal networkers, or community builders. Each type plays an essential role in 
building a learning culture and moving the organization toward excellence. The local line leaders undertake meaningful organizational experiments to test whether new learning capabilities lead to improved business results (Senge, 1995).

The executive leaders provide support for line leaders, develop learning infrastructures, and lead by example in the gradual process of evolving the norms and behaviors of a learning culture (Senge, 1995). And the internal networkers, or community builders act as the "seed carriers" for the new culture, who can move freely about the organization to find those who are predisposed to bringing about change, help out in organizational experiments, and aid in the diffusion of new learnings (Senge, 1995).

Senge agrees with Harvard's Chris Argyris, in a 1994 Harvard Business Review article, Good Communication That Blocks Real Learning when he says:

Corporate communication programs rolled out from the top can actually inhibit learning and communication. Organizational surveys and focus groups, for example, by focusing attention on "telling" top management what is wrong, can block learning because they do nothing to encourage individual accountability and tend to reinforce the mind-set that only top management has the power to fix problems (Senge, 1995, p. 44).

To achieve organizational excellence can require a shift in the organization's culture and thinking about the value of a learning organization. Peter Senge (1990) defines learning organizations as: ...organizations where people continually expand their capacity to create the results they truly desire, where new and expansive patterns of thinking are nurtured, where collective aspiration is set free, and where people are continually learning to see the whole together.

Garry Ridge explains how he created what he called "fields of learning" in his organization by breaking up a culture of 'knowledge silos' into a culture where learning was valued and shared, and information could move easily (Blanchard \& Ridge, 2009).

Quint Studer identifies two types of corporate culture: those divided by blame and finger-pointing and those united by teamwork and shared responsibility. He calls the first type the "we/they phenomenon" and stands quite firm on the premise that if an organization is to change from a we/they type of culture to a culture of teamwork and shared responsibility an investment in training for all levels of employees must occur (Studer, 2008).

Leaders and authors in management have also championed the value of workplace learning. Tom Peters and Robert Waterman in their management classic In Search of 
Excellence: Lessons from America's Best-Run Companies (1982) underscore the importance of employee development when identifying factors behind the incredible productivity of Sony and Matsushita's success in their plants in the United States said, "The productivity proposition is not so esoterically Japanese as it is simply human ... loyalty, commitment through effective training, personal identification with the company's success and, most simply, the human relationship between the employee and his supervisor" (p. 39).

James Collins and Jerry Porras' landmark study of the most successful businesses in the world Built to Last: Successful Habits of Visionary Companies (1994) supports this commitment to employee development. Visionary companies develop, promote, and carefully select managerial talent grown from inside the company to a greater degree than the comparison companies (p. 173).

The role of the workplace learning professional is to develop the leaders and workforce that will lead the organization to excellence. It is to link learning to performance, to introduce innovative learning initiatives, and to champion the value of learning throughout the organization.

The challenge is to define workplace learning excellence by seeking answers. What are the workplace learning practices of organizations of excellence? Are there similarities between them? What are the differences?

We shall see. 


\section{CHAPTER 3}

\section{METHODS}

A man should look for what is, and not for what he thinks should be.

Albert Einstein

This study sought to identify the role the workplace learning function has on overall organizational excellence. To achieve this goal, the study examined the workplace learning practices of recipients of the Malcolm Baldrige Quality Award as compared to criteria established by the ASTD's BEST award. The study used qualitative methodology to answer the following research question:

1. What are the workplace learning practices of organizations who have won the Malcolm Baldrige National Quality Award that support the organization's mission, vision, values, and goals?

2. What evidence is there that workplace learning initiatives are supported at the executive level in organizations that have received the Malcolm Baldrige National Quality Award?

\section{QuAlitative Methodology}

A qualitative study was chosen to allow the researcher to burrow down in the participants world and ferret out those factors impacting how workplace learning decisions were made. It emphasizes the researcher's role as an active learner who can tell the story from the participants' viewpoint (Creswell, 1998). Denzin and Lincoln (2005) offer an excellent description of qualitative research:

Qualitative research is a situated activity that locates the observer in the world. It consists of a set of interpretive, material practices that make the world visible. These practices transform the world. They turn the world into a series of representations, including field notes, interviews, conversations, photographs, recordings, and memos to the self. At this level, qualitative research involves an interpretive, naturalistic approach to the world. This means that qualitative researchers study things in their natural settings, attempting to make sense of, or interpret, phenomena in terms of the meanings people bring to them (p. 3).

Qualitative research casts the researcher as bricoleur, or maker of quilts, to piece together a picture using whatever strategies, methods, and empirical materials are at hand 
(Becker [1998] as cited in Denzin \& Lincoln, 2005). The combination of multiple methodological practices, empirical materials, perspectives, and observers in a single study is best understood, then, as a strategy that adds rigor, breadth, complexity, richness, and depth to any inquiry (Flick [2002] as quoted in Denzin \& Lincoln, 2005).

While much has been written about the value of using qualitative research inquiry in a variety of disciplines: education (Jacob, 1987; Lancy, 1993), social sciences (Denzin \& Lincoln, 2005; Miles \& Huberman, 1994); psychology (Moustakas, 1994; Slife \& Williams, 1995 ) and nursing (Morse \& Field, 1994; Munhall, 2010), the use of qualitative inquiry is not without its detractors.

As Denzin and Lincoln (2005) report, qualitative research has been termed unscientific, or only exploratory, or subjective (p. 8). Critics claim qualitative research does not require well-defined variables or causal models (p. 9). The observations and measurements of qualitative scholars are not based on subjects' random assignment to experimental groups (p. 9). Qualitative researchers do not generate hard evidence (p. 9).

As Denzin and Lincoln (2005) report the experimental (positivist) sciences (physics, chemistry, economics, and psychology, for example) are often seen as the crowning achievements of Western civilization, and in their practices it is assumed that "truth" can transcend opinion and personal bias (p. 8). Qualitative research is seen as an assault on this tradition, whose adherents often retreat into a "value-free objectivist science" (p. 8).

The beauty of qualitative research is not only in its acknowledgement of the value of the subjective but also in its ability to view the subjective through a variety of looking glasses, e.g., phenomenology, grounded theory, ethnography. This study will pick up the case study looking glass to examine the workplace learning practices of six Baldrige recipients.

\section{Multiple Case Study}

This study was a multiple case study which shares many features of a single case study. According to Robert Stake case study is not a methodological choice but a choice of what is to be studied. It is defined by interest in an individual case, not by the methods of inquiry used (Denzin \& Lincoln, 2005). The case is a bounded system (Creswell, 1998; 
Denzin \& Lincoln, 2005) meaning that certain features are within the system, within the boundaries of the case, and other features outside (Denzin \& Lincoln, 2005).

The case can be a program, an event, an activity, or an individual (Creswell, 1998).

The case is driven by asking, "What can be learned about the single case" (Denzin \& Lincoln, 2005). An interesting feature of a case study is that it's both a process of inquiry as well as the product of that inquiry (Denzin \& Lincoln, 2005). Robert Stake identifies three types of case study: intrinsic, instrumental, and multiple or collective (Stake, 2005).

Intrinsic study is undertaken because the researcher wants better understanding of this particular case (Denzin \& Lincoln, 2005). It is not because the case represents other cases or because it illustrates a particular trait or problem, but instead because, in all its particularity and ordinariness, the case itself is of interest (Denzin \& Lincoln, 2005).

Instrumental case study is examined mainly to provide insight into an issue or to redraw a generalization. The case is of secondary interest, it plays a supportive role, and it facilitates our understanding of something else (Denzin \& Lincoln, 2005).

The multiple or collective case study is an instrumental study extended to several cases (Denzin \& Lincoln, 2005). As Stake (2005) states, the collection of cases may be similar or dissimilar, with redundancy and variety each important. They are chosen because it is believed that understanding them will lead to better understanding, and perhaps better theorizing, about a still larger collection of cases (p. 446). Multiple case study is especially useful when investigating a phenomenon, population, or general condition (Stake, 2005). In this case, the workplace learning practices of Baldrige recipients.

Baldrige recipients were chosen because it is believed that investigating them will lead to better understanding, and perhaps better theorizing, about workplace learning practice excellence in general (Denzin \& Lincoln, 2005).

\section{PARTICIPANTS}

A multiple case study meets the definition of a naturalistic design posited by Stephen Isaac and William Michael (1995). The naturalistic design strives to preserve the real life context in which events occur and the manner in which the many complex variables interact, with a minimum of intrusion and an absence of any attempt to control or manipulate variables (p. 219). 
A method of sampling data that is particularly appropriate of naturalistic research is purposeful sampling (Creswell, 1998; Isaac \& Michael, 1995). The power of purposeful sampling lies in selecting information-rich cases for in-depth study (Isaac \& Michael, 1995). This study will select participants based on what Isaac \& Michael refer to as criteria sampling (p. 224).

The logic of this strategy is to study all cases that meet some predetermined criteria of importance. In particular, it sets out to understand cases which are likely to be information rich because they may reveal major system weaknesses (or strengths) leading to program improvement (Creswell, 1998; Isaac \& Michael, 1995). The criteria used to select participants for this study is winning the Baldrige award.

There have been 87 recipients of the Baldrige award, divided into the following six sectors: healthcare, education, small business, service, manufacturing, and public/nonprofit since the award's inception in 1988 (NIST, 2009a). Six recipient organizations, one from each sector, ranging in size from 130 employees to over 38,000 were chosen to participate in a face-to-face, semi structured interview. The organizations were chosen by geographic location for financial and convenience purposes.

Two organizations were located in San Diego; one from the health care sector and another from manufacturing. One organization in the service sector was located in Southern California. Travel arrangements were made to meet with three organizations located outside of California in locations where the researcher had family or friends helping to reduce the financial burden. Two organizations, one from the small business sector and one from the education sector were located in Oklahoma and a third was located in New Mexico. The name of the Baldrige sector, year Baldrige award received, organization name, number of employees, location of company headquarters, and title of person interview is shown in Table 6.

The persons interviewed were chosen by the organization and were knowledgeable in three areas: the workplace learning function within the organization, the Baldrige review process, and the history and culture of the organization.

A promise to share study results was offered as an incentive to those agreeing to participate. While all participants readily accepted the offer, award recipients are required to share nonproprietary information about their successful performance and quality strategies 
Table 6. Participant Information

\begin{tabular}{|c|c|c|c|c|}
\hline $\begin{array}{c}\text { Baldridge Sector } \\
\text { \& Year Award } \\
\text { Received }\end{array}$ & Organization Name & $\begin{array}{l}\text { Number of } \\
\text { Employees }\end{array}$ & $\begin{array}{c}\text { Location of } \\
\text { Company } \\
\text { Headquarters }\end{array}$ & $\begin{array}{l}\text { Title of Person } \\
\text { Interviewed }\end{array}$ \\
\hline $\begin{array}{l}\text { Manufacturing } \\
1998\end{array}$ & *Solar Turbines, Inc. & 7,000 & San D1ego, CA & $\begin{array}{l}\text { HR \& Learnıng } \\
\text { Consultant }\end{array}$ \\
\hline $\begin{array}{l}\text { Health Care } \\
\text { Strategy } \\
2007\end{array}$ & Sharp Health Care & 15,000 & San Diego, CA & $\begin{array}{l}\text { VP Customer } \\
\text { Strategy The Sharp } \\
\text { Expenience \& The } \\
\text { Sharp University }\end{array}$ \\
\hline $\begin{array}{l}\text { Small Business } \\
2006\end{array}$ & Mesa Products, Inc. & 130 & Tulsa, OK & President \\
\hline $\begin{array}{l}\text { Service } \\
1992 \& 1999\end{array}$ & $\begin{array}{l}\text { Ritz-Carlton Hotel Co., } \\
\text { LLC }\end{array}$ & 38,000 & Chevy Chase, MD & $\begin{array}{l}\text { Hotel Manager, } \\
\text { Laguna N1gel, CA }\end{array}$ \\
\hline $\begin{array}{l}\text { Education } \\
2006\end{array}$ & $\begin{array}{l}\text { Jenks Public School } \\
\text { District }\end{array}$ & 1,200 & Jenks, OK & $\begin{array}{l}\text { Assıstant } \\
\text { Superintendent } \\
\text { Curriculum \& } \\
\text { School } \\
\text { Improvement }\end{array}$ \\
\hline $\begin{array}{l}\text { Non-profit/Public } \\
2009\end{array}$ & $\begin{array}{l}\text { VA Cooperatıve Studıes } \\
\text { Program Clınıcal } \\
\text { Research Pharmacy } \\
\text { Coordınatıng Center }\end{array}$ & 140 & Albuquerque, NM & $\begin{array}{l}\text { Chief Strategic } \\
\text { Planning \& } \\
\text { Learning }\end{array}$ \\
\hline
\end{tabular}

*Solar Turbınes, Inc. 1s a subsıdiary of Caterpıllar Inc. While reference may be made to Caterpillar, this study examınes the workplace learnıng practıces of Solar Turbınes, Inc. and not those of Caterpillar, Inc.

with other U.S. organizations by the sponsoring agency for the Baldrige Award the National Institute of Standards and Technology (NIST, 2009b).

It is worth noting that even though the researcher was conducting research for academic purposes and did not represent an organization seeking to apply for the Baldrige, every organization contacted agreed to participate in this academic endeavor.

\section{INSTRUMENTS}

A one hour, semi-structured interview consisting of 17 items was developed and used in six face-to-face interviews (Appendix). A semi-structured interview was chosen over a structured or an unstructured interview for two reasons: to insure that items relevant to the research questions were asked and to give the interviewee (subject) maximum flexibility in answering the items.

Andrea Fontana and James Frey describe the difference between an unstructured and structured interview as follows: [The structured interview] aims at capturing data of a codable nature so as to explain behavior within pre-established categories whereas [an unstructured interview] attempts to understand the complex behavior of members of society 
without imposing any a priori categorization that may limit the field of inquiry (Fontana \& Frey, 2005).

A semi-structured interview is a hybrid of the unstructured and structured interview. Tom Wengraf explains that a semi-structured interview is designed to have a number of interviewer questions prepared in advance but such prepared questions are designed to be sufficiently open that the subsequent questions of the interviewer cannot be planned in advance but must be improvised in a careful and theorized way (Wengraf, 2001).

Fontana and Frey offer several steps to consider prior to conducting an unstructured interview (Fontana \& Frey, 2005). Even though these considerations were made with regard to an unstructured interview, they seemed relevant to a semi-structured format and provided some guidelines for the researcher. The steps to consider are as follows: accessing the setting, understanding the language and culture of the respondents, deciding how to present oneself, locating an informant, gaining trust, establishing rapport and collecting empirical material (Fontana \& Frey, 2005). The remainder of this section will outline how each of the steps was addressed.

Access to the setting for this research was made initially by an email to each participant explaining the intent and focus of the study. The language and culture concerns were avoided because the researcher is a practitioner in the workplace learning field and speaks workplace learning fluently. The participants acted as informants allowing the researcher access to their organizations. Trust was established by making sure the participant's needs were addressed with regard to the scheduling of the interview. Each participant selected the time of day and date best for the one hour interview and the researcher accommodated their requests and stayed within the one hour time frame. In addition the interview questions were given to each participant prior to the interview to allow them to reflect and to prepare.

Rapport was established by the researcher with each of the respondents by trying to find common ground beyond working as workplace learning practitioners. For example, the participant at the VA Cooperative Studies Program Clinical Research Pharmacy Coordinating Center had recently received her doctorate from the University of New Mexico. There was much discussion and commiserating. Finally, collecting empirical data was 
achieved by taking voracious notes and using a recording devise to capture the interview word for word.

The interview consisted of 17 items (Appendix). Twelve items addressed research question one: What are the workplace learning practices of organizations who have won the Malcolm Baldrige National Quality Award that support the organization's mission, vision, values, and goals?

Five items addressed research question two: What evidence is there that workplace learning initiatives are supported at the executive level in organizations that have received the Malcolm Baldrige National Quality Award?

\section{Procedures}

The data collection time for this study was approximately two months and proceeded as follows:

1. Six participants, one from each Baldrige sector, were identified and invited via email to participate in study.

2. Appointments were made to conduct and record face-to-face interviews.

3. Face-to-face interviews were conducted and recorded over a four week period from February 17 to March 9.

4. Travel plans were made to fly to Oklahoma and New Mexico to conduct three interviews.

5. Out-of-state interviews were conducted and recorded over a six day period as follows:

a. Mesa Products, Inc. - February 17, 2011 - Tulsa, OK

b. Jenks Public School District - February 18, 2011 - Jenks, OK

c. VA Cooperative Studies Program Clinical Research Pharmacy Coordinating Center - February 22, 2011 - Albuquerque, NM

6. The three remaining interviews were conducted and recorded in the following order:

d. The Ritz-Carlton Hotel Company, LLC - March 2, 2011 - Laguna Nigel, CA

e. Solar Turbines, Inc. - March 4, 2011 - San Diego, CA

f. Sharp HealthCare - March 9, 2011 - San Diego, CA

7. Recorded interviews were sent to be transcribed into Word documents for analysis.

8. Transcribed interviews were read for common themes and metaphors and were categorized.

9. Baldrige applications were reviewed to compare interview themes with those stated in applications.

10. Member checks were conducted for verification of themes with each organization. 


\section{Data Analysis}

This study used qualitative analysis methods as described by Creswell (1998) to review the data. Recorded interviews were transcribed and a general review was conducted by reading through all collected information to obtain a sense of the overall data and to write notes in the form of reflections (p. 140). Next, words used by participants were closely examined watching for common metaphors and themes (p. 140). Categories were developed and identified themes and metaphors were sorted into these categories (p. 140). Tables were constructed as a means for visualizing the information and representing it by theme (p. 140). Finally, all categories were reduced to use in narration of the results (p. 142).

Robert Stake (1995) also advocates use of these methods with regard to case study analysis in particular (Creswell, 1998). He states the researcher establishes patterns and looks for a correspondence between two or more categories. These correspondences might take the form of a table showing the relationship between two categories (Creswell, 1998).

In addition to establishing patterns Stake believes the researcher develops naturalistic generalizations from analyzing the data, generalizations that people can learn from the case either for themselves or for applying it to a population of cases (Creswell, 1998). This study hopes to draw generalizations that can be used by workplace learning practitioners seeking excellence in practice.

Criticisms of qualitative research usually revolve around the quantitative terms validity and reliability. Validity is measuring what we say we are measuring. It also addresses the generalizability of the findings (Creswell, 1998; Rudestam \& Newton, 2007). Reliability is about the replication of the study under similar circumstances (Creswell, 1998; Rudestam \& Newton, 2007).

Creswell (1998) reports that many authors (Eisner, 1991; Ely, Anzul, Friedman, Garner \& Steinmetz, 1991; Lincoln \& Guba, 1985) object to using quantitative terminology to describe qualitative research. They see it as a defensive measure that muddies the water (Ely et al., 1991). Lincoln and Guba (1985) argue for the use of alternative terms such as credibility, transferability, and dependability as replacements for internal validity, external validity, and reliability (Creswell, 1998).

To operationalize these terms Creswell (1998) offers a list of eight techniques: prolonged engagement, triangulation, peer review, negative case analysis, clarifying 
researcher bias, member checks, rich, thick description and external audits (p. 201-203). Creswell (1998) also recommends that qualitative researchers engage in at least two of these techniques in any given study (p. 203).

Prolonged engagement is as it implies, persistent observation in the field, building trust with participants, learning the culture, and checking for misinformation that stems from distortions introduced by the researcher or informant (Creswell, 1998). Triangulation is a process of using multiple perceptions to clarify meaning, verifying the repeatability of an observation or interpretation (Denzin \& Lincoln, 2005). In triangulation, the researcher makes use of multiple and different sources, methods, investigators, and theories to provide corroborating evidence. Typically, this process involves corroborating evidence from different sources to shed light on a theme or perspective (Creswell, 1998).

Peer review provides an external check of the research process (Creswell, 1998). The role of the peer reviewer has been likened to a devil's advocate. The peer reviewer asks the hard questions about the methods, meanings, and interpretations (Creswell, 1998). In negative case analysis the researcher refines working hypotheses a the inquiry advances in light of negative or disconfirming evidence (Creswell, 1998).

Clarifying researcher bias requires the researcher to disclose any biases or assumptions the researcher may have based on past experiences, biases, prejudices, and orientations that have shaped the interpretation and approach to the study (Creswell, 1998). Member checks, according to Stake (1995) help establish validity to the study (Creswell, 1998) by testing interpretations made and conclusions drawn from the interview with the participants from which the data was originally obtained.

Rich, thick description allows the reader to make decisions regarding transferability because the writer describes in detail the participants or setting under study (Creswell, 1998). Finally, external audits allow an external consultant, to examine both the process and the product of the account, assessing their accuracy (Creswell, 1998).

This study will use triangulation and member checks to provide credibility, transferability, and reliability. 


\section{CHAPTER 4}

\section{RESULTS}

However beautiful the strategy, you should occasionally look at the results.

Winston Churchill

This chapter presents the findings from data gathered through semi-structured, faceto-face interviews with six Malcolm Baldrige Quality Award recipients representing the six sectors in which the award is given: manufacturing, health care, education, small business, non-profit/public, and service.

The purpose of this study was to investigate the impact of the workplace learning function upon organizational excellence by examining the workplace learning practices of organizations that have received one of the most prestigious awards given for organizational excellence in the United States.

There were two research questions:

1. What are the workplace learning practices of organizations who have received the Malcolm Baldrige National Quality Award that support the organization's mission, vision, values, and goals?

2. What evidence is there that workplace learning initiatives are supported at the executive level in organizations that have received the Malcolm Baldrige National Quality Award?

\section{RESEARCH QUESTION RESULTS}

A total of 17 items were asked of each participant. These 17 items were distributed among the two research questions as follows: twelve items addressed research question one and five items addressed research question two.

Each transcribed interview item was analyzed for key terms and themes. A comparison of all interviews was made and common themes for each interview item were identified. The interview items along with a list of identified key terms and themes for that item were then sent to each participant, via email, for confirmation of accuracy of intent and to act as a member check. The findings of each interview will be presented next. 


\section{RESEARCH QUESTION ONE}

Twelve interview items, identified as Items One - Twelve, were developed to address research question one: What are the workplace learning practices of organizations who have received the Malcolm Baldrige National Quality Award that support the organization's mission, vision, values, and goals?

Interview item one asked: What factors does your organization consider when making a decision to provide workplace learning? Analysis revealed that all six organizations developed workplace learning initiatives by identifying organizational needs. While this was a consistent theme, the ways in which needs were identified varied.

Mesa Products, Inc. (Mesa) determines needs by conducting a gap analysis. The organization determines where they want to go and measures that against where they are and then develops learning initiatives that help fill in the gap. As Mesa Products President stated, "Once we kind of determine or assess what we think those gaps are, then we'll start looking at how can we fill those gaps? What are the specific learning initiatives that we can put in place to do it? Would it be leadership, technical, sales?" (T. May, personal communication, February 17, 2011).

The Ritz-Carlton Hotel Co. LLD (Ritz-Carlton) conducts annual departmental SWOT analyses to help determine annual goals and then identifies areas where workplace learning initiatives can be implemented to help them reach their goals. They also use the results of customer satisfaction surveys to determine areas of need. The Laguna Niguel Hotel Manager describes these practices this way,

Every single department submits their own SWOT analysis. All that information goes back to the corporate office and it gets incorporated into our long range plans which would then identify areas for training or areas that need to be focused on. Gallup Organization surveys our guests in terms of their experiences which may also reveal an opportunity to organize some training (S. Kelton-Rogers, personal communication, March 1, 2011).

Sharp HealthCare uses what they refer to as their six pillars of excellence: quality, service, people, finance, growth, and community to establish strategic targets. The Vice President of Customer Strategy, The Sharp Experience and Sharp University describes the process best,

There are one and up to three systems targets every year that we are aiming for. ...our strategic plan is aligned by those same pillars. Everything is aligned in that 
same way where we can identify strengths and gaps or strengths and opportunities and where we are going to put the focus on our learning opportunities for team members and leaders (S. Rhodes, personal communication, March 9, 2011).

The VA Cooperative Studies Program, Clinical Research Pharmacy Coordinating Center (VA) uses a very hierarchical approach to identifying learning needs by starting at the bottom of what they refer to as their "quality pyramid" and moving up. As the Chief of Strategy Planning and Workforce Learning explained,

We start out with obviously all the regulatory requirements and regulatory training because if we don't get that done we can potentially get shut down.... Then anything that would be related to our ISO (International Organization Standards) and our quality journey would be kind of in the next tier. And then those things that are strategic initiatives would kind of come in that area as well as professional development, so it kind of pyramids up in that respect (Dr. W. Umber, personal communication, February 22, 2011).

Solar Turbines, Inc. (Solar) uses, "The voice of the customer" to determine workplace learning needs. There are several customers from which this information is gathered. One is the Operations Counsel which includes, the company's president, three division vice presidents, the CFO, HR and all of the directors. The Operations Counsel meets regularly to determine where the business is going and then assesses what needs the organization has to be ready and competitive. Other customers include class participants, focus groups, and business unit leaders. Class participant's voices are heard through course feedback forms asking them what additional classes they would like to see and business unit leaders make direct requests for training specific to their functions.

One organization, Jenks Public School District (Jenks) develops workplace learning initiatives by examining outcomes against previously established goals. Student outcomes are used to identify areas for faculty professional development while productivity outcomes such as an increase in bus accidents may reflect a need for additional driver training. As the Assistant Superintendent of Curriculum and School Improvement stated, "An increase in accidents would obviously be a trigger of what can we analyze, what are the factors that are causing these and what can we do to provide training for our bus drivers to reduce this " ( $\mathrm{L}$. Muller, personal communication, February 18, 2011).

Several of these organizations described many literature reviewed practices. Mesa uses gap analysis, a part of Robert Camp's four category, benchmarking process (Camp, 1989). The Ritz-Carlton uses SWOT analysis (Friesner, 2011) and customer satisfaction 
surveys (Stewart, 1999) to improve strategic planning and knowledge transfer. The Sharp HealthCare strategy of aligning their workplace learning strategic plan to their six pillars of excellence is an example of what Clark and Kwinn (2005) were referring to when they said, "Unless you align corporate training to organizational goals, any returns you realize from the training investment will be by chance alone."

All six organizations consider needs when making decisions regarding what workplace learning initiatives to provide but utilize different methods to determine needs as shown in Table 7.

Table 7. Item Number 1: What Factors Does Your Organization Consider when Making a Decision to Provide Workplace Learning?

\begin{tabular}{|c|c|c|c|c|c|c|}
\hline Theme(s) & Mesa & Jenks & VA & Ritz-Carlton & Solar & $\begin{array}{c}\text { Sharp } \\
\text { HealthCare }\end{array}$ \\
\hline Needs & $\begin{array}{l}\text { Conduct a } \\
\text { gap analysis }\end{array}$ & $\begin{array}{l}\text { Student and } \\
\text { productivity } \\
\text { outcomes }\end{array}$ & $\begin{array}{l}\text { Movement } \\
\text { up the } \\
\text { "Quality } \\
\text { Pyramıd" }\end{array}$ & $\begin{array}{c}\text { SWOT } \\
\text { analysis and } \\
\text { Customer } \\
\text { Satisfaction } \\
\text { Surveys } \\
\end{array}$ & $\begin{array}{l}\text { "Voice of the } \\
\text { nternal } \\
\text { customer" }\end{array}$ & $\begin{array}{l}\text { Alignment } \\
\text { with the "Six } \\
\text { p1llars of } \\
\text { excellence" }\end{array}$ \\
\hline
\end{tabular}

Interview item two asked: How are your workplace learning initiatives planned, approved and communicated to the organization? What stakeholders participate? After analysis two themes were identified: (a) those using a team approach and (b) those using an individual approach. The results of this item will be presented in Tables 8-10 as follows: (a) how workplace learning initiatives are planned, (b) how they are approved and (c) how they are communicated throughout the organization. Participating stakeholders will be identified in each step of the process.

Five out of six of the organizations start the planning process using a team approach. Mesa has a 13 member leadership team including the president and Solar begins the process with input from Caterpillar's business initiatives regarding what Solar needs to do to provide results to the parent company. From there the HR Director and her staff ask the appropriate HR Manager to provide initiatives relative to their business purpose. Each HR Manager then meets with his/her staff to set goals to accomplish the overall business initiatives given to HR. 
Table 8. Item Number 2a: How Are Your Workplace Learning Initiatives Planned? What Stakeholders Participate?

\begin{tabular}{|c|c|c|c|c|c|c|}
\hline Theme(s) & Mesa & Jenks & VA & Ritz-Carlton & Solar & $\begin{array}{c}\text { Sharp } \\
\text { HealthCare }\end{array}$ \\
\hline $\begin{array}{c}\text { Team } \\
\text { Approach }\end{array}$ & $\begin{array}{l}13 \text { member } \\
\text { leadership } \\
\text { team } \\
\text { 1ncluding the } \\
\text { President }\end{array}$ & $\begin{array}{l}\text { Coordinator of } \\
\text { Professional } \\
\text { Development } \\
\text { and } \\
\text { representatives } \\
\text { from all } 9 \\
\text { schools }\end{array}$ & & $\begin{array}{c}\text { Members of } \\
\text { two } \\
\text { divisions } \\
\text { Human } \\
\text { Resources \& } \\
\text { Quality }\end{array}$ & $\begin{array}{c}\text { Human } \\
\text { Resources } \\
\text { Director and } \\
\text { staff }\end{array}$ & $\begin{array}{c}\text { Sharp } \\
\text { Unıversity } \\
\text { Advisory } \\
\text { Committee } \\
\text { 1ncluding the } \\
\text { CEO }\end{array}$ \\
\hline $\begin{array}{l}\text { Individual } \\
\text { Approach }\end{array}$ & & & $\begin{array}{c}\text { Chief of } \\
\text { Strategic } \\
\text { Plannıng and } \\
\text { Learnıng } \\
\text { Resources }\end{array}$ & & & \\
\hline
\end{tabular}

Table 9. Item Number 2b: How Are Your Workplace Learning Initiatives Approved? What Stakeholders Participate?

\begin{tabular}{|c|c|c|c|c|c|c|}
\hline Theme(s) & Mesa & Jenks & VA & Ritz-Carlton & Solar & $\begin{array}{c}\text { Sharp } \\
\text { HealthCare }\end{array}$ \\
\hline $\begin{array}{c}\text { Team } \\
\text { Approach }\end{array}$ & $\begin{array}{l}13 \text { member } \\
\text { leadership } \\
\text { team } \\
\text { including the } \\
\text { President }\end{array}$ & & $\begin{array}{c}\text { Center } \\
\text { Management } \\
\text { Team and } \\
\text { Center } \\
\text { Executive } \\
\text { Committee }\end{array}$ & $\begin{array}{c}\text { Corporate } \\
\text { Operations } \\
\text { Committee } \\
\text { 1ncludıng } \\
\text { COO and } \\
\text { CEO }\end{array}$ & $\begin{array}{c}\text { Learnıng } \\
\text { Consultant, } \\
\text { Busıness } \\
\text { Unit } \\
\text { Managers \& } \\
\text { Employee's } \\
\text { Supervisors }\end{array}$ & $\begin{array}{c}\text { Sharp } \\
\text { University } \\
\text { Advisory } \\
\text { Committee } \\
\text { including the } \\
\text { CEO }\end{array}$ \\
\hline $\begin{array}{l}\text { Individual } \\
\text { Approach }\end{array}$ & & $\begin{array}{l}\text { Director of } \\
\text { Curriculum }\end{array}$ & & & & \\
\hline
\end{tabular}

Table 10. Item Number 2c: How Are Your Workplace Learning Initiatives Communicated to the Organization? What Stakeholders Participate?

\begin{tabular}{|c|c|c|c|c|c|c|}
\hline Theme(s) & Mesa & Jenks & VA & Ritz-Carlton & Solar & $\begin{array}{c}\text { Sharp } \\
\text { HealthCare }\end{array}$ \\
\hline $\begin{array}{c}\text { Team } \\
\text { Approach }\end{array}$ & & $\begin{array}{l}\text { Coordinator of } \\
\text { Professional } \\
\text { Development } \\
\text { and } \\
\text { representatives } \\
\text { from all } 9 \\
\text { schools }\end{array}$ & & $\begin{array}{c}\text { Members of } \\
\text { two } \\
\text { divisions } \\
\text { Human } \\
\text { Resources \& } \\
\text { Quality }\end{array}$ & $\begin{array}{l}\text { Learning } \\
\text { Consultants } \\
\text { and HR } \\
\text { Specialists }\end{array}$ & $\begin{array}{c}\text { The Sharp } \\
\text { University } \\
\text { Team }\end{array}$ \\
\hline $\begin{array}{l}\text { Individual } \\
\text { Approach }\end{array}$ & $\begin{array}{l}\text { Human } \\
\text { Resources } \\
\text { Analyst }\end{array}$ & & $\begin{array}{c}\text { Chief of } \\
\text { Strategic } \\
\text { Planning } \\
\text { and } \\
\text { Learnıng } \\
\text { Resources }\end{array}$ & & & \\
\hline
\end{tabular}


Jenks created a Coordinator of Professional Development who works with a team made up of representatives from each of the nine schools in the district, the planning process at the Ritz-Carlton starts with team members from the human resources and quality divisions, and Sharp Healthcare has a Sharp University Advisory Committee, a sub-committee of the executive team, which includes the CEO.

The Assistant Superintendent of Curriculum and School Improvement describes the Jenks workplace learning planning process as follows:

We have a Coordinator of Professional Development and that person works in a district wide capacity both with our certified staff members, which is our teaching staff, counselors, administrators as well as what we call our classified staff members. That's our support side. So she has that entire umbrella. And supporting her is a Professional Development Team which has representatives from each one of our school sites. So they are responsible for the bulk of the planning (L. Muller, personal communication, February 18, 2011).

The VA takes a different approach and asks one person, the Chief of Strategic Planning and Learning Resources, to develop a learning plan for the organization. The chief starts this process by sending an assessment to select members of the organization. Safety committee members and subject matter experts help determine regulatory training needs and section chiefs help identify learning needs to meet strategic initiatives. Once the data has been collected and analyzed a workforce learning plan is created.

The approval process for workplace learning is conducted at the highest level in five out of six of the organization but in all organizations is once again made by a team or an individual. Mesa continues to use their same 13 member leadership team and Sharp HealthCare seeks approval with the same planning group, the Sharp University Advisory Committee which includes the CEO.

The Ritz-Carlton continues with the team approach for the approval process but moves the plan from the human resources and quality division teams into the hands of the Corporate Operations Committee which includes the Chief Operating Officer and Chief Executive Officer. The VA moves from individual planning to team approval. Once the Chief of Strategic Planning and Workforce Learning has created the learning plan for the VA it moves on for endorsement by the Center Management Committee, a group of first level managers, and then to the Center Executive Committee for resource approval and the on to the budget. 
Solar also uses a team approach. Each learning consultant is entrusted with developing and implementing programs for their own internal clients but uses input from their HR Managers as well. As the Learning Consultant at Solar stated, "I will often review [programs I am developing] with my manager, who has great skills as a trainer and a facilitator, and who knows the business well" (S. Murphy, personal communication, March 4 , 2011). Once the program has been developed approval comes from the business unit manager or an employee's direct supervisor.

It's at the approval stage that Jenks shifts from a team approach to an individual responsibility. Once the plan has been developed by the Coordinator of Professional Development and the team of representatives from each school site, it moves on to the Director of Curriculum for approval.

The final step in this three part process is communicating the approved plan to the rest of the organization and once again may be an individual or team responsibility. The individual approach is used by Mesa through their Human Resource Specialist and the VA through the Chief of Learning Resources.

Solar, Jenks, Ritz-Carlton, and Sharp Healthcare all use teams to communicate to their organizations: Solar uses the individual learning consultants along with one of the three HR Specialists, Jenks returns the responsibility to the Coordinator of Professional Development and her team of school site members, Ritz-Carlton relies on the Human Resources and Quality Divisions to communicate new learning initiatives and Sharp HealthCare communicates through The Sharp University team. Once workplace learning is planned, approved, and communicated to the organization the expectation for participation in learning is high across all organizations but is nowhere more evident than at Sharp HealthCare. The Vice President of Customer Strategy, The Sharp Experience, and The Sharp University explains the communication process and expectation for participation in their leadership program as follows:

Every single leader, the way we define a leader is anyone who has one person reporting to them regardless of title is expected to participate in our leadership development sessions. Quarterly we take all fifteen hundred leaders off-site for eight hours. So we do communicate, it's all via e-mail our communication systems. They have on-line registration we track everything if they don't attend, don't show up, walk in, whatever it all gets reported back to their leaders and it's an expectation that vacations are scheduled around it and that they're all there. It's 
a very high intensity expectation that leaders attend (S Rhodes, personal communication, March 9, 2011)

The use of employee teams by each of these organızations in the planning, approving, or communicatıng workplace learning initiatıves is an example of employee engagement as reviewed in the literature Research shows employees are engaged when they feel their work matters and helps drive the business (Bingham \& Jeary, 2007, Fox, 2010, Pink, 2009, Soldat1, 2007)

All six organızations use either a team or an individual approach when learning initıatıves are planned, approved and communicated The stakeholders are shown in Tables 8 $-10$

Interview item three asked: Is the CEO or equivalent directly involved in the planning of, participatıng in or evaluatıng of your workplace learnıng initıatıves? Across all organizatıons the CEO or equivalent was involved in at least one of these activities (Table 11) The president of Mesa, the CEOs of Sharp HealthCare and Ritz-Carlton, and the Center Director for the VA are all involved in the planning process As the president of Mesa stated, "I am directly involved, I lead and facilitate that work" (T May, personal communication, February $17,2011)$

Table 11. Item Number 3: Is the CEO or Equivalent Directly Involved in the Planning of, Participating in or Evaluating of Your Workplace Learning Initiatives?

\begin{tabular}{ccccccc}
\hline Theme(s) & Mesa & Jenks & VA & Ritz-Carlton & Solar & $\begin{array}{c}\text { Sharp } \\
\text { HealthCare }\end{array}$ \\
\hline Planning & Yes & No & Yes & Yes & No & Yes \\
$\begin{array}{c}\text { Participating } \\
\text { as }\end{array}$ & No & Trainer & $\begin{array}{c}\text { Student and } \\
\text { Trainer }\end{array}$ & No & Speaker & Trainer \\
Evaluating & No & Yes & Yes & No & No & Yes \\
\hline
\end{tabular}

Participation was interpreted to be either attending a workplace learnıng program as a partıcıpant, delivering sectıons of a program as a trainer or speakıng about the merits of the program durıng the kick-off The Center Director for the VA not only encourages employee participation in workplace learnıng initiatives but as the Chief of Learnıng Resources says, he "walks the talk" by frequently presentıng content and by attendıng classes as a student 
Mesa's president, the Superintendent of Jenks Public School District, and the CEO of Sharp HealthCare all participate by delivering sections of workplace learning programs. An example of CEO participation was described by the VP of Sharp University,

I think we are a terrific example of what a leader is supposed to be when you look at our CEO. We believe leaders are learners. He is the best role model of a "learning leader." He teaches a piece of every leadership development program and has never so much as left the room without making a comment from the podium as to why he wouldn't be in the room for that period of time (S. Rhodes, personal communication, March 9, 2011).

The President of Solar welcomed the participants on opening day and spoke about the value of participating in the leadership program in relationship to individual and organizational success.

Evaluation of workplace learning initiatives was conducted by the Center Director of the VA as a student and by the President of Mesa, the Superintendent of Jenks Public Schools and the CEO of Sharp HealthCare as a trainer.

The willingness of each of the CEOs or equivalents to be involved in either the planning, participating in, or evaluating workplace learning initiatives supports the literature showing that employees will value the workplace learning function more when it is visibly supported by the CEO or equivalent (Bennis \& Namus, 1985; Kouzes \& Posner, 2002, 2010; Senge, 1995; Studer, 2003; Ulrich et al, 2008; Zenger \& Folkman, 2002).

Four out of six of the CEOs or equivalent are involved in planning workplace learning initiatives, four out of six participate in workplace learning as either a participant, a trainer, delivering a portion of the content, or as a speaker, promoting the program at the kick off, and three out of six are directly involved in the evaluation of workplace learning initiatives as shown in Table 11.

Interview item four asked: Is there an annual planning schedule for workplace learning or are training programs developed and delivered as the need arises? Two responses were revealed: (a) annual plan and (b) combination (Table 12). All six organizations plan annually and four of the six add an as-need-arises component.

Mesa and Ritz-Carlton preferred an annual plan approach. As the hotel manager for the Ritz-Carlton's Laguna Nigel property explained,

Actually prior to budget is when we start this once a year approach. The reason we do it [this way] is because a lot of the things that come out of this planning session gets incorporated into budget instructions for the following year. So if we 
Table 12. Item Number 4. Is There an Annual Planning Schedule for Workplace Learning or Are Training Programs Developed and Delivered as the Need Arises?

\begin{tabular}{|c|c|c|c|c|c|c|}
\hline Theme(s) & Mesa & Jenks & VA & Ritz-Carlton & Solar & $\begin{array}{c}\text { Sharp } \\
\text { HealthCare }\end{array}$ \\
\hline $\begin{array}{c}\text { Annual Plan } \\
\text { Only }\end{array}$ & Yes & & & Yes & & \\
\hline $\begin{array}{c}\text { Combination } \\
\text { of Annual } \\
\text { Plan \& As } \\
\text { Need Arises } \\
\end{array}$ & & Yes & Yes & & Yes & Yes \\
\hline
\end{tabular}

decide that we're going to roll an initiative out it gives the hotels, the properties the opportunity to work it into their budgets so it's not a question of "Oh we can't afford it." We also bring the ownership on board if needed so that we get their support, so they can see what that means to their investments (S. Kelton-Rogers, personal communication, March 1, 2011).

When asked how important ownership approval was in the planning process, the response was, "At the end of the day we're a management company and we decide what makes sense for our hotels in terms of rolling them [workplace learning initiatives] out" (S. Kelton-Rogers, personal communication, March 1, 2011).

Jenks, Sharp HealthCare, Solar and the VA use a combination of annual planning and a more spontaneous, plan-as-needed approach. The VP of the Sharp University explains it this way:

We use a combination of both. We plan our, quarterly leadership development sessions. They're set eighteen months in advance so that we can have them calendared and everybody knows what's expected of them. We also bring all fifteen thousand people off-site once a year we count that as one leadership development session (S. Rhodes, personal communication, March 9, 2011).

As an example of what types of learning initiatives are delivered as the need arises the VP offered this example: "...for instance I have at any given time a series of boot camps that are taking place on core foundational elements, either foundations of the Sharp Experience that any team member can participate in or Leadership Essentials" (S. Rhodes, personal communication, March 9, 2011).

Creating a plan for the learning function is a good example of what Kaplan and Norton refer to as mobilizing and aligning an intangible asset. In their 2004 book Strategy Maps: Converting Intangible Assets into Tangible Outcomes, Kaplan and Norton posit that 
an organization's strategy should describe how it intends to create value for its shareholders, customers, and citizens. They believe an organization creates value by connecting strategic objectives in explicit cause-and-effect relationships with each other in four areas: financial, customer, processes, and learning and growth (p. 5).

All six organizations plan workplace learning initiatives annually while four combine that effort with an as-the-need arises component as shown in Table 12.

Interview item five asked: What one workplace learning initiative do you believe has impacted your organization the most and how, e.g., sales training that increased sales; change management training that helped the employees embrace a significant change in the way things are done; customer service training that reduced the number of customer complaints.

Even though this item asked for one example three of the six organizations offered two examples of workplace learning initiatives they believe have positively impacted their organizations. From all the examples offered three themes emerged: (a) culture reinforcement, (b) employee engagement, and (c) process improvement (Table 13).

Table 13. Item Number 5. What One Workplace Learning Initiative Do You Believe Has Impacted Your Organization the Most and How, e.g., Sales Training that Increased Sales; Change Management Training that Helped the Employees Embrace a Significant Change in the Way Things Are Done; Customer Service Training that Reduced the Number of Customer Complaints

\begin{tabular}{|c|c|c|c|c|c|c|}
\hline Themes & Mesa & Jenks & VA & Ritz-Carlton & Solar & $\begin{array}{c}\text { Sharp } \\
\text { HealthCare }\end{array}$ \\
\hline $\begin{array}{c}\text { Culture } \\
\text { Reinforcement }\end{array}$ & $\begin{array}{c}\text { New } \\
\text { Employee } \\
\text { Orientation \& } \\
\text { Oklahoma } \\
\text { Quality } \\
\text { Award } \\
\text { Examiner } \\
\text { Participation }\end{array}$ & & & $\begin{array}{c}\text { Two day } \\
\text { New } \\
\text { Employee } \\
\text { Orientation } \\
\& \\
\text { Daily } \\
\text { Lineups }\end{array}$ & & \\
\hline $\begin{array}{c}\text { Employee } \\
\text { Engagement }\end{array}$ & & Data Teams & $\begin{array}{l}\text { Gallup's } \\
\text { Strength } \\
\text { Finder }\end{array}$ & & $\begin{array}{c}\text { Field Service } \\
\text { Supervisory } \\
\text { Program }\end{array}$ & $\begin{array}{c}\text { Annual All } \\
\text { Staff } \\
\text { Meeting }\end{array}$ \\
\hline $\begin{array}{c}\text { Process } \\
\text { Improvement }\end{array}$ & & & $\begin{array}{c}\text { Project } \\
\text { Management } \\
\text { Initiative }\end{array}$ & & & \\
\hline
\end{tabular}


Mesa and Ritz-Carlton shared examples of culture reinforcement. New employee orientation was cited by both organizations. In addition Mesa's president believes that employees who have participated in the Oklahoma State Quality Award as examiners have helped strengthen Mesa's culture. He offers this insight,

We've probably had at least twenty people participate in the state quality award. That's not something that immediately, dramatically changes the company, but from a culture standpoint each time somebody goes through, it incrementally supports and reinforces what the culture is (T. May, personal communication, February 17, 2011).

In addition to the new employee orientation, which is a two day event for the RitzCarlton, the Laguna Nigel Property's Hotel Manager said the program referred to as "Daily Lineups" continues to reinforce the organization's very strong commitment to their culture. She explains it this way:

We do what's called "Daily Lineups" with all of our ladies and gentlemen. This daily lineup focuses around a document called "The Commitment to Quality." This Commitment to Quality is shared world-wide. So, for instance this week we talked about a "Wow" story that was created at the Ritz Carlton Lake Tahoe. Every single Ritz-Carlton in our company talked about that same story and how the Ritz-Carlton Lake Tahoe made the wish of a five year old little boy who lives with liver failure, is probably going to die, through the "Make a Wish Foundation" created a memorable experience for his family and for him.

So we talk about the same value, we share the same stories and then we're able to customize the same Commitment to Quality document with information that's important to our hotels or our properties. For us, we might talk about sunrise, sunset and what the surf looks like because a lot of our guests like surfing. It's an absolutely brilliant concept that works world-wide and it really does align us as a company (S. Kelton-Rogers, personal communication, March 1, 2011).

Jenks, Sharp HealthCare, and the VA all offered examples of programs that engage the employee. Sharp HealthCare cited their All Staff Assembly, a once a year event that brings together all 15,000 employees (5,000 at a time) over three days. It's an event filled with inspirational stories and engaging activities all designed to show the employees their individual contributions in the bigger picture.

Solar developed a four day program for their field service supervisors to facilitate moving them from individual contributors to supervisors. Participants were brought to San Diego to attend classes on performance management, behavioral interviewing, and 
Situational Leadership. As the learning consultant at Solar stated, "These field service supervisors were hungry for the information."

The VA initiated the Gallup organization's Strength Finder program. Every employee has taken the Strength Finder assessment and all new employees are also given a coach to help them better understand how their particular strengths can be leveraged within the organization. Managers have also received training on how to manage based on strengths. The program has not only helped the organization identify individual strengths leading to better communication and understanding but also the strengths of the organization as a whole. They have found that as an organization one of their top strengths is "Learner," a strength they are very proud of.

Jenks also identified a program that encourages engagement and promotes discussion between their certified staff, the teachers. As a school district their primary concern is, of course, student learning. They believe that the initiative that has had the biggest impact on increases in student learning is training their teachers how to work on what they refer to as "data teams." The Assistant Superintendent of Curriculum explains it best:

Our elementary teachers, even though they teach in self-contained classrooms, they're on what we call "Pods". So there might be a group of four who are working together. So the way data teams would work they would determine, for example, that getting automaticity on multiplication facts is always a challenge. So they would do a pre-test and assess where all our students on the mastery of the multiplication facts are and then they would decide looking at this data here are some strengths, here are some weaknesses; here are different patterns we're seeing. We're going to do these things over the next three to four weeks. And then we'll come back together and conduct a mid-test and see how they're doing, talk about it, adjust, figure out and that also gives them a chance to look and say oh wow you've clearly taught the "9's". What's your trick for doing this? So it promotes sharing among teachers and then at the end you do your post-test and say alright have we gotten to our goal, have we gotten mastery or what else do we need to do to keep on helping with students?

The third theme identified was process improvement. Only one organization, the VA, offered an example that fell into this category. The VA made a decision to become a project management organization. To help them with this endeavor they created a program with the assistance of a consultant incorporating: instructor led training classes, side-by-side coaching sessions, and the development of procedures and policies to support the journey.

Employee engagement and process improvement are two themes examined in the literature. Workplace learning initiatives that engage employees help them work with 
passion and feel a profound connection to their company. They drive innovation and move the organization forward (Fox, 2010). While those that improve processes are part of an organized group of related activities working together to transform one or more kinds of input into outputs that are of value to the customer (Hammer, 2001). In this case the customer is internal, the employee.

Two organizations identified culture reinforcement, four organizations identified employee engagement, and one organization identified process improvement as the type of workplace learning initiatives that have had the most significant impact on their organizations. The names of each of these initiatives is shown in Table 13.

Interview item six asked: What role do you believe your workplace learning strategy played in helping your organization receive the Baldrige? Three themes emerged: (a) dollars spent per employee on training, (b) a focus on continuous improvement, and (c) leadership development (Table 14).

Table 14. Item Number 6. What Role Do You Believe Your Workplace Learning Strategy Played in Helping Your Organization Receive the Baldrige?

\begin{tabular}{|c|c|c|c|c|c|c|}
\hline Theme(s) & Mesa & Jenks & VA & $\begin{array}{l}\text { Ritz- } \\
\text { Carlton }\end{array}$ & Solar & $\begin{array}{c}\text { Sharp } \\
\text { HealthCare }\end{array}$ \\
\hline $\begin{array}{c}\text { Dollars Spent } \\
\text { per Employee } \\
\text { on Training }\end{array}$ & $\begin{array}{l}\text { Greater than } \\
\text { twice the } \\
\text { average } \\
\text { amount } \\
\text { spent per } \\
\text { employee } \\
\text { nationally }\end{array}$ & & & & & \\
\hline $\begin{array}{c}\text { Focus on } \\
\text { Contınuous } \\
\text { Improvement }\end{array}$ & & $\begin{array}{l}\text { Professional } \\
\text { Development } \\
\text { \& Student } \\
\text { Achievement }\end{array}$ & $\begin{array}{c}\text { Regulatory } \\
\text { Compliance } \\
\text { and } \\
\text { Standardization } \\
\text { Processes }\end{array}$ & Quality & $\begin{array}{l}\text { Grant funded } \\
\text { Process } \\
\text { Improvement } \\
\text { Program }\end{array}$ & \\
\hline $\begin{array}{l}\text { Leadership } \\
\text { Development }\end{array}$ & & & & & & Accountability \\
\hline
\end{tabular}

Mesa's president believes the investment of training dollars directly correlated to organizational improvements and therefore played a significant role in receiving the Baldrige. He explained,

The national average [for workplace learning] is six, seven hundred dollars per employee, per year. We were in the seventeen, eighteen hundred per employee 
per year. So we were making a significant investment and we saw our organizational performance, at least from the Baldrige stand point improve dramatically. So do I think it played a role in helping us win the award, yeah absolutely, but more important it proved to us the value of the training, that it does make us a better company (T. May, personal communication, February 17, 2011).

Jenks, Ritz-Carlton, Solar and the VA all believe their focus on continuous improvement was instrumental in helping them receive the Baldrige. Jenks' commitment to professional development and student achievement, Ritz-Carlton's focus on quality, Solar's grant funded process improvement program which for the first time delivered training to employees in operations, i.e., employees who work on the shop floor building turbines, adding the electronics, etc., and the VA's regulatory compliance and standardization processes were offered as examples of a commitment to continuous improvement.

Sharp HealthCare believes their leadership development program was critical to their success. Every new process, e.g., performance management system, six sigma, is first introduced at the leadership level and "cascades" down to the rest of the organization. All leaders have an "accountability grid" and are responsible for taking what they've learned in training and making it part of their everyday practice. They are also expected to report their results to their supervisors. Accountability is an important part of their leadership development.

The themes identified from the workplace learning strategies these organizations believed played a role in helping their organizations receive the Baldrige are themes identified as best practices in the literature. Mesa's focus on dollars spent on employee training was found to be a positive contributing factor in predicting a company's stock price (Sugrue, 2004). Workplace learning as a driver of continuous improvement has been identified and written about as a contributor to the success of organizations such as Sony (Peters \& Waterman, 1982) and Disney (Capodagli \& Jackson, 1999).

Leadership development is seen by many as a catalyst for disseminating knowledge throughout an organization. These leaders act as role models and stimulate learning organization-wide (Bennis \& Namus, 1985; Kouzes \& Posner, 2002, 2010; Studer, 2003; Ulrich et al, 2008; Zenger \& Folkman, 2002).

One organization identified dollars spent per employee on training as a workplace learning strategy that helped their organization receive the Baldrige, four organizations 
identified strategies that focused on continuous improvement and one focused on leadership development as shown in Table 14.

Interview item number seven asked: Do you want to say anything else about how you conceptualize and deliver a strategic plan for workplace learning? Of the six organizations interviewed only five answered this question. The Ritz-Carlton believed previous answers given on other items sufficiently described the Ritz-Carlton's strategy for workplace learning. For the remaining five organizations one theme was consistent. the conceptualization and delivery of a strategic plan for workplace learning is an on-going effort.

While each organization acknowledged this effort, each drives that effort differently (Table 15). Mesa returned to identifying needs as critical to the effort, Jenks described a "think tank" of employees, including the Superintendent, called the Continuous Improvement Leadership Team as well as a set of district wide goals that help guide their workplace learning initiatives.

Table 15. Item Number Seven. Do You Want to Say Anything Else about How You Conceptualize and Deliver a Strategic Plan for Workplace Learning?

\begin{tabular}{ccccccc}
\hline Theme(s) & Mesa & Jenks & VA & Ritz-Carlton & Solar & Sharp \\
\hline & Driver & Driver & Driver & Driver & Driver \\
\hline $\begin{array}{c}\text { Ongoing } \\
\text { effort }\end{array}$ & $\begin{array}{c}\text { Identification } \\
\text { of Needs } \\
\text { of } \\
\text { employees } \\
\text { combined } \\
\text { with district } \\
\text { wide goals }\end{array}$ & $\begin{array}{c}\text { Learning } \\
\text { tunction tied } \\
\text { to strategic } \\
\text { plan }\end{array}$ & N/A & Communication & $\begin{array}{c}\text { Development } \\
\text { of a re- } \\
\text { stakeholders }\end{array}$ & $\begin{array}{c}\text { 1mmersion } \\
\text { program for } \\
\text { leaders }\end{array}$ \\
\hline
\end{tabular}

The VA cited two factors they believe are crucial to this effort the first: tying the learning function to the strategic plan as opposed to the human resource function. The second: participation in the Harvard Business Review's Learning Organization Study where they were named a "best practice" leader. Being named a best practice leader provided evidence (for them) that the learning function at the VA is headed in the right direction.

The learning consultant for Solar reiterated listening to the "voice of the customer" as playing an instrumental role in the continuing effort to develop and deliver successful workplace learning initiatives. She offered the following as an example, "Talk with the 
directors of the Customer Services group and tell them what we're planning, do they have input, what input do they have and what would they like to see implemented, what changes would they like to see?" (S. Murphy, personal communication, March 4, 2011).

To illustrate the importance of continually driving the workplace learning strategic effort Sharp HealthCare has developed a "re-immersion program" called On Stage Leadership that will help their 1500 leaders understand the role they play as a leader. The VP of The Sharp University explains the reason this program was developed, "It's an ongoing endeavor and I think we are in an interesting refresh, re-immersion right now. Just teaching a concept is never enough. It has to be woven into the fabric of the organization" (S. Rhodes, personal communication, March 9, 2011).

The drivers identified by each organization for the ongoing effort to conceptualize and deliver a strategic plan for workplace learning were practices reviewed in the literature. Mesa's identification of needs (Camp, 1989); Jenks "think tank" as a form of employee engagement (Fox, 2010; Pink, 2009; Soldati, 2007); the VA's commitment to tie the learning function to the strategic plan (Clark \& Kwinn, 2005) and Sharp HealthCare's leadership development initiatives (Bennis \& Namus, 1985; Kouzes \& Posner, 2002, 2010; Studer, 2003; Ulrich et al, 2008; Zenger \& Folkman, 2002) are all considered best practices.

Five of the six organizations chose to answer this item. The identified theme was consistent; it is an ongoing effort to conceptualize and deliver a strategic plan for workplace learning. Each organization identified the driver for this ongoing effort as shown in Table 15.

Interview item eight asked: Do you evaluate and measure the effectiveness of your workplace learning initiatives? If not, why? If so, are all programs evaluated and with what metrics, e.g., training attendance, employee retention figures, employee satisfaction surveys, productivity, increased sales, customer satisfaction, etc?

All organizations responded yes, all programs are evaluated at some level. Five themes emerged. Three of the six correlate to the Kirkpatrick Evaluation Model levels: satisfaction, learning, behavior and results. (For this study respondents found it very difficult to differentiate between levels three, behavior and four, results. For this reason responses will be combined.) The fifth theme is numbers meaning the number of participants and the 
number of classes offered. The metrics used by these organizations will also be reported (Table 16).

Table 16. Item Number 8. Do You Evaluate and Measure the Effectiveness of Your Workplace Learning Initiatives? If Not, Why? If so, Are All Programs Evaluated and with What Metrics, e.g., Training Attendance, Employee Retention Figures, Employee Satisfaction Surveys, Productivity, Increased Sales, Customer Satisfaction, etc?

\begin{tabular}{|c|c|c|c|c|c|c|}
\hline Themes & Mesa & Jenks & $\mathrm{VA}$ & Ritz-Carlton & Solar & $\begin{array}{c}\text { Sharp } \\
\text { HealthCare }\end{array}$ \\
\hline Satisfaction & $\begin{array}{c}\text { Course } \\
\text { evaluations/ } \\
\text { employee } \\
\text { satisfaction } \\
\text { surveys }\end{array}$ & $\begin{array}{c}\text { Course } \\
\text { evaluations }\end{array}$ & $\begin{array}{c}\text { Course evaluations/ } \\
\text { employee satisfaction } \\
\text { surveys }\end{array}$ & $\begin{array}{c}\text { Course } \\
\text { evaluations/ } \\
\text { employee } \\
\text { satisfaction } \\
\text { surveys }\end{array}$ & $\begin{array}{c}\text { Course } \\
\text { evaluations/ } \\
\text { employee } \\
\text { satisfaction } \\
\text { surveys }\end{array}$ & $\begin{array}{l}\text { Course } \\
\text { evaluations/ } \\
\text { employee } \\
\text { satisfaction } \\
\text { surveys }\end{array}$ \\
\hline Learnıng & $\mathrm{N} / \mathrm{A}$ & $\begin{array}{l}\text { Open ended } \\
\text { questions on } \\
\text { course } \\
\text { evaluations }\end{array}$ & $\begin{array}{c}\text { Quizzes/"return } \\
\text { demonstrations"/dialog } \\
\text { between participant \& } \\
\text { supervisor }\end{array}$ & $\mathrm{N} / \mathrm{A}$ & $\begin{array}{l}\text { Open ended } \\
\text { questions } \\
\text { on course } \\
\text { evaluations }\end{array}$ & $\begin{array}{l}\text { Open ended } \\
\text { questions on } \\
\text { course } \\
\text { evaluations }\end{array}$ \\
\hline $\begin{array}{c}\text { Behavior/ } \\
\text { Results }\end{array}$ & $\begin{array}{l}\text { Customer } \\
\text { Satısfaction } \\
\text { Surveys/ } \\
\text { Employee } \\
\text { Retention }\end{array}$ & $\mathrm{N} / \mathrm{A}$ & $\begin{array}{l}\text { Process Management } \\
\text { Maturity Level using } \\
\text { OPM3 project } \\
\text { management } \\
\text { benchmarking tool }\end{array}$ & $\begin{array}{c}\text { Customer } \\
\text { Satısfaction } \\
\text { Surveys/ } \\
\text { Employee } \\
\text { Retention/Profit } \\
\text { \& Loss } \\
\text { Statements }\end{array}$ & $\begin{array}{l}\text { Safety \& } \\
\text { On-time } \\
\text { Delivery } \\
\text { Reports }\end{array}$ & $\begin{array}{l}\text { Customer } \\
\text { Satisfaction } \\
\text { Surveys/ } \\
\text { Employee } \\
\text { Retention }\end{array}$ \\
\hline Numbers & $\begin{array}{l}\text { Participants/ } \\
\text { Courses } \\
\text { offered } / \$ \\
\text { investment } \\
\text { per } \\
\text { employee } \\
\end{array}$ & $\begin{array}{c}\text { Participants/ } \\
\text { Courses } \\
\text { offered }\end{array}$ & $\begin{array}{c}\text { Participants/ } \\
\text { Courses offered/ } \\
\text { \$ investment per } \\
\text { employee/Learning } \\
\text { hours per employee }\end{array}$ & $\begin{array}{l}\text { Participants/ } \\
\text { Courses offered }\end{array}$ & $\begin{array}{c}\text { Participants/ } \\
\text { Courses } \\
\text { offered }\end{array}$ & $\begin{array}{c}\text { Particıpants/ } \\
\text { Courses offered }\end{array}$ \\
\hline
\end{tabular}

All organizations measured level one: satisfaction. Each used an evaluation sheet asking the participant to rate their satisfaction of the training content, usefulness, instructor, etc. using a likert scale, e.g., Solar Turbines' Course Evaluation sheet asks "I received tools and information that I can apply to my job" then asks the participant to rate that statement from $1=$ Poor to $5=$ Excellent.

In addition to evaluating satisfaction of each individual training class, five out of six of the organizations conduct employee satisfaction surveys, which measures, among many other variables, workplace learning satisfaction.

Level two: learn, was measured by four out of six of the organizations. Sharp HealthCare, Jenks and Solar Turbines gather information about what was learned in the session through open ended questions on their evaluation form. Solar asks, "What is the most valuable skill/information you learned during this program?" Sharp HealthCare takes a 
more novel approach and asks participants, "From today, what will you share at the dinner table tonight?"

The VA conducts post class quizzes or asks for a "return demonstration" to prove learning has occurred during the training session. They also incorporate a form that must be filled out after the participant has had a conversation with their supervisor about "what you know, where you went and what you learned."

Change in job behavior, as a result of the training, is the third Kirkpatrick level and for each of these organizations is directly tied to the fourth Kirkpatrick level: results. For example customer satisfaction surveys were named by three of the six organizations as a metric used to measure results. Although no formal research has been conducted by these organizations to determine whether or not customer service training is directly associated with a rise in customer satisfaction, an assumption is made that employee training in this area, leads to improved customer service behavior which contributes to higher satisfaction scores.

Other metrics used by these organizations to measure behavior/results are employee retention used by three of the six organizations, one cited profit and loss statements and another reviews employee injury and on-time delivery reports as indicators of results.

Two of the six organizations addressed the problem of being able to tie workplace learning initiatives to increases or decreases in performance or satisfaction scores. The Assistant Superintendent at Jenks stated it this way, "We have not found an effective way to absolutely say that it's because of this professional development that student achievement increased" (L. Muller, personal communication, February 18, 2011).

The Chief of Workforce Learning at the VA offers this interesting viewpoint when asked about the link between training and the return on training investment in terms of changes in behavior and those metrics used to measure results, "Do we do ROI and long term stuff? No not really because it would cost me more to try to generate the metrics, than the metrics would be worth to the organization" (Dr. W. Umber, personal communication, February 22, 2011). Instead the VA looks at the level of maturity they are gaining in a process. As an example they use the metrics of OPM3, a project management benchmarking tool, to determine whether or not they are making progress with their process management 
initiative. Once again an assumption is made that workplace learning is directly tied to behavior which is tied to these metrics.

A fifth theme was named by all of the organizations and that is numbers. All of these organizations measure the number of participants attending classes and the number of classes offered. In addition, Mesa and the VA reported they look at the dollar investment per employee for training and the VA also tracks the number of learning hours per employee.

Many of the practices used by these organizations are supported in the literature, e.g., course evaluations that include open ended questions, employee and customer satisfaction surveys, and dollars spent on per employee training. Course evaluations that include open ended questions to gather information about level one: satisfaction and level two: learning of the Kirkpatrick model were used by all six organizations. Measurement of these two levels is consistent with research conducted by ASTD and i4cp Consulting that shows they are the most evaluated levels in organizations (ASTD, 2009b).

Employee and customer satisfaction surveys are also considered excellent methods for measuring and managing customer and human capital within an organization (Stewart, 1999). Dollars spent per employee on training has also resulted in an increase in stock value. A connection is assumed by the shareholder that the organization is committed to growth and improvement by spending training dollars on its employees (Sugrue, 2004).

All six organizations evaluate and measure effectiveness of each of their workplace learning initiatives. All organizations measure satisfaction as defined by the Kirkpatrick model, four out of six measure learning, five out of six measure behavior/results, and all six measure numbers of classes offered and participants attending. The metrics used for measurement are shown in Table 16.

Interview item nine asked: What delivery methods do you use? The following four themes emerged: instructor led, computer based, non-traditional, and new technology (Table 17). All six organizations utilize an instructor led method of training delivery. Computer based training is defined as either synchronous or asynchronous. All six of the organizations reported using asynchronous training while one reported using both synchronous and asynchronous.

Solar addressed some of the issues facing workplace learning professionals regarding instructor led vs. synchronous computer based training, "What we have found out is that a lot 
Table 17. Item Number 9. What Delivery Methods Do You Use?

\begin{tabular}{|c|c|c|c|c|c|c|}
\hline Themes & Mesa & Jenks & VA & Ritz-Carlton & Solar & $\begin{array}{c}\text { Sharp } \\
\text { HealthCare }\end{array}$ \\
\hline $\begin{array}{l}\text { Instructor } \\
\text { Led }\end{array}$ & Yes & Yes & Yes & Yes & Yes & Yes \\
\hline $\begin{array}{l}\text { Computer } \\
\text { Based }\end{array}$ & Asynchronous & Asynchronous & $\begin{array}{l}\text { Asynchronous \& } \\
\text { Synchronous }\end{array}$ & Asynchronous & Asynchronus & Asynchronous \\
\hline $\begin{array}{c}\text { Non- } \\
\text { traditional }\end{array}$ & $\begin{array}{l}\text { Outside peer } \\
\text { groups }\end{array}$ & $\begin{array}{c}\text { Demonstration } \\
\text { Lesson/instructional } \\
\text { coaches/professional } \\
\text { learning } \\
\text { communities }\end{array}$ & $\begin{array}{l}\text { Coaching/ } \\
\text { Library }\end{array}$ & $\begin{array}{l}\text { Daily Line } \\
\text { ups }\end{array}$ & N/A & $\begin{array}{l}\text { All Staff } \\
\text { Assembly }\end{array}$ \\
\hline $\begin{array}{c}\text { Newer } \\
\text { Technology }\end{array}$ & N/A & W1k1s & $\mathrm{N} / \mathrm{A}$ & $\begin{array}{c}\text { Facebook at } \\
\text { hotel not } \\
\text { corporate } \\
\text { level }\end{array}$ & N/A & N/A \\
\hline
\end{tabular}

of our people don't like web-based training and we just don't have the equipment to do online or training via video" (S. Murphy, personal communication, March 4, 2011).

The non-traditional theme involves active involvement with another person but not in the traditional classroom setting. Examples of this theme are one-on-one coaching, participation in peer groups, demonstration \& observation, job shadowing or what the VA calls "details." The Chief of Learning Resources describes details in this way, "We send somebody who's coming into a job here, maybe to one of our sister centers to learn how to do a job somewhere else, you know, do that same job because there's not peers here" (Dr. W. Umber, personal communication, February 22, 2011).

The Ritz calls their non-traditional method "daily lineups" (a daily department meeting) to reinforce their commitment to service and to keep the organization brand strong. Sharp HealthCare gathers all 15,000 employees, 5,000 at a time, for what they refer to as "an all staff assembly" for a day of learning, teambuilding and inspirations. Five of the six organizations use non-traditional methods to deliver training.

The fourth and final theme is called new technology and includes: facebook, Twitter, wikis, blogs, hand-held devices, second life, etc. to deliver training. Two of the organizations reported using new technology for delivering training, Ritz-Carlton uses Facebook at the hotel level and Jenks uses wikis. The Assistant Superintendent at Jenks describes the districts use of wikis to help teachers share best practices, "Using the wiki allows the teachers to share lessons and talk back and forth about here's what I've tried or 
here's a lesson that's worked really well with my kids" (L. Muller, personal communication, February 18, 2011).

All six organizations in this study reported that a majority of their programs are instructor led with some use of asynchronous computer based instruction. These percentages are consistent with what is found in the literature. The ASTD's 2009 State of the Industry Report reported that a majority of workplace learning is offered using an instructor led format while computer based training occupies a smaller percentage.

Wikis and coaching were two other forms of delivery used by these organizations that are literature based practices. Wikis are used at Jenks by teachers to share best practices and according to Karrer (2007) are best used to share information among knowledge workers within a team or across an organization. Jenks and the VA also use internal coaches which according to Goldsmith and Morgan (2004) can make a positive difference in work performance.

All six organizations deliver workplace learning using instructor led and asynchronous computer based programs. Only one reported use of synchronous computer based learning. Four of the six organizations use non-traditional delivery methods while two use new technology as shown in Table 17.

Interview item ten asked: What determines the delivery method? Two themes emerged: content and resources (Table 18). All of the organizations considered both content and resources when making delivery method decisions. The goal and or type of training, i.e., regulatory vs. soft skill drove the content considerations. Regulatory or technical training such as sexual harassment, safety, federal, state or organizational policy and procedure topics, and computer software instruction are delivered on-line. Soft-skill training such as leadership, customer service, professional development, etc. are delivered using methods that bring instructor and student together physically, e.g., classroom, coaching, daily line ups.

The second theme was resources. Again all organizations considered their internal capacities, e.g., expertise, time and cost. The VP of The Sharp University explains it as follows, "... how can we get it to the most people, most efficient, at the lowest cost..." (S. Rhodes, personal communication, March 9, 2011).

All six organizations considered content when planning the most effective and efficient delivery method. As reported in this study the most frequent use of asynchronous 
Table 18. Item Number 10. What Determines the Delivery Method?

\begin{tabular}{ccccccc}
\hline Theme(s) & Mesa & Jenks & VA & Ritz-Carlton & Solar & HealthCare \\
\hline \multirow{2}{*}{ Content } & $\begin{array}{c}\text { Regulatory } \\
\text { vs Soft Skill }\end{array}$ & $\begin{array}{c}\text { Regulatory vs } \\
\text { Soft Skill }\end{array}$ & $\begin{array}{c}\text { Regulatory vs } \\
\text { Soft Skill }\end{array}$ & $\begin{array}{c}\text { Regulatory } \\
\text { vs. Soft Skill }\end{array}$ & $\begin{array}{c}\text { Regulatory } \\
\text { vs Soft } \\
\text { Skıll }\end{array}$ & $\begin{array}{c}\text { Regulatory } \\
\text { vs Soft Skill }\end{array}$ \\
& $\begin{array}{c}\text { Time, } \\
\text { Resources } \\
\text { Exprtise, } \\
\text { Cost }\end{array}$ & $\begin{array}{c}\text { Time, Expertise, } \\
\text { Cost }\end{array}$ & $\begin{array}{c}\text { Time, } \\
\text { Expertise, } \\
\text { Cost }\end{array}$ & $\begin{array}{c}\text { Time, } \\
\text { Expertise, } \\
\text { Cost }\end{array}$ & $\begin{array}{c}\text { Time, } \\
\text { Expertise, } \\
\text { Cost }\end{array}$ & $\begin{array}{c}\text { Time, } \\
\text { Expertise, } \\
\text { Cost }\end{array}$ \\
\hline
\end{tabular}

computer based delivery was to offer regulatory content that tests technical knowledge in areas such as safety, harassment, etc. These findings are similar to those found by Rossett and Marshall (2010) regarding the most frequently occurring e-learning practice in the corporate and governmental workplace was to test skills and knowledge (p. 36).

All six organizations consider content in terms of regulatory vs. soft skill and resources in terms of time, expertise, and cost when determining delivery methods as shown in Table 18.

Interview item eleven asked: Do you develop training withın the organization, hire consultants, buy off-the-shelf content or use a combination? All six organizations used a combination of internal development, buying off-the-shelf content or hiring a consultant to develop content but the motivation for doing so varies (Table 19).

Table 19. Item Number 11. Do You Develop Training within the Organization, Hire Consultants, Buy Off-the-shelf Content or Use a Combination?

\begin{tabular}{|c|c|c|c|c|c|c|}
\hline Themes & Mesa & Jenks & VA & Ritz-Carlton & Solar & $\begin{array}{c}\text { Sharp } \\
\text { HealthCare }\end{array}$ \\
\hline & Motivation & Motivation & Motivation & Motıvation & Motivation & Motivation \\
\hline $\begin{array}{l}\text { Develop } \\
\text { Withın }\end{array}$ & $\begin{array}{l}\text { Unıque } \\
\text { Industry } \\
\text { Issues }\end{array}$ & $\begin{array}{l}\text { Protect the } \\
\text { Culture }\end{array}$ & $\begin{array}{l}\text { IT Security } \\
\text { Restraints }\end{array}$ & $\begin{array}{l}\text { Protect the } \\
\text { Culture }\end{array}$ & $\begin{array}{l}\text { Protect the } \\
\text { Culture }\end{array}$ & $\begin{array}{l}\text { Protect the } \\
\text { Culture }\end{array}$ \\
\hline $\begin{array}{c}\text { Hire } \\
\text { Consultants }\end{array}$ & $\begin{array}{l}\text { Subject } \\
\text { Matter } \\
\text { Experts or } \\
\text { Motivational } \\
\text { Speakers }\end{array}$ & $\begin{array}{l}\text { Address } \\
\text { credibility } \\
\text { factor }\end{array}$ & $\begin{array}{l}\text { Subject Matter } \\
\text { Experts }\end{array}$ & Reputation & $\begin{array}{l}\text { Subject } \\
\text { Matter } \\
\text { Experts }\end{array}$ & $\begin{array}{c}\text { To } \\
\text { supplement } \\
\text { internally } \\
\text { developed } \\
\text { content }\end{array}$ \\
\hline $\begin{array}{l}\text { Buy } \\
\text { off-the- } \\
\text { shelf }\end{array}$ & N/A & N/A & $\begin{array}{l}\text { Exposure to } \\
\text { different } \\
\text { perspectıves of } \\
\text { leadershıp }\end{array}$ & $\begin{array}{l}\text { Exposure to } \\
\text { different } \\
\text { perspectives } \\
\text { of leadershıp }\end{array}$ & $\begin{array}{l}\text { Exposure to } \\
\text { different } \\
\text { perspectives } \\
\text { of } \\
\text { leadership }\end{array}$ & $\begin{array}{l}\text { Exposure to } \\
\text { different } \\
\text { perspectives } \\
\text { of leadership }\end{array}$ \\
\hline
\end{tabular}


For purposes of this study internal development is defined as designing, developing and delivering content using internal personnel. Off-the-shelf content is defined in two ways: (1) purchasing an online content library which is accessed through the developer's website and provides canned online content, and (2) bringing in a consultant to deliver nationally or internationally recognized content, e.g. Gallup's Strength Finder, Steven Covey's Seven Habits, and Ken Blanchard's Shared Leadership. These classes are not customized for the organization.

Hiring a consultant is defined as bringing in a subject matter expert to design, develop and deliver customized training in areas such as supervisor training, project management, etc. In addition to using consultants as subject matter experts consultants were used to address the "credibility" issue. The credibility issue is an interesting phenomenon that occurs in many organizations where an outside consultant is considered more credible than an internal resource.

The Ritz-Carlton, Jenks, Sharp HealthCare and Solar develop most of their programs internally. Each of these organizations cites protecting their culture as motivation for internal development of their workplace learning initiatives. Mesa develops and delivers their own safety classes because of better understanding of issues unique to their industry and the VA develops policy and procedure programs internally because of IT security restraints.

The Ritz Carlton is the biggest user of off-the-shelf content utilizing the online content library, Harvard ManageMentor and instructor led programs such as Gallup's Strength Finder, Steven Covey's Seven Habits, and Ken Blanchard's Shared Leadership. The VA uses Gallup's Strength Finders as part of their onboarding process and Sharp HealthCare also offers Strength Finder training to those who are interested. Solar brings in an instructor to deliver Hersey, Blanchard and Dewey's Situational Leadership. Solar also uses online content provided by their parent company, Caterpillar, Inc. to address the organizations values. The motivation for bringing in representatives from these internationally known companies is to expose their workforce to different perspectives and models of leadership.

All six organizations hire consultants. Mesa uses consultants to design and deliver customized supervisory training or to serve as motivational speakers. Jenks uses consultants to address the credibility factor and Sharp HealthCare brings in "thought leaders and experts" to deliver topics to supplement internally developed content. The Ritz-Carlton used Gallup 
consultants to help develop their Service Values. The VA works with consultants to develop and deliver content in areas such as project management, business writing, and priority management. Solar uses retired employees as consultants to turn instructor led programs into online classes.

While the merits of each of the development methods was not examined in the literature, Solar identified one example of off-the-shelf content, delivered by an instructor that was reviewed. This example was Situational Leadership a model created by Paul Hersey, Ken Blanchard, and Dewey Johnson in the late 1960's that asks the leader to adjust his/her leadership style to the readiness level of the direct report in a given situation (Hersey et. al., 2001).

All six organizations develop training internally and hire consultants. Four of the six buy off-the-shelf training ranging from content libraries to internationally known leadership concepts. The motivation for utilizing each method is presented in Table 19.

Interview item twelve asked: What would you say are the most critical issues facing your organization today and how will the learning function provide solutions to these issues? The themes that emerged were varied, interesting and are: people, competition, technology, funding, and growth (Table 20).

Solar identified competition and people as critical issues. As the Learning Consultant stated, "The competition is getting smarter and going after us very heavily [we will need to] increase our bench strength with our leadership programs so we have people ready to move into [leadership positions] because we're all expecting the boomer group to retire" (S. Murphy, personal communication, March 4, 2011).

Mesa identified the connection between people and growth as a critical issue. Mesa believes finding the right people is crucial to their continued growth and acknowledges the role workplace learning will play in this endeavor. Mesa's CEO puts it this way, "If we can't find people, trained experience people, to either sustain us or allow us to continue growing then we're going to have to create them" (T. May, personal communication, February 17, 2011).

The VA cites a younger employee base and the use of technology to provide workplace learning as two critical issues. As the Chief of Strategic Planning and Learning Resources explains, "People are coming into the organization that are younger, they learn in 
Table 20. Item Number 12. What Would You Say Are the Most Critical Issues Facing Your Organization Today and How Will the Learning Function Provide Solutions to These Issues?

\begin{tabular}{|c|c|c|c|c|c|c|}
\hline Themes & Mesa & Jenks & VA & Ritz-Carlton & Solar & $\begin{array}{c}\text { Sharp } \\
\text { HealthCare }\end{array}$ \\
\hline People & $\begin{array}{c}\text { In the } \\
\text { absence of } \\
\text { findıng } \\
\text { qualıfied } \\
\text { people will } \\
\text { need to } \\
\text { develop } \\
\text { nnternally }\end{array}$ & & $\begin{array}{l}\text { As younger } \\
\text { employees } \\
\text { come on } \\
\text { board the } \\
\text { expectation } \\
\text { for training } \\
\text { will change }\end{array}$ & & $\begin{array}{l}\text { Replacing } \\
\text { the retırıng } \\
\text { "Boomers" }\end{array}$ & \\
\hline Growth & $\begin{array}{l}\text { Trained } \\
\text { people } \\
\text { critical to } \\
\text { contınued } \\
\text { growth }\end{array}$ & & & $\begin{array}{c}\text { International } \\
\text { growth while } \\
\text { protecting } \\
\text { the brand }\end{array}$ & & \\
\hline Technology & & & $\begin{array}{l}\text { Meetıng the } \\
\text { demand for } \\
\text { virtual } \\
\text { trainıng }\end{array}$ & & & \\
\hline Funding & & $\begin{array}{c}\text { Deliver } \\
\text { professional } \\
\text { development } \\
\text { with fewer } \\
\text { dollars }\end{array}$ & $\begin{array}{c}\text { Deliver } \\
\text { learning with } \\
\text { fewer dollars }\end{array}$ & & & $\begin{array}{l}\text { Maintaining } \\
\text { the standard } \\
\text { created with } \\
\text { funding } \\
\text { uncertainties }\end{array}$ \\
\hline Competition & & & & & $\begin{array}{l}\text { Increasing } \\
\text { "leadership } \\
\text { bench } \\
\text { strength" to } \\
\text { meet } \\
\text { increasing } \\
\text { competition }\end{array}$ & \\
\hline
\end{tabular}

different ways and the federal government, especially, is not very well set up for informal, social networking kind of learning" (Dr. W. Umber, personal communication, February 22, 2011).

Another people and technology issue for the VA is the increasing number of employees working remotely. "Learning how to become an organization that works virtually is going to be a huge challenge."

The Ritz-Carlton named international growth and the protection of the Ritz-Carlton brand and culture as a critical issue. The workplace learning function will be instrumental in making certain the Ritz-Carlton culture and its Gold Standards are understood and demonstrated by all new employees at every new property around the globe. 
Funding was named as a critical issue for Jenks, the VA, and Sharp HealthCare. The reduction in federal and/or state funding is a major concern for Jenks and the VA. The State of Oklahoma freed up money earmarked for professional development to be used where needed by all districts in the state. Jenks still dedicated these funds for professional development but may be unable to continue doing so.

The Chief of Learning Resources at the VA expressed concern about the future of offering workplace learning initiatives, "I would say the fact that money is getting tighter in the Federal Government is going to be a huge thing for us. Our ability to continue to deliver learning with fewer dollars is certainly going to be an issue" (Dr. W. Umber, personal communication, February 22, 2011).

As a not-for-profit Sharp HealthCare receives both state and federal funds. Concerns over health care reform and the ways in which it will be funded are critical to this organization. The VP of Customer Strategy, The Sharp Experience, and Sharp University addresses the progress the organization has made in quality and the role workplace learning has in this effort:

We've set a new standard for who we are as an organization, to our patients and prospective customers. The most important thing is that we exceed that [standard] every day. So it's an ongoing improvement endeavor for us to really be what our patients deserve us to be. And that requires consistency. And that requires training and development (S. Rhodes, personal communication, March 9, 2011).

Two of the critical issues named by these organizations were examined in the literature: people and technology. Growing and creating a talented workforce is for Dave Ulrich and colleagues (2008) a combination of engaging current talent for immediate success and building leaders to insure future success. Garry Ridge believes future success lies in creating a culture where learning is valued and shared, and information can move easily between groups (Blanchard \& Ridge, 2009).

Some of the issues regarding meeting the technological demands of a younger workforce focused on preparing instructors to deliver synchronous content (Clark, 2005); working with IT to overcome security and firewall issues (Gronstedt, 2007); and the cost of developing and updating learning modules (Harris, 2009; Laff, 2007b). 
Three of the six organizations identified people as a critical issue facing organizations for them today, two identified growth, one technology, three funding and one competition as shown in Table 20.

\section{SUMMARY RESEARCH QUESTION ONE}

Research question one asked: What are the workplace learning practices of organizations who have received the Malcolm Baldrige National Quality Award that support the organization's mission, vision, values, and goals? Twelve interview items, identified as items one through twelve, were developed to answer this question.

Item one asked: What factors does your organization consider when making a decision to provide workplace learning? Analysis revealed two themes: (a) needs and (b) outcomes. Five organizations revealed they use needs while one said they rely on outcomes.

Item two asked: How are your workplace learning initiatives planned, approved and communicated to the organization? What stakeholders participate? After analysis two themes were identified: (a) those using a team approach and (b) those using an individual approach. During the planning process five organizations use a team approach while one uses an individual. During the approval stage five organizations use a team approach while one relies on individuals and during the communication stage the four organizations use a team and two use an individual approach.

Item three asked: How involved is the CEO in planning, participating in and evaluating your workplace learning initiatives? Across all organizations the CEO or equivalent was involved in at least one of these activities. Four organizations reported their CEO or equivalent was involved in the planning stage. Three organizations said their CEO or equivalent participated by training, one was a student, and one acted as a speaker to initiate the program. Four organizations reported their CEOs or equivalent evaluated the workplace learning initiatives.

Item four asked: Is there an annual planning schedule for workplace learning or are training programs developed and delivered as the need arises? Two responses were revealed: (a) annual plan and (b) combination. Two of the organizations reported using an annual plan while the remaining four organizations use a combination of annual planning and an as needed basis. 
Item five asked: What one workplace learning initiative do you believe has impacted your organization the most and how, e.g., sales training that increased sales; change management training that helped the employees embrace a significant change in the way things are done; customer service training that reduced the number of customer complaints. From all the examples offered three themes emerged: (a) culture reinforcement, (b) employee engagement, and (c) process improvement. Two organizations reported the workplace initiative offering the most impact reinforced their culture. Four organizations reported employee engagement was impacted the most and one reported process improvement.

Item six asked: What role do you believe your workplace learning strategy played in helping your organization receive the Baldrige? Three themes emerged that the respondents believed influenced the Baldrige examiners: (a) dollars spent per employee on training, (b) a focus on continuous improvement, and (c) leadership development. Training dollars spent per employee was reported by one organization. Four organizations cited focus on continuous improvement and one believed it was their leadership development initiatives that helped their organization receive the Baldrige.

The seventh interview item asked: Do you want to say anything else about how you conceptualize and deliver a strategic plan for workplace learning? Of the six organizations, only five answered this item. For the remaining five organizations one theme was consistent: the conceptualization and delivery of a strategic plan for workplace learning is an on-going effort. While each organization acknowledged this effort, each drives that effort differently.

One organization shared the importance of identification of needs, another said the creation of a "think tank" of employees combined with the development of district wide goals was important. One organization reported that it was critical to tie learning to the strategic plan, while another identified the importance of communicating with stakeholders. The final driver for this ongoing effort was reported to be the development of a re-immersion program for the organizations leaders.

The eighth item asked: Do you evaluate and measure the effectiveness of your workplace learning initiatives? If not, why? If so, are all programs evaluated and with what metrics, e.g., training attendance, employee retention figures, employee satisfaction surveys, productivity, increased sales, customer satisfaction, etc? All organizations responded yes, all programs are evaluated at some level. Six themes emerged. Four of the six correlate to the 
Kirkpatrick Evaluation Model levels: satisfaction, learning, behavior and results. The fifth theme is numbers meaning the number of participants and the number of classes offered. The metrics used by these organizations varied.

All six organizations reported measuring satisfaction using course evaluations and five reported measuring satisfaction using employee satisfaction surveys. Four of the six organizations measure learning. Three organizations used open-ended questions on their course evaluations while one used a combination of quizzes, return demonstrations, and conversations with supervisor about what was learned and how it will be applied.

Behavior and results were reported together and all six organizations used a variety of metrics to measure these Kirkpatrick levels. Three organizations used customer satisfaction surveys and employee retention to measure behavior and results. One reported using safety and on-time delivery reports and another used profit and loss statements.

All six organizations reported using numbers to evaluate workplace learning initiatives; numbers of participants attending training sessions as well as number of sessions being offered.

Item number nine asked: What delivery methods do you use? The following four themes emerged: traditional, computer based, non-traditional, and new technology. All six organizations reported using traditional instructor led and asynchronous computer based delivery of courses. Only one reported using synchronous computer based delivery.

Four organizations used a non-traditional form of delivery. One used peer groups, another demonstration lessons and professional learning communities, and two used coaches. One recognized their library as a delivery method and another acknowledged their "daily line-ups."

Only two of the organizations used a new technology delivery method. One used wikis and another reported limited use of facebook.

Item ten asked: What determines the delivery method? Two themes emerged: content and resources. All six organizations reported using both content and resources as determinates of delivery method.

Item eleven asked: Do you develop training within the organization, hire consultants, buy off-the-shelf content or use a combination? All six organizations reported internal 
development and hiring a consultant to develop content. Four of the six organizations bought off-the-shelf content.

Item twelve was the final item asked to address research question one: What would you say are the most critical issues facing your organization today and how will the learning function provide solutions to these issues? Three organizations identified developing people into future leaders. Three expressed concerns over future funding and two addressed growth issues. One organization had concerns about meeting future generations' expectations for delivering training using the newest technology and another addressed the role workplace learning will play in keeping the organization competitive.

\section{RESEARCH QUESTION Two}

Five interview items, identified as Items Thirteen - Seventeen, were developed to address research question two: What evidence is there that workplace learning initiatives are supported at the executive level in organizations that have received the Malcolm Baldrige National Quality Award?

Interview item thirteen asked: Is there a $\mathrm{C}$ level Officer of Learning? If not, what is the title of the person responsible for the workplace learning function and to whom does this person report? Of the six organizations interviewed not one had a $\mathrm{C}$ level Officer of Learning. The responses to this item could not be categorized into themes because of the objective nature of the question (Table 21).

Three of the six organizations reported that the person responsible for the organization's learning function (in two of those cases the interviewee was this person) report directly to the CEO or equivalent. The Chief of Strategic Planning and Learning Resources offered a perspective on this strategy,

By reporting to the Center Director, I'm more connected to strategy than operations. Without a formal connection to strategic leadership, I think it is easy for the department to be relegated to day-to-day operations. While that isn't necessarily bad, it makes it more difficult for the learning function to be a change agent if they are operational (Dr. W. Umber, personal communication, February 22, 2011).

Two of the remaining organizations reported that the person responsible for the learning function was two levels below the CEO while the last organization reported this person three levels beneath the CEO. 
Table 21. Item Number 13. Is There a C Level Officer of Learning? If Not, What Is the Title of the Person Responsible for the Workplace Learning Function and to Whom Does This Person Report?

\begin{tabular}{|c|c|c|c|c|c|c|}
\hline Responses & Mesa & Jenks & VA & Ritz-Carlton & Solar & $\begin{array}{c}\text { Sharp } \\
\text { HealthCare }\end{array}$ \\
\hline $\begin{array}{l}\text { Do you } \\
\text { have a C } \\
\text { level } \\
\text { Officer of } \\
\text { Learning }\end{array}$ & No & No & No & No & No & No \\
\hline $\begin{array}{l}\text { What is the } \\
\text { title of the } \\
\text { person } \\
\text { responsible } \\
\text { for the } \\
\text { learning } \\
\text { function? }\end{array}$ & HR Specialıst & $\begin{array}{l}\text { Coordınator of } \\
\text { Professional } \\
\text { Development }\end{array}$ & $\begin{array}{l}\text { Chief of Strategic } \\
\text { Planning \& } \\
\text { Learnıng } \\
\text { Resources }\end{array}$ & $\begin{array}{l}\text { VP Ritz- } \\
\text { Carlton } \\
\text { Leadershıp } \\
\text { Center }\end{array}$ & $\begin{array}{l}\text { Learnıng } \\
\text { Manager }\end{array}$ & $\begin{array}{l}\text { VP Customer } \\
\text { Strategy, The } \\
\text { Sharp } \\
\text { Experience \& } \\
\text { The Sharp } \\
\text { University }\end{array}$ \\
\hline $\begin{array}{l}\text { To whom } \\
\text { does this } \\
\text { person } \\
\text { report? }\end{array}$ & $\underset{\mathrm{CEO}}{\text { Adminıstrative }} \stackrel{\text { Director }}{\downarrow}$ & $\begin{array}{c}\text { Director of } \\
\text { Curriculum } \\
\text { Assistant } \\
\text { Superintendent of } \\
\text { Curriculum \& } \\
\text { School Improvement } \\
\text { Superintendent of } \\
\text { Schools }\end{array}$ & Center Director & CEO & $\begin{array}{c}\text { HR } \\
\text { Director } \\
\downarrow \\
\text { President }\end{array}$ & CEO \\
\hline
\end{tabular}

Titles for the person responsible for the workplace learning function ranged from HR Specialist at Mesa to Learning Manager at Solar to Coordinator of Professional Development at Jenks to the VA's Chief of Strategic Planning and Learning Resources and the Vice Presidents of the Learning Center at the Ritz-Carlton and the Sharp University at Sharp HealthCare.

The literature reported the results of a study that measured the levels between the CEO or equivalent and the person responsible for the learning function in the organization where a 1 meant the person responsible for the workplace learning function reported directly to the CEO, a 2 meant the person responsible reported to someone who reported to the CEO and so on. The results of the survey revealed the average number of levels for the 96 participating organizations was 3.2 (Phillips \& Phillips, 2009). For the six organizations participating in this study the average was 1.7 . It would appear the CEOs or equivalent of 
the organizations participating in this study perceive their workforce learning function to be critical, important, and central to the organization's success.

Table 21 shows the title of the person at each organization responsible for the workplace learning function along with the hierarchy of reporting.

Interview item fourteen asked: Is the person responsible for the workforce learning function included in the organization's strategic planning sessions? If not, how are new strategic plans and organizational changes conveyed to this person? (An assumption is made that if the person in charge of the workplace learning function is part of the strategic planning process any changes in strategy requiring training are more immediately addressed).

Responses to this item are reported in Table 22.

Table 22. Item Number 14. Is the Person Responsible for the Workforce Learning Function Included in the Organization's Strategic Planning Sessions? If Not, How Are New Strategic Plans and Organizational Changes Conveyed to This Person?

\begin{tabular}{|c|c|c|c|c|c|c|}
\hline Responses & Mesa & Jenks & VA & Ritz-Carlton & Solar & $\begin{array}{c}\text { Sharp } \\
\text { HealthCare }\end{array}$ \\
\hline $\begin{array}{l}\text { Is the } \\
\text { person } \\
\text { responsible } \\
\text { for the } \\
\text { workplace } \\
\text { learning } \\
\text { function } \\
\text { involved in } \\
\text { strategic } \\
\text { planning? }\end{array}$ & No & Yes & Yes & Yes & Yes & Yes \\
\hline $\begin{array}{l}\text { Through } \\
\text { which } \\
\text { person are } \\
\text { changes in } \\
\text { the strategic } \\
\text { planned } \\
\text { conveyed? }\end{array}$ & $\begin{array}{l}\text { Admınistrative } \\
\text { Director }\end{array}$ & N/A & N/A & $\mathrm{N} / \mathrm{A}$ & N/A & $\mathrm{N} / \mathrm{a}$ \\
\hline
\end{tabular}

Five of the six organizations, Jenks, the VA, the Ritz-Carlton, Solar, and Sharp HealthCare all reported that the person responsible for workplace learning takes part in the organization's strategic planning sessions. Mesa is the only organization that does not include the person in the strategic planning process but as the CEO revealed, "Plans have been made to promote and include this person" (T. May, personal communication, February 
17, 2011). Currently this person receives information about upcoming changes in strategy through the Administrative Director.

Typically strategy is developed at the executive level of an organization and information about changes is cascaded down with the help of the workforce learning personnel. The Chief of Strategic Planning and Learning Resources at the VA explained their unique approach to strategic planning:

Our strategic planning events here are kind of unique. They are not planned by the executives; they are planned by an employee sponsored committee. The agenda is passed to the Center Executive Committee to approve. And, of course they actually approve the outcomes of strategic planning and they're involved in that process. But the events themselves, and the structure of the agenda and how we manage the process of the strategic planning are actually all controlled by an employee based committee. Once the plan is in place the Workforce Learning Group, of which I'm a part, work together to implement the change (Dr. W. Umber, personal communication, February 22, 2011).

Including the person responsible for the workplace learning function in the organization's strategic planning session is a best practice reported in the literature by many researchers (Bingham \& Jeary, 2007; Clark \& Kwinn, 2005; Ellis, 2005; Studer, 2003, 2008). Five of the six organizations include the person responsible for the learning function in the organization's strategic planning sessions as shown in Table 22.

Interview item fifteen asked: Do all employees have access to workplace learning? Do the executives of the organization attend training? In what other ways do the senior level members show support for workplace learning? All six organizations reported that every employee has access to workplace learning and that each of the executives is expected to attend training. Sharp HealthCare's VP of The Sharp University explained it this way, "The executives not only attend but are required to attend and most of them attend more than one time in the quarterly sessions."

In response to what other ways senior level members shows support for workplace learning two themes emerged: providing resources and leadership presence (Table 23). All six organizations reported their senior members support the workplace learning function by allocating resources in the form of funding, and time away from job to attend training programs.

The second theme was leadership presence. Leadership presence is provided when the CEO or equivalent attends class, announces a new training initiative, or teaches a portion 
Table 23. Item Number 15. In What Other Ways Do Senior Level Members Show Support for Workplace Learning?

\begin{tabular}{ccccccc}
\hline Themes & Mesa & Jenks & VA & Ritz-Carlton & Solar & $\begin{array}{c}\text { Sharp } \\
\text { HealthCare }\end{array}$ \\
\hline $\begin{array}{c}\text { Providing } \\
\text { Resources }\end{array}$ & $\begin{array}{c}\text { Funding and } \\
\text { Time to } \\
\text { attend } \\
\text { training }\end{array}$ & $\begin{array}{c}\text { Funding and Time } \\
\text { to attend training }\end{array}$ & $\begin{array}{c}\text { Funding and } \\
\text { Time to attend } \\
\text { training }\end{array}$ & $\begin{array}{c}\text { Funding and } \\
\text { Time to } \\
\text { attend } \\
\text { training }\end{array}$ & $\begin{array}{c}\text { Funding } \\
\text { and } \\
\text { Time to } \\
\text { attend } \\
\text { training }\end{array}$ & $\begin{array}{c}\text { Funding and } \\
\text { Time to } \\
\text { attend } \\
\text { training } \\
\text { Presence }\end{array}$ \\
$\begin{array}{c}\text { Neadership } \\
\text { N/A }\end{array}$ & Attends & Teaches & Announces & N/A & $\begin{array}{c}\text { Attends and } \\
\text { Teaches }\end{array}$ \\
\hline
\end{tabular}

of a program. Four of the six organizations reported the CEO or equivalent participates in one or more of these activities. As the hotel manager for the Laguna Nigel Ritz-Carlton explained, "If we're rolling out training cooperate wide it literally it starts with the CEO speaking before the General Managers. He'll communicate the motivation, he'll communicate the importance, he'll communicate the expectations and then it starts there" (S. Kelton-Rogers, personal communication, March 1, 2011).

Each respondent in this study reported that every employee in their organization has access to workplace learning. In $1982 \mathrm{~W}$. Edwards Deming a pioneer in quality management processes identified what he referred to as 14 points he believed were critical for American organizations to adopt in order to stay competitive on a global market. One of those 14 points was to train and educate every employee (Cohen, n.d.).

Interview item sixteen asked: Do you have a leadership development program(s) and if so how are participants chosen? Five of the six organizations have a formal leadership program: Mesa, VA, Ritz-Carlton, Solar and Sharp HealthCare.

Jenks does not have a formal leadership development program because the Baldrige criterion for education does not require a leadership development program. Educational leaders such as Superintendents, Assistant Superintendents, etc. are selected on the basis of their education. Even though this is not a requirement Jenks sends one representative a year to participate in the Leadership Tulsa Program, which is a community leadership development program. 
In response to how participants are chosen three themes emerged: invitation, mandatory and open (anyone can attend) (Table 24). The VA describes their leadership program as self-directed and open:

It involves taking part in a series of Center and external activities that show that you have leadership potential. Those things might include becoming an ISO Auditor, becoming an examiner for one of our quality programs or being involved in your professional discipline or a community group in some way. Taking some leadership role within the Center or doing something that's voluntary beyond your job (Dr. W. Umber, personal communication, February 22, 2011).

Table 24. Item Number 16. Do You Have a Leadership Development Program(s) and if so How Are Participants Chosen?

\begin{tabular}{|c|c|c|c|c|c|c|}
\hline & Mesa & Jenks & VA & Ritz-Carlton & Solar & $\begin{array}{c}\text { Sharp } \\
\text { HealthCare }\end{array}$ \\
\hline $\begin{array}{l}\text { Do you } \\
\text { have a } \\
\text { leadership } \\
\text { program? }\end{array}$ & $\begin{array}{c}\text { Yes } \\
\text { Leadership } \\
\text { Development }\end{array}$ & N/A & $\begin{array}{c}\text { Yes } \\
\text { Participation in } \\
\text { Center and } \\
\text { Community } \\
\text { Activities and } \\
\text { outside } \\
\text { programs }\end{array}$ & $\begin{array}{c}\text { Yes } \\
\text { Senıor } \\
\text { Leadershıp, } \\
\text { New College } \\
\text { Graduates, } \\
\text { and } \\
\text { Leadershıp } \\
\text { Development } \\
\text { Serıes }\end{array}$ & $\begin{array}{c}\text { Yes } \\
\text { Leadershıp } \\
\text { Foundatıon } \\
\text { Program, } \\
\text { Makıng } \\
\text { Great } \\
\text { Leaders, } \\
\text { and } \\
\text { Thunderbırd } \\
\text { University }\end{array}$ & $\begin{array}{l}\text { Yes } \\
\text { Leadershıp } \\
\text { Program } \\
\text { through } \\
\text { Sharp } \\
\text { University }\end{array}$ \\
\hline $\begin{array}{l}\text { How are } \\
\text { participants } \\
\text { chosen? }\end{array}$ & $\begin{array}{l}\text { Invitation } \\
\text { only }\end{array}$ & N/A & $\begin{array}{l}\text { Open to } \\
\text { anyone }\end{array}$ & $\begin{array}{l}\text { Invitation } \\
\text { only for } \\
\text { Senıor } \\
\text { Leadership } \\
\text { and New } \\
\text { College } \\
\text { Open for } \\
\text { Leadership } \\
\text { Development } \\
\text { Series }\end{array}$ & $\begin{array}{l}\text { Invitation } \\
\text { only for all } \\
\text { programs }\end{array}$ & $\begin{array}{c}\text { Mandatory } \\
\text { for anyone } \\
\text { having at } \\
\text { least one } \\
\text { direct report }\end{array}$ \\
\hline
\end{tabular}

The Ritz-Carlton has three leadership programs. Two are by invitation only: the Senior Leadership Training and a special program for new college graduates designed to help them become future leaders of the organization. A third program is a series of leadership development classes and is open to anybody,.

Sharp HealthCare's leadership program is open only to those that have at least one person reporting to them and is mandatory. Mesa's program participants are by invitation only. 
Solar has three programs available to leaders and all are by invitation only: Solar Leadership Foundation Program, Making Great Leaders, and an invitation to participate in an international business program at Thunderbird University in Arizona. Participants for the Leadership Foundation Program and Making Great Leaders are chosen on recommendation from managers to directors who along with HR make the final selection in a succession planning session. Participants in the Thunderbird program are chosen by the VPs.

The VA also gives their employees the opportunity to participate in outside programs including those sponsored by the Federal Executive Board, the Medical Center and the local VA and the VA nationally.

While the literature reviewed does not examine how to select participants for leadership development programs, it does offer many models for developing these programs, e.g., Situational Leadership (Hersey, Blanchard, \& Johnson, 2001); Leadership Code (Ulrich et al., 2008); The Leadership Challenge (Kouzes \& Posner,2002), and The Extraordinary Leader (Zenger \& Folkman, 2002).

Five of the six organizations have leadership programs and participation varies from open to anyone, mandatory, or by invitation only as shown in Table 24.

Interview item seventeen asked: How does workplace learning factor into your employees' performance review? Do your employees write performance goals that include training? Every organization had the expectation that every employee, including those at the executive level, develop at least one learning goal on their annual performance plan. The motive for including these learning goals varied and became the basis for two themes: organizational value and improved job performance (Table 25).

While it can be argued that improved job performance is important to all six organizations the motive to include a learning objective on the performance review was not always just about improved job performance. Three of the organizations require their employees to tie performance goals to either the organization's values or goals. These three organizations are the Ritz-Carlton, the VA, and Jenks.

The Ritz-Carlton and the VA name continuous learning as a corporate value. Number eight of the Ritz-Carlton's service values states: I have the opportunity to continuously learn and grow. Each employee is expected to develop performance goals based on the organization's service values and attend training in these areas. They are then scored and are 
Table 25. Item Number 17. How Does Workplace Learning Factor into Your Employees' Performance Review? Do Your Employees Write Performance Goals that Include Training?

\begin{tabular}{|c|c|c|c|c|c|c|}
\hline Theme(s) & Mesa & Jenks & VA & Ritz-Carlton & Solar & $\begin{array}{c}\text { Sharp } \\
\text { HealthCare }\end{array}$ \\
\hline $\begin{array}{c}\text { Tred to } \\
\text { Organizational } \\
\text { Values/Goals }\end{array}$ & & $\begin{array}{l}\text { One goal } \\
\text { must be } \\
\text { linked to } \\
\text { one district } \\
\text { goal }\end{array}$ & $\begin{array}{c}\text { Must } \\
\text { demonstrate to } \\
\text { supervisor } \\
\text { organizational } \\
\text { value of } \\
\text { contınuous } \\
\text { learning }\end{array}$ & $\begin{array}{l}\text { Must develop } \\
\text { goal based on } \\
\text { the } \\
\text { organization's } \\
\text { service value }\end{array}$ & & \\
\hline $\begin{array}{l}\text { Improved Job } \\
\text { Performance }\end{array}$ & $\begin{array}{l}\text { Must } \\
\text { 1dentıfy } \\
\text { performance } \\
\text { goals that } \\
\text { will improve } \\
\text { job } \\
\text { performance }\end{array}$ & & & & $\begin{array}{c}\text { Does not } \\
\text { require but } \\
\text { encourages } \\
\text { individual } \\
\text { responsibility } \\
\text { for } \\
\text { development }\end{array}$ & $\begin{array}{c}\text { Must } \\
\text { Identıfy } \\
\text { performance } \\
\text { goals that } \\
\text { will ımprove } \\
\text { job } \\
\text { performance }\end{array}$ \\
\hline
\end{tabular}

expected to stay in the Green Zone a very narrow window of excellence at the top of the scorecard.

The VA has four organizational values: Continuous Learning, Customer Service, Teamwork, and Leadership. Employees have the choice to participate in either internal or external learning programs. To receive and "outstanding" rating on their performance review they must demonstrate the learning to their supervisor.

Jenks requires all staff, certified and classified, to create a goal that links directly to one of the district's three year goals. The Assistant Superintendent describes it this way:

Every employee in the district, and that's on both sides classified and certified, has a goal that ties to the district goal. That goal is expected to include what kind of professional development is going to be needed for you to accomplish this goal (L. Muller, personal communication, February 18, 2011).

In addition all staff must complete a certain number of professional development hours per year. Classified must complete six hours and certified fifteen.

Mesa, Solar and Sharp HealthCare do not have stated continuous learning values nor do they require their employees to tie learning goals to organizational goals. Mesa and Sharp HealthCare do require their employees to identify individual learning goals and participate in training programs improve their job performance. Solar encourages individual responsibility for development and offers a program titled Managing Professional Growth. The purpose of 
this program is to help them find and use internal resources for advancement within the organization.

Themes identified with the link between performance reviews and workplace learning are tied to organizational values/goals and improved job performance. While the link between performance reviews and workplace learning was not explored in the literature an argument could be made that says, if there is evidence that linking the workforce learning function to the organizations strategic plans has value (Bingham \& Jeary, 2007; Clark \& Kwinn, 2005; Ellis, 2005; Studer, 2003, 2008), then an individual's performance goals could be considered an individual strategic plan and therefore should be linked to workplace learning.

Three of the six organizations require their employees to develop performance goals that are tied to either the organization's values or goals. Two of the organizations require performance goals to be tied to job performance and one organization encourages individual responsibility for development as shown in Table 25.

\section{SUMMARY RESEARCH QUESTION TWO}

Research question two asked: What evidence is there that workplace learning initiatives are supported at the executive level in organizations that have received the Malcolm Baldrige National Quality Award? Five items were developed to answer this question.

Item number thirteen asked: Is there a $\mathrm{C}$ level Officer of Learning? If not, what is the title of the person responsible for workplace learning and to whom does this person report? Not one of the organizations reported having a $\mathrm{C}$ level Officer of Learning. The titles of the person responsible for workplace learning varied and included one specialist, one coordinator, one chief, one manager, and two vice presidents. Three organizations reported the person responsible for workplace learning reported directly to the CEO or equivalent, two organizations reported to someone who reported to the CEO or equivalent and one organization reported to someone three levels under the CEO or equivalent.

Item number fourteen asked: Is the person responsible for the workforce learning function included in the organization's strategic planning sessions? If not, how are new strategic plans and organizational changes conveyed to this person? Five of the six 
organizations reported that the person responsible for the workforce learning function was included in the strategic planning sessions. One organization reported that the person responsible for workplace learning was not included in the planning process and that strategic plans were communicated via this person's supervisor.

Interview item fifteen asked: Do all employees have access to workplace learning? Do the executives of the organization attend training? In what other ways do the senior level members show support for workplace learning? All six organizations reported that every employee has access to learning and that all executives attend training. In response to what other ways the senior level members show support for workplace learning two themes emerged: providing resources and leadership presence. All organizations reported the senior executives show support by providing resources while four reported that leadership presence was provided.

The sixteenth interview item asked: Do you have a leadership development program? How are participants chosen? Five organizations reported having at least one leadership development program. Three themes emerged with regard to how participants were chosen: invitation, open, mandatory. Three organizations reported participants were by invitation only. Two organizations reported participation was open to anyone who wanted to attend and one reported mandatory participation by all managers.

Item seventeen asked: How does workplace learning factor into your employees' performance review? Do your employees write performance goals that include training? While every organization reported that every employee was expected to include at least one learning goal on their performance review, the motives for doing were evenly split and fell into one of two themes: organizational value and improved job performance. Three organizations reported learning as an organizational value and tied performance goals to these values and three organizations asked employees to identify learning goals that would improve job performance.

\section{CONCLUSION}

One additional item revealed itself during the process of interviewing and identifying themes. This was not an item asked during the interviews but one that was answered by all participants. The item is: How has winning the Baldrige impacted your organization? 
All six organizations revealed that participation in the Baldrige process was an experience that changed the organization forever. The Baldrige criteria provided a framework to identify areas for improvement. As Sharp HealthCare stated, "So that mechanism of Baldrige really helped us get really tight on what we needed to do" (S. Rhodes, personal communication, March 9, 2011).

Solar continues the pursuit of quality across all of the organizations functions: their people, their processes, and their products.

Jenks and the VA still use the Baldrige criteria to identify areas for professional development/workplace learning. As Jenks acknowledged, "We continue to use the Baldrige criteria and look at what are we doing and what are some areas where we can improve? So I would say we actually use it more for professional development now than we did even prior to recẹiving the award" (L. Muller, personal communication, February 18, 2011).

Ritz-Carlton reported that when they were going through the Baldrige process, back in the 1990's, they created a book on quality they referred to as the "Green Book" as well as a VP of Quality and Directors of Quality to educate the employees and to improve quality corporate wide. Today the positions have changed but the focus on quality remains the same. As the Laguna Nigel Hotel Manager describes:

We've got an Area Director of Performance Improvement, an Area Director of Performance Development, we have an Area Quality Analyst and an Area Manager of Performance Improvement. These four individuals support our region, they come to our properties, organize quality improvement teams and help solve any quality related problems we might have (S. Kelton-Rogers, personal communication, March 1, 2011).

The Mesa CEO described the impact this way, "You can't really judge when you're in the middle of it [Baldrige process]. You have to look back to say, 'Man this has really changed, we've really moved forward"' (T. May, personal communication, February 17, 2011). 


\section{CHAPTER 5}

\section{DISCUSSION}

The voyage of discovery is not in seeking new landscapes but in having new eyes.

Marcel Proust

The findings of this study support the hypothesis that the workplace learning function in organizations of excellence is considered an integral part of the strategic planning process. They revealed that those responsible for the workplace learning function sit shoulder to shoulder with the organization's CEO or equivalent at the strategy table and are responsible for developing future leaders committed to growing and sustaining the organization.

The remainder of this section will review how organizations of excellence were determined and the criteria used to develop the semi-structured interview items used to gather the data.

Organizations of excellence were identified as having won the Malcolm Baldrige National Quality Award. This award is significant in four ways: (1) it is proof of meeting or exceeding criteria established by the Malcolm Baldrige National Quality Improvement Act of 1987 ; (2) the criteria is rigorous, applicants are evaluated on performance in seven areas: leadership; strategic planning; customer focus; measurement, analysis, and knowledge management; workforce focus; process management; and results (NIST, 2009b); (3) the criteria serves as a template for 37 states that have established quality awards (Alliance for Performance Excellence, n.d.); and (4) the award is so prestigious that the President of the United States presents it at an annual awards ceremony. Six organizations were chosen from a pool of 87one from each of the six Baldrige sectors: Small Business, Education, Public/Non-Profit, Service, Manufacturing, and Healthcare.

The workplace learning practices of each of the six organizations was examined using criteria from the ASTD's BEST award as a guide for development of the interview questions. Because the ASTD is indisputably the voice of the workplace learning professional and because the BEST award is coveted recognition for a job well done with regard to workplace learning efforts, it seemed a reasonable place to start. 


\section{RESEARCH QUESTION ONE}

Twelve items were developed to answer research question one: What are the workplace learning practices of organizations who have received the Malcolm Baldrige National Quality Award that support the organization's mission, vision, values, and goals?

The findings for this research question showed that organizations of excellence develop workplace learning strategies and programs that help employees align with the organization's mission, vision, values and goals. These programs help reinforce the organization's culture, engage the employee, and improve processes to make the organization more efficient and effective.

The findings also revealed that the CEO or equivalent is involved in one or more levels of the workplace learning development process including: planning, approving, evaluating and participating. In addition, the CEO or equivalent, as well as other senior level executives, communicates the value of workplace learning to the entire organization by acknowledging the role workplace learning initiatives play in strengthening the organization today and will play in helping the organization address critical issues in the future.

The findings also showed that these organizations evaluate all workplace learning initiatives and use a combination of instructor led and asynchronous computer based delivery methods.

The remainder of this section will present the detailed findings to items one through twelve including references to the literature and will include any previously held hypotheses or editorial opinion of the researcher.

Item number one asked what factors were considered when making a decision to provide workplace learning. While all of the organizations cited needs the tools used to determine those needs varied. Mesa used gap analysis, a part of Robert Camp's four category, benchmarking process (Camp, 1989). The Ritz-Carlton used SWOT analysis (Friesner, 2011) and customer satisfaction surveys (Stewart, 1999) to improve strategic planning and knowledge transfer. The Sharp HealthCare strategy of aligning their workplace learning strategic plan to their six pillars of excellence is an example of what Clark and Kwinn (2005) were referring to when they said, "Unless you align corporate training to organizational goals, any returns you realize from the training investment will be by chance alone." 
It was reaffirming to see that for each of these organizations the same care was given to the development of workplace learning strategy as might be given to product development or process improvement considerations.

Item number two asked how workplace learning initiatives were planned, approved and communicated to the organization and what stakeholders participated. The use of employee teams by each of the organizations in the planning, approving, or communicating workplace learning initiatives is an example of employee engagement as reviewed in the literature. Research shows employees are engaged when they feel their work matters and helps drive the business (Bingham \& Jeary, 2007; Fox, 2010; Pink, 2009; Soldati, 2007).

The team approach, that reached beyond the workplace learning team, and engaged multiple members of the organization in either planning, approving or communicating new workplace learning initiatives was a surprise. It was hypothesized that most of these activities would remain with the workplace learning team.

Item number three asked about the involvement of the CEO in planning, participating in, or evaluating workplace learning initiatives. Research reports there is a serious lack of participation by senior executives in workplace learning (Laff, 2007a) and that senior executives hold a perception that the workplace learning function is not critical to organizational success (Phillips \& Phillips, 2009). This is in direct contrast to the findings of this study. All six organizations reported that the CEO was involved in at least one aspect of workplace learning functions: planning, participating in, or evaluating. In fact, in their opinion, CEO involvement was critical to the success of their workplace learning efforts.

Item number four asked about a planning schedule for workplace learning. The results showed that all organizations used either a specified annual planning period or a combination of an annual plan plus a more nimble as-needed approach.

Creating a plan for the learning function is a good example of what Kaplan and Norton refer to as mobilizing and aligning an intangible asset. In their 2004 book Strategy Maps: Converting Intangible Assets into Tangible Outcomes, Kaplan and Norton posit that an organization's strategy should describe how it intends to create value for its shareholders, customers, and citizens. They believe an organization creates value by connecting strategic objectives in explicit cause-and-effect relationships with each other in four areas: financial, customer, processes, and learning and growth (Kaplan \& Norton, 2004, p. 5). 
These results were not surprising. It was hypothesized that each of these Baldrige recipients would have a plan and that workplace learning was not a willy-nilly event.

Items five asked the respondents to name the one workplace initiative they believed impacted their organization the most. Item six asked about the role workplace learning played in receiving the Baldrige and item seven asked the respondents to reflect on other ways in which workplace learning strategy was conceptualized and delivered. Each of these items was asked to encourage reflection on past workplace learning strategies.

Each organization offered examples that were supported in the literature and included initiatives that engaged the employee (Fox, 2010) or improved a process (Hammer, 2001) as impacting the organization the most. Dollars spent on employee training (Sugrue, 2004) and the learning initiatives that were committed to continuous improvement (Capodagli \& Jackson, 1999; Peters \& Waterman, 1982) were cited as those that played a hand in receiving the Baldrige.

Each organization acknowledged that conceptualizing and delivering a workplace learning strategy was an ongoing effort but each drove that effort differently. Mesa's identified needs (Camp, 1989); Jenks employed a "think tank" as a form of employee engagement (Fox, 2010; Pink, 2009; Soldati, 2007); the VA was committed to tyin the learning function to the strategic plan (Clark \& Kwinn, 2005) and Sharp HealthCare created leadership development initiatives (Bennis \& Nanus, 1985; Kouzes \& Posner, 2002, 2010; Studer, 2003; Ulrich et al, 2008; Zenger \& Folkman, 2002).

The responses from all six organizations were interesting for what they did not focus on with regard to the contribution of workplace learning: cost reductions, increased revenues, or efficiency. While each of these factors is important these professionals believed the greatest contribution workplace learning strategy makes is on developing the people within the organization. Whether it was called "engaging the workforce", "building future leaders", "bringing training to new employees" or to a "previously neglected population" within the organization, each participant believed their ultimate responsibility was the continuous improvement of the people within their organizations. They believe it was and is the driving force and is always an ongoing effort.

Item number eight addressed evaluation of workplace learning effectiveness. In 2009 ASTD and i4cp consultants conducted research about the actual use of the 
Kirkpatrick/Phillips 5 level training evaluation model in the workplace. The results showed that even though respondents thought level 1 : satisfaction, held very little value, over ninety percent of the 704 respondents measured at this level. Conversely while level 5: ROI was believed to deliver the most valuable information less than twenty percent measured Level 5 : ROI.

The results of this study are consistent with the findings of the ASTD/4icp survey. All six organizations evaluated level 1: satisfaction, while not one organization reported conducting any ROI metrics to measure level 5. This is not surprising given the complexities involved with developing these metrics. Two of the participants addressed two of the issues that many organizations face regarding measuring level 5: ROI.

Jenks acknowledged the difficulty of tying specific professional development initiatives to increases in student performance. This dilemma resonates with workplace learning professionals, not just in education, but in organizations both public and private. The question is, how does one isolate out all other outside factors, e.g., personality traits, outside peer/family pressure, executive level support or lack of, etc. that can play a role in the outcome of ROI?

The VA addressed the reality of the lack of resources needed to produce these metrics in combination with the lack of interest by the senior level executives. The ASTD/i4cp study revealed executives are not that interested in these metrics. Personal experience backs up the findings of this study. Executives trust their own instincts regarding the value of workplace learning initiatives and would much rather a workplace learning professional make adjustments to existing programs or scrap them and start over rather than go through an elaborate measurement process.

At the end of the day measuring level 1: satisfaction has its merits: satisfaction with the instructor and the content. It measures satisfaction with those variables that can be controlled and it's practical. If the participants do not find satisfaction with the training they will not attend or if required to do so will participate grudgingly. This researcher agrees with Allison Rossett (2007), "Level one has taken a bad rap."

Item number nine asked about delivery methods. All six of the organizations continue to rely heavily on instructor led programs or asynchronous computer based training. These finding were aligned with the results reported in research conducted by Rossett and 
Marshall in 2010. They found government and corporations are not using the newest technology, e.g., synchronous computer based training, social media, mobile media, or virtual worlds to deliver training as expected would happen ten years ago. They also found that most companies still use a majority of instructor led training sessions along with asynchronous computer based learning for testing of skills and knowledge (Rossett \& Marshall, 2010, p. 36). For the organizations in this study the cost and security issues associated with adopting the newer technology is prohibitive.

Item number ten asked what determines the delivery method. All six organizations considered content when planning the most effective and efficient delivery method. As reported in this study the most frequent use of asynchronous computer based delivery was to offer regulatory content that tests technical knowledge in areas such as safety, harassment, etc. These findings are similar to those found by Rossett and Marshall (2010) regarding the most frequently occurring e-learning practice in the corporate and governmental workplace was to test skills and knowledge (p. 36).

Item number eleven asked about developing content internally, hiring a consultant, buying off the shelf or using a combination of these methods. While the merits of each of the development methods were not examined in the literature, Solar identified one example of off-the-shelf content, delivered by an instructor that was reviewed. This example was Situational Leadership a model created by Paul Hersey, Ken Blanchard, and Dewey Johnson in the late 1960's that asks the leader to adjust his/her leadership style to the readiness level of the direct report in a given situation (Hersey et. al., 2001).

Items ten and eleven responses offered no surprises or revelations.

Item twelve asked about what critical issues were facing the organization and the role that workplace learning play in providing solutions for these issues. The themes identified by the participants were: people, growth, technology, funding, and competition.

Two of the critical issues named were examined in the literature: people and technology. Growing and creating a talented workforce is for Dave Ulrich and colleagues (2008) a combination of engaging current talent for immediate success and building leaders to insure future success. Garry Ridge believes future success lies in creating a culture where learning is valued and shared, and information can move easily between groups (Blanchard \& Ridge, 2009). 
Some of the issues regarding meeting the technological demands of a younger workforce focused on preparing instructors to deliver synchronous content (Clark, 2005); working with IT to overcome security and firewall issues (Gronstedt, 2007); and the cost of developing and updating learning modules (Harris, 2009; Laff, 2007b).

Although funding was not a reviewed topic it is of major concern for many organizations. Even though the Baldrige criterion mandates evidence of workplace learning and its role in an organization's strategic plan and the ASTD works tirelessly to educate workplace learning professionals and there are numerous studies to prove the value of workplace learning it runs the risk of being eliminated during poor economic times.

\section{RESEARCH QUESTION TWO}

Five items were developed to answer research question two: What evidence is there that workplace learning initiatives are supported at the executive level in organizations that have received the Malcolm Baldrige National Quality Award?

The findings of research question number two revealed that while not one of the six organizations studied had a $\mathrm{C}$ level officer of learning, the levels separating the person responsible for the workplace learning function from the CEO was 1.7 as opposed to the 3.2 levels reported in the results of Phillips and Phillips (2009).

The findings also revealed that in five out of six of the organizations, the person responsible for the workplace learning function was involved in the strategic planning process. This finding was inconsistent with the hypothesis that all organizations would include this person in strategic planning but as stated earlier the one organization that did not include this person had plans to promote and include them in future planning sessions.

The findings also showed that all senior level officers at these organizations support workplace learning by providing resources and/or presence in the classroom.

The findings showed that leadership development programs were established in five of the six organizations and seen as critical to sustaining the organization in the future. A surprising finding was that individual performance reviews were tied to the organization's values or goals in only half of these organizations. 
The remainder of this section will present the detailed findings to items thirteen through seventeen including references to the literature and will include any previously held hypotheses or editorial opinion of the researcher.

Items thirteen, fourteen, and fifteen examined the role senior leadership plays in a creating a successful learning environment.

Item thirteen asked if there was a $\mathrm{C}$ level officer of learning and if not what was the title for the person responsible for workplace learning and to whom did this person report. This study revealed that not one of the six organizations interviewed had a $\mathrm{C}$ level officer of learning. In fact the person in charge of the workplace learning function was known by a variety of titles ranging from Specialist to Vice President. The important question then was to whom does this person report? Three of the six reported directly to the CEO, two reported to someone who reported to the CEO and only one reported to someone, who reported to someone, who reported to the CEO.

Even though it was hypothesized that these organizations would all have a $\mathrm{C}$ level officer of learning or at the very least the person responsible for workplace learning would report directly to the CEO the results from this research were better than the results reported in Phillips and Phillips (2009). Of the 96 Fortune 500 CEOs asked how many reporting levels there were between themselves and the person in charge of learning the average was 3.2. This meant that the CEO is at least three levels above the person in charge of learning. For the six organizations participating in this study the average was 1.7.

Item fourteen asked if the person responsible for workplace learning was included in the organization's strategic planning sessions and if not how were strategic plans conveyed to this person. Five of the six organizations included the person responsible for workplace learning in the organization's strategic planning sessions. Sitting close to the CEO is valuable for two very important reasons: (1) knowing what new changes or initiatives are being planned for the organization allows the workplace learning function to align strategically, (2) there is no delay or communication breakdown if the information is received directly to the organization's workplace learning lead and (3) workforce learning capabilities can be addressed at the planning stage. 
This study's findings also support research in this area suggesting that all workplace learning strategies must be tied to organizational strategies to keep the organization strong and the training relevant (Bingham \& Jeary, 2007; Clark \& Kwinn, 2005).

Item fifteen asked if all employees have access to workplace learning, do the executives of the organization attend training and in what other ways do the senior level members show support for workplace learning. Each organization in this study reported that every employee has access to workplace learning. It is interesting to note that in $1982 \mathrm{~W}$. Edwards Deming a pioneer in quality management processes identified what he referred to as 14 points he believed were critical for American organizations to adopt in order to stay competitive on a global market. One of those 14 points was to train and educate every employee (Cohen, n.d.).

Leaders at all six organizations supported workplace learning in this study by providing resources and/or presence in training classes. While it is very important for leaders to support workplace learning financially their presence in the classroom has the greatest impact on the workforce. Workplace learning professionals are united regarding the significance of leadership participation. When leaders participate in training the value of the program is heightened in the eyes of the workforce and the barrier between "us and them" is removed.

Item sixteen asked if there was a leadership development program and if so how were participants chosen. The literature reviewed offered several models for leadership programs e.g., Situational Leadership (Hersey et al., 2001); Leadership Code (Ulrich et al., 2008 ); The Leadership Challenge (Kouzes \& Posner,2002), and The Extraordinary Leader (Zenger \& Folkman, 2002) but did not examine how to select participants for these programs.

In addition to the reviewed models, leadership is one of the seven Baldrige criterion, in fact, it is criteria number one. Whether or not being number one criteria implies importance, the fact that leadership is included, does. The Baldrige leadership criteria looks at ways leaders communicate, set goals, and act in ethical ways. Baldrige also looks at the role current leaders play in organizational learning and future leader development. Section 1.1.a.3. bullet point 5 of the Baldrige criteria asks, "How do senior leaders achieve the following: participate in organizational learning, succession planning, and the development of future organizational leaders." 
It is important to note that the Baldrige criterion for the education sector does not look at development of or participation in leadership development classes. School districts leaders are typically chosen using other determinates such as education and reputation. Therefore Jenks Public School District does not have a leadership development program and was not included in the results.

Item number seventeen and the last item in this study looked at the inclusion of learning goals in the performance review. Three of the six organizations tied individual performance goals to workplace learning. This was a somewhat surprising finding.

It was hypothesized that each of these organizations would have established individual performance learning goals, a seemingly rational thought from a practitioner's viewpoint. If we do better at aligning individual performance goals with learning objectives, the more knowledgeable the individual, the more efficient the department, the more successful the organization.

\section{STRENGTHS OF THE STUDY}

The findings of this study are significant in two ways: they identify specific workplace learning practices for organizations seeking excellence and they represent a combination of academic theory and practitioner practicality.

The first way in which this study is significant is identifying specific workplace learning practices for those seeking organizational excellence. While some practices are not consistent across all organizations there are certain practices that are non-negotiable if organizations are serious about achieving organizational excellence.

These practices address the value the executive level of the organization places on the workplace learning function and the role it plays in the future of the organization. Those responsible for organizational learning must have access to the CEO or equivalent and must be part of the strategic planning process. In addition senior level leaders need to support the learning function by participating in or showing outward support for learning programs.

Leadership development programs must be developed and implemented. All participating organizations across all Baldrige sectors (except education) had established leadership programs and believed these programs were essential to the future success of the organization, preserving its culture and insuring organizational sustainability. 
The second way in which this study is significant is that it is a combination of academic theory and practitioner practicality. Too often there is tension between academics and practitioners regarding application of academic theory. As an example, this study looked at the ways in which Baldrige recipients evaluate workplace learning effectiveness and ways in which they deliver workplace learning programs. Academic theory would suggest practitioners should always evaluate at Level 5:ROI of the Kirkpatrick/Phillips model and deliver workplace learning using Web 2.0 technology. The findings of this research reported the exact opposite.

These Baldrige winning organizations for organizational excellence do not evaluate at Level 5:ROI nor do they use extensively Web 2.0 technology to deliver training. As a practitioner this researcher is neither surprised nor offended. There are many practical reasons organizations do not engage in these practices, e.g., money and time that are understood by this practitioner/researcher.

\section{LIMITATIONS OF THE STUDY}

There are three limitations to this study:

1. This study was a multiple case study examining the workplace learning practices of six Baldrige recipients. According to Denzin and Lincoln (2005) case studies by nature tend not to be generalizable.

2. Only six organizations, one per Baldrige sector, were interviewed for this study. If there are differences in workplace learning practices by sector then generalizability may be limited.

3. Due to the financial constraints of the researcher the location of the participants was a consideration which may have resulted in a selection that did not adequately represent that sector.

\section{RECOMMENDATIONS FOR FURTHER STUDY}

The findings of this study were provocative and would suggest further research in many aspects of the workplace learning function. Although the methodology used to conduct this research turned out to be very powerful, unless the researcher had unlimited resources to conduct similar qualitative in depth, unstructured, face-to-face interviews the three recommendations for further study presented here would require the development of a quantitative instrument. 
The first recommendation would be to expand the study to examine the workplace learning practices of all Baldrige recipients. While this seems an ambitious endeavor there have been only 87 recipients to date and in the quantitative methodology world a very doable sample. The focus of the study may need to be narrowed, e.g., workplace learning and performance reviews to enable the development of an instrument that was not too unwieldy.

The second recommendation would be to examine the workplace practices of all organizations within one Baldrige sector to see what or if any, similarities exist. This would give workplace learning professionals in individual sectors information that was specific to their needs.

One final recommendation, that is the direct result of the findings of this study, would be to survey the CEOs in organizations that have received the Baldrige to gather their personal thoughts on organizational learning. It would be very interesting to see if these individuals actually walk the mission, vision, and values talk.

A fourth idea would be to compare Baldrige recipients across Baldrige criterion to organizations that have not received the Baldrige but are recognized in their industries as leaders.

\section{CONClusions}

This qualitative, multiple case study, using in-depth, semi-structured, face-to-face interview methodology, examined the workplace learning practices of six Malcolm Baldrige National Quality Award (Baldrige) recipients. The purpose of this study was to explore the impact of the workplace learning function on the pursuit of organizational excellence.

Literature on the seven criterion used by the National Institute of Standards and Technology to determine Baldrige recipients was reviewed. In addition, literature on four criterion used by the American Society for Training and Development's BEST award for workplace learning excellence was also reviewed. Literature on the relationship between organizational excellence and workplace learning was also presented.

The study presented findings on the factors these organizations consider when planning workplace learning initiatives, how these initiatives are planned, approved, and communicated throughout their organizations. The findings also answered questions about 
planning schedules, what factors determine delivery methods, and who develops the learning content.

The study supported previous research on delivery methods, evaluating workplace learning effectiveness, and the perceived value of the workplace learning function by the senior executives. The study also supported previous research on the importance of providing leadership development programs.

The study examined the role of the CEO in the planning, approval, and communication of workplace learning initiatives. It also looked at the value of including learning objectives as a performance goal. The study also presented findings on the role the workplace learning function played in creating excellence as well as its future role in the sustainability of the organization.

The strength of the study was in providing workplace learning professionals relevant, current information that was a combination of a practitioner's reality combined with academic rigor.

Further research is recommended to expand to all Baldrige recipients and to include a quantitative instrument, not to enrich data, but to address the practicalities of gathering research from organizations across the country.

Each of the organizations participating in this study clearly demonstrated the contribution of the workplace learning function toward the pursuit of excellence. These learning organizations were to quote Peter Senge, ..."organizations where people continually expand their capacity to create the results they truly desire, where new and expansive patterns of thinking are nurtured, where collective aspiration is set free, and where people are continually learning to see the whole together." 


\section{REFERENCES}

1000advices. (n.d.). Deming's 14 point plan for total quality management. Retrieved from http://www.1000advices.com/guru/quality_tqm_14points_deming.html

Akdere, M. (2005). The relationship between quality-focused human resource practices and performance outcomes in long-term healthcare organizations (Doctoral dissertation). Abstract retrieved from http://www.astd.org/NR/rdonlyres/D8E4455D-ED7A-40358F9B-8E051E3620C5/0/AwardsBookletfor2005awards.pdf

Aldrich, C. (2007). Engaging mini-games find niche in training: Quick, interactive simulations are meeting the training needs of businesses. Training + Development, $61(7), 22-24$.

Alliance for Performance Excellence. (n.d.). State and local programs. Retrieved from http://www.baldrigepe.org/alliance/programs.aspx

American Society for Quality [ASQ]. (n.d.-a). Basic concepts: Process view of work. Retrieved from http://asq.org/learn-about-quality/process-view-ofwork/overview/overview.html

American Society for Quality [ASQ]. (n.d.-b). Organization wide approaches: Lean. Retrieved from http://asq.org/learn-about-quality/lean/overview/overview.html

American Society for Quality [ASQ]. (n.d.-c). Organization wide approaches: Six sigma. Retrieved from http://asq.org/learn-about-quality/six-sigma/overview/overview.html

American Society for Training \& Development [ASTD]. (2009a). State of the industry report 2009: ASTD's annual review of trends in workplace learning and performance. Retrieved from http://store.astd.org/Default.aspx?tabid=143\&action=ECD ProductDetails\&args $=19786$

American Society for Training \& Development [ASTD]. (2009b). The value of evaluation: Making training evaluations more effective. Alexandria, VA: Author.

American Society for Training \& Development [ASTD]. (2011). Dissertation award. Retrieved from http://www.astd.org/ASTD/aboutus/AwardsandBestPractices/ advancingWorkplaceAwards/dissertationAward.htm

American Society for Training \& Development [ASTD] San Diego Chapter. (2010, May). The realities and myths about learning measurement. Discussion conducted at the meeting of the ASTD, San Diego.

Argyris, C. (1994). Good communication that blocks real learning. Harvard Business Review. Retrieved from http://hbr.org

Bassi, L. J., Ludwig, J., McMurrer, D. P., \& Van Buren, M. (2009). Profiting from learning: Do firms' investments in education and training pay off? Alexandria, VA: American Society for Training \& Development.

Bennis, W., \& Nanus, B. (1985). Leaders. New York, NY: Harper \& Row. 
Bernthal, P. (2005). Measurement gets strategic. Training + Development, 59(5), 53-59.

Bingham, T., \& Jeary, T. (2007). Communicating the value of learning. Training + Development, 61(5), 80-84.

Blake, R., \& Mouton, J. (1964). The managerial grid: The key to leadership excellence. Houston, TX: Gulf.

Blanchard, K., \& Ridge, G. (2009). Helping people win at work: A business philosophy called "don't mark my paper, help me get an $A$ ". Upper Saddle River, NJ: Polvera and Gerry Ridge.

Boehle, S. (2005). Simulations: The next generation of e-learning. Training + Development, $42(1), 22-31$.

Boehle, S. (2009). Don't leave home without it. Training + Development, 46(7), 30-33.

Brinkerhoff, R. (2003). The success case method: Find out quickly what's working and what's not. San Francisco, CA: Berrett-Koehler.

Brown, J. (2010). Can you hear me now? Training + Development, 64(2), 28-30.

Burns, J. (2003). Transforming leadership. New York, NY: Grove Press.

Business Dictionary. (n.d.). Strategic planning. Retrieved from http://www.businessdictionary.com/definition/strategic-planning.html

Byham, T. (2006). Factors affecting the acceptance and application of developmental feedback from an executive assessment program (Doctoral dissertation). Abstract retrieved from http://www.astd.org/NR/rdonlyres/DBF2B3F3-30A6-4B19-9F6273727D2BC5D2/12180/2006AwardsBooklet_singlepages5.pdf

Camp, R. C. (1989). Benchmarking: The search for industry best practices. Portland, OR: ASQC Quality Press.

Capodagli, B., \& Jackson, L. (1999). The Disney way: Harnessing the management secrets of Disney in your company. New York, NY: McGraw-Hill.

Ciporen, R. (2008). The role of personally transformative learning in leadership development: A case study examining the transfer of learning from an executive education program (Doctoral dissertation). Abstract retrieved from http://www.astd.org/NR/rdonlyres/D0BD5864-EC30-4CC0-9F77202146540D56/0/AwardsBookletfor2008Awards.pdf

Clark, C. R. (2005). Harnessing the virtual classroom. Training + Development, 59(11), 4045.

Clark, R., \& Kwinn, A. (2005). Aligning training to business results: Seven routes to explore with your CEO. Training + Development, 59(6), 34-39.

Cohen, P. (n.d.). Deming 's 14 points. Retrieved from http://www.hci.com.au/hcisite2/ articles/deming.htm

Collins, J., \& Porras, J. (1994). Built to last: Successful habits of visionary companies. New York, NY: HarperCollins. 
Conner, M. (2009). Inside the enterprise, up the next hill. Training + Development, 63(10), 21-23.

Crawford, K. M., \& Cox, J. F. (1990). Designing performance measurement systems for justin-time operations. International Journal of Production Research, 28(11), 2025-2036.

Creswell, J. (1998). Qualitative inquiry and research design: Choosing among five traditions. Thousand Oaks, CA: Sage.

Davenport, R. (2006). In God we trust; all others bring data. Training + Development, 60(4), 44-46.

Deming, W. E. (1982). Out of the crisis. Cambridge, MA: MIT Press.

Denzin, N., \& Lincoln, Y. (Eds.). (2005). The Sage handbook of qualitative research (3rd ed). Thousand Oaks, CA: Sage.

Dixon, J. R., Nanni, A. J., \& Vollmann, T. E. (1990). The new performance challenge measuring operations for world-class competition. Homewood, IL: Dow Jones-Irwin.

Dolence, M. (2004). The curriculum-centered strategic planning model. Educause Center for Applied Research, 2004(10), 2-11.

Dolezalek, H. (2007). Virtual vision. Training + Development, 44(9), 39-46.

Eisner, E. W. (1991). The enlightened eye: Qualitative inquiry and the enhancement of educational practice. New York, NY: Macmillan.

Ellis, K. (2005). The mindset that matters: Linking learning to the business. Training, 42(5), $38-43$.

Ely, M., Anzul, M., Friedman, T., Garner, D., \& Steinmetz, A. C. (1991). Doing qualitative research: Circles within circles. New York, NY: Falmer.

Federman, B. (2009). Employee engagement: A roadmap for creating profits, optimizing performance, and increasing loyalty. San Francisco, CA: Jossey-Bass.

Fontana, A., \& Frey, J. H. (2005). The interview: From neutral stance to political involvement. In N. Denzin \& Y. Lincoln (Eds.), The Sage handbook of qualitative research (3rd ed, pp. 695-728). Thousand Oaks, CA: Sage.

Fox, A. (2010). Raising engagement. HRMagazine, 55(5), 34-40.

Frame, M. (2004). Self-and direct report-performance ratings at the executive level: The impact of gender on performance ratings and potential career-related outcomes (Doctoral dissertation). Abstract retrieved from http://www.astd.org/NR/rdonlyres/ FF71B299-0F99-412F-9F84-8C549F0AD425/0/AwardsBooklet2004.pdf

Friesner, T. (2011). History of SWOT analysis. Retrieved from http://www.marketingteacher.com/swot/history-of-swot.html

Galagan, P. (2008). Second that. Training + Development, 62(2), 34-37.

Galagan, P. (2009). Twitter as a learning tool, really: Savvy trainers are using microblogging to foster informal learning and meet like-minded peers. Training + Development, 63(3), 28-31. 
George, S. (2009). Interpreting results. Retrieved from http://www.baldrige.com/ criteria_results/interpreting-results/

Giguere, P., \& Minotti, J. (2005). Rethinking web-based learning: It's all about your goals. Training + Development, 59(1), 15-16.

Gilbert, D. (2003). Psychometric determination of job stress in health occupations (Doctoral dissertation). Abstract retrieved from http://www.astd.org/NR/rdonlyres/BDC2ACD0-4FB1-440A-8B66E4C645B9F70E/0/020404awardbook.pdf

Goldsmith, M., \& Morgan, H. (2004). Leadership is a contact sport: The "follow-up factor" in management development. Strategy + Business, 36, 71-79.

Greenleaf, R. (1977). Servant leadership: A journey into the nature and legitimate power of greatness. New York, NY: Paulist Press.

Grensing-Pophal, L. (2009). To ask or not to ask. HRMagazine, 54(2), 53-55.

Groenstedt, A. (2007). Second life produces real training results. Training + Development, $61(8), 44-49$.

Hammer, M. (2001). The agenda: What every business must do to dominate the decade. New York, NY: Crown.

Harris, P. D. (2009). Immersive learning seeks a foothold. Training + Development, 63(1), 40-45.

Hersey, P., Blanchard, K., \& Johnson, D. (2001). Management of organizational behavior: Leading human resources (8th ed.). Upper Saddle River, NJ: Prentice Hall.

Horton, W. (2005). Evaluating e-learning. Training + Development, 42(9), 35-39.

Huselid, M. A. (1995). The impact of human resource management practices on turnover, productivity, and corporate financial performance. Academy of Management Journal, $38,635-672$.

Isaac, S., \& Michael, W. (1995). Handbook in research and evaluation: For education and the behavioral sciences (3rd ed.). San Diego, CA: EdITS.

Jacob. E. (1987). Qualitative research traditions: A review. Review of Educational Research, 57(1), 1-50.

Kaplan, S., \& Beinhocker, E. (2003). The real value of strategic planning. MIT Sloan Management Review, 44(2), 71-76.

Kaplan, S., \& Norton, D. (1992). The balanced scorecard-measures that drive performance. Harvard Business Review. Retrieved from http://hbr.org

Kaplan, R., \& Norton, D. (2004). Strategy maps: Converting intangible assets into tangible outcomes. Boston, MA: Harvard Business School.

Karrer, T. (2007). Learning and networking with a blog. Training + Development, 61(9), 2022.

Keegan, D. P., Eiler, R. G., \& Jones, C. R. (1989). Are your performance measures obsolete? International Journal of Operations \& Production Management, 15(4), 1228-1263. 
Kirkpatrick, D. L. (1975). Evaluating training programs (1st ed.). Alexandria, VA: American Society for Training and Development.

Kirkpatrick, J. (2005). The real key to demonstrating value and driving strategy. Training + Development, 59(4), 19-21.

Kirkpatrick, J. (2007). The hidden power of kirkpatricks four levels. Training + Development, 61(8), 34-37.

Kotler, P. (n.d.). Kotler marketing group. Retrieved from http://www.kotlermarketing.com/

Kouzes, J., \& Posner, B. (2002). The leadership challenge (3rd ed.). San Francisco, CA: Jossey-Bass.

Kouzes, J., \& Posner, B. (2010). The truth about leadership: The no-fads, heart-of-the-matter facts you need to know. San Francisco, CA: Jossey-Bass.

Laff, M. (2007a). Senior managers absent from training table. Training + Development, $61(7), 20$.

Laff, M. (2007b). Serious gaming: The trainer's new best friend. Training + Development, $61(1), 52-57$.

Lancy, D. (1993). Qualitative research in education: An introduction to the major traditions. New York, NY: Longman.

Learn Marketing. (n.d.). Michael Porter's value chain. Retrieved from http://www.learnmarketing.net/valuechain.htm

Likert, R. (1961). New patterns of management. New York, NY: McGraw-Hill.

Lincoln, Y. S., \& Guba, E. G. (1985). Naturalistic inquiry. Beverly Hills, CA: Sage.

Lopker, G., \& Askeland, R. (2009). More than a smile sheet: Using level 1 evaluation effectively. Training + Development, 63(9), 74-75.

McGregor, D. (1960). The human side of enterprise. New York, NY: McGraw-Hill.

Miles, M., \& Huberman, A. M. (1994). Qualitative data analysis: An expanded resource (2nd ed.). Thousand Oaks, CA: Sage.

Mindtools. (n.d.). The marketing mix and 4ps: Understanding how to position your market offering. Retrieved from http://www.mindtools.com/pages/article/newSTR_94.htm

Morse, J., \& Field, P. A. (1994). Qualitative research methods health professional (2nd ed.). Thousand Oaks, CA: Sage.

Moustakas, C. (1994). Phenomenological research methods. Thousand Oaks, CA: Sage.

Munhall, P. (2010). Nursing research: A qualitative perspective (5th ed.). Sudbury, MA: Jones and Bartlett Learning.

Natchez, M. (2008). Measuring up. Training + Development, 62(1), 26-28.

National Institute of Standards and Technology [NIST]. (2009a). Baldrige FAQs: Baldrige Award recipients. Retrieved from http://www.nist.gov/baldrige/about/ faqs_recipients.cfm 
National Institute of Standards and Technology [NIST]. (2009b). Baldrige performance excellence program. Retrieved from http://www.nist.gov/baldrige

Neely, A., Gregory, M., \& Platts, K. (1995). Performance measurement system design: A literature review and research agenda. International Journal of Operations \& Production Management, 15(4), 80-116.

Orvis, K. (2007). Supervisory performance feedback as a catalyst for high quality employee self-development (Doctoral dissertation). Abstract retrieved from http:/www.astd.org/ NR/rdonlyres/555C3D6F-BECC-4303-A9D4-A457CB6CF66E/0/ AwardsBookletfor2007awards.pdf

Pall, G. (2000). The process centered enterprise: The power of commitments. New York, NY: CRC Press

Parry, S. (1997). Evaluating the impact of training. Alexandria, VA: ASTD Press.

Peters, T., \& Waterman Jr., R. (1982). In search of excellence: Lessons from America's bestrun companies. New York, NY: Harper \& Row.

Phillips, J. (1996). Measuring ROI: The fifth level of evaluation. Technical \& Skills Training, April, 10-13.

Phillips, J. (2007). Measuring ROI: Fact, fad, or fantasy? Training + Development, 61(4), 42-46.

Phillips, J., \& Phillips, P. P. (2009). Measuring what matters: How CEOs view learning success. Training + Development, 63(8), 45-49.

Phillips, J., \& Phillips, P. P. (2010). Confronting CEO expectations about the value of learning. Training + Development, 64(1), 52-57.

Pink, D. H. (2009). Drive: The surprising truth about what motivates us. New York, NY: Riverhead Books.

Porter, M. E. (1985). The competitive advantage: Creating and sustaining superior performance. New York, NY: Free Press.

QuickMBA. (n.d.). Ansoff matrix. Retrieved from http://www.quickmba.com/strategy/ matrix/ansoff

Richardson, P. R., \& Gordon, J. R. M. (1980). Measuring total manufacturing performance.

Sloan Management Review, 21(2), 47-58.

Rivenbark, L. (2010). Tools of engagement. HRMagazine, 55(2), 48-51.

Rossett, A. (2007). Leveling the levels. Training + Development, 61(2), 49-53.

Rossett, A. (2010). Metrics matters. Training + Development, 64(3), 64-69.

Rossett, A., \& Marshall, J. (2010). E-learning: What's old is new again. Training + Development, 64(1), 34-38.

Rost, J. (1993). Leadership for the twenty-first century. Westport, CT: Praeger.

Rudestam, K., \& Newton, R. (2007). Surviving your dissertation: A comprehensive guide to content and process (3rd ed.). Thousand Oaks, CA: Sage. 
Seagraves, T. (2005). The inside pitch. Training + Development, 59(2), 40-45.

Senge, P. (1990). The fifth discipline: The art \& practice of the learning organization. New York, NY: Doubleday.

Senge, P. (1995). Leading learning organization: The bold, the powerful, and the invisible. In F. Hesselbein, M. Goldsmith \& R. Beckhard (Eds.), The leader of the future (pp. 4158). San Francisco, CA: Jossey-Bass.

Slife, B. D., \& Williams, R. (1995). What's behind the research?: Discovering hidden assumptions in the behavioral sciences. Thousand Oaks, CA: Sage.

Sloman, M. (2004). Learning evaluation, or not? Training + Development, 58(9), 45.

Smartcode. (n.d.). Porter's five forces model of competition. Retrieved from http://software-porter-five-forces.smartcode.com

Smith, S. (2008). Why follow levels when you can build bridges? Training + Development, 62(9), 58-62.

Soldati, P. (2007). Employee engagement: What exactly is it? Management-Issues. Retrieved from http://www.management-issues.com/2007/3/8/opinion/employee-engagementwhat-exactly-is-it.asp

Stake, R. (1995). The art of case study research. Thousand Oaks, CA: Sage.

Stake, R. (2005). Qualitative case studies. In N. Denzin \& Y. Lincoln (Eds.), The Sage handbook of qualitative research (3rd ed, pp. 443-466). Thousand Oaks, CA: Sage.

Steiner, G. (1969). Strategic planning: What every manager must know. New York, NY: Free Press Paperbacks.

Stewart, T. (1999). Intellectual capital: The new wealth of organizations. New York, NY: Bantam Doubleday Dell.

Studer, Q. (2003). Hardwiring excellence: Purpose, worthwhile work, making a difference. Gulf Breeze, FL: Fire Starter.

Studer, Q. (2008). Results that last: Hardwiring behaviors that will take your company to the top. Hoboken, NJ: John Wiley \& Sons.

Sugrue, B. (2004). Making the case for learning. Training + Development, 58(10), 74-77.

Sussman, D. (2005). Now hear this. Training + Development, 59(9), 53-57.

Taylor, F. (1911). The principles of scientific management. New York, NY: Harper \& Brothers.

Tradekey Community. (n.d.). Ansoff Matrix. Retrieved from www.community.tradekey.com

Ulrich, D., Smallwood, N., \& Sweetman, K. (2008). The leadership code: Five rules to lead by. Boston, MA: Harvard Business Press.

University of South Australia. (n.d.). Planning and assurance services. Retrieved from www.unisa.edu.au/pas/qap/planning/glossary.asp

Vellios, G. (2008). On the level. Training + Development, 62(12), 26-29. 
Weinstein, M. (2007a). Assessment acumen. Training + Development, 44(1), 33-35.

Weinstein, M. (2007b). Mobility movement. Training + Development, 44(8), 14-16.

Weinstein, M. (2008). Got game? Training + Development, 45(8), 39-42.

Weinstein, M. (2009). Your c-suite seat. Training + Development, 46(3), 26-29.

Wengraf, T. (2001). Qualitative research interviewing. Thousand Oaks, CA: Sage.

Withers, B. (2009). Leveling the field. Training + Development, 63(5), 36-38.

Zenger, J., \& Folkman, J. (2002). The extraordinary leader: Turning good managers into great leaders. New York, NY: McGraw-Hill.

Zenger, J., Folkman, J., \& Sherwin, R. (2005). 123 the promise of phase. Training + Development, 59(1), 30-35. 


\section{APPENDIX}

INTERVIEW ITEMS 
Research Question One:

1. What factors does your organization consider when making a decision to provide workplace learning?

2. How are your workplace learning initiatives planned, approved and communicated to the organization? What stakeholders participate?

3. Is the CEO or equivalent involved in the planning of, participating in and/or evaluating of your workplace learning initiatives?

4. Is there an annual planning schedule for workplace learning or are training programs developed and delivered as the need arises?

5. What one workplace learning initiative do you believe has impacted your organization the most and how, e.g., sales training that increased sales; change management training that helped the employees embrace a significant change in the way things are done; customer service training that reduced the number of customer complaints; etc?

6. What role do you believe your workplace learning strategy played in helping your organization receive the Baldrige?

7. Do you want to say anything else about how you conceptualize and deliver a strategic plan for workplace learning?

8. Do you evaluate and measure the effectiveness of your workplace learning initiatives? If not why? If so, are all programs evaluated and with what metrics, e.g., training attendance, employee retention figures, employee satisfaction surveys, productivity, increased sales, customer satisfaction, etc?

9. What delivery methods do you use?

10 . What determines the delivery method?

11. Do you develop training within your organization, hire consultants, buy off- the-shelf content or use a combination?

12. What would you say are the most critical issues facing your organization today and how will the learning function provide solutions to these issues? 
Research Question Two

1. Is there a $\mathrm{C}$ level Officer of Learning? If not, what is the title of the person responsible for workplace learning and to whom does this person report?

2. Is the person responsible for the workforce learning function included in the organization's strategic planning sessions? If not, how are new strategic plans and organizational changes conveyed to this person?

3. Do all employees have access to workplace learning? Do the executives of the organization attend training? In what other ways does the senior level members show support for workplace learning?

4. Do you have a leadership development program (s) and if so how are participants chosen?

5. How does workplace learning factor into your employees' performance review? Do your employees write performance goals that include training? 